Portland State University

PDXScholar

Dissertations and Theses

Dissertations and Theses

Winter 3-20-2013

\title{
Mechanisms of Methane Transport Through Trees
}

Ellynne Marie Kutschera

Portland State University

Follow this and additional works at: https://pdxscholar.library.pdx.edu/open_access_etds

Part of the Environmental Indicators and Impact Assessment Commons, and the Physics Commons Let us know how access to this document benefits you.

Recommended Citation

Kutschera, Ellynne Marie, "Mechanisms of Methane Transport Through Trees" (2013). Dissertations and Theses. Paper 643.

https://doi.org/10.15760/etd.643

This Thesis is brought to you for free and open access. It has been accepted for inclusion in Dissertations and Theses by an authorized administrator of PDXScholar. Please contact us if we can make this document more accessible: pdxscholar@pdx.edu. 
Mechanisms of Methane Transport Through Trees

by

Ellynne Marie Kutschera

A dissertation submitted in partial fulfillment of the requirements for the degree of

\author{
Doctor of Philosophy \\ in \\ Applied Physics
}

\author{
Dissertation Committee: \\ Mohammad Aslam Khan Khalil, Chair \\ Andrew Rice \\ Todd Rosenstiel \\ Raj Solanki \\ Scott Burns
}

Portland State University

2013 


\begin{abstract}
Although the dynamics of methane $\left(\mathrm{CH}_{4}\right)$ emission from croplands and wetlands have been fairly well investigated, the contribution of trees to global $\mathrm{CH}_{4}$ emission and the mechanisms of tree transport are relatively unknown. $\mathrm{CH}_{4}$ emissions from the common wetland tree species Populus trichocarpa (black cottonwood) native to the Pacific Northwest were measured under hydroponic conditions in order to separate plant transport mechanisms from the influence of soil processes. Roots were exposed to $\mathrm{CH}_{4}$ enriched water and canopy emissions of $\mathrm{CH}_{4}$ were measured using a canopy enclosure. Measurements of $\mathrm{CH}_{4}$ flux from 28 trials on eight trees indicate that emissions are normally constant over the half-hour sampling period. The average canopy $\mathrm{CH}_{4}$ flux for the 18 trials with constant emission was $3.0 \pm 2.6 \mu \mathrm{g} \mathrm{CH} \mathrm{CH}_{4}{ }^{-1}$. Flux magnitudes from stem experiments scaled to the area of the main tree stem are comparable to whole-canopy flux values, indicating that the majority of $\mathrm{CH}_{4}$ emitted from the tree leaves through the stem. Stem experiments also show that $\mathrm{CH}_{4}$ flux decreases in magnitude with height of the tree. Samples for stable carbon isotope composition were taken during the canopy experiments. Compared to the isotopic composition of root water $\mathrm{CH}_{4}$, canopy $\mathrm{CH}_{4}$ was depleted in ${ }^{13} \mathrm{C}$ on average by $8.6 \pm$ $3.3 \%$; this indicates that $\mathrm{CH}_{4}$ moving through the tree is not following a purely bulk flow pathway (where no depletion would occur), but is instead subject to at least one fractionating mechanism. Isotopic measurements of emitted $\mathrm{CH}_{4}$ reveal information
\end{abstract}


about transport mechanisms, but transport mechanisms do not necessarily correlate with any particular physical pathway.

Using the same procedure as the canopy enclosure trials, temperature was varied from $17.1{ }^{\circ} \mathrm{C}$ to $25.2{ }^{\circ} \mathrm{C}$ over several weeks. The flux at the coolest temperature is significantly different from the higher flux at the warmest temperature ( $p$-value less than 0.02). The calculated $\mathrm{Q}_{10}$ for $\mathrm{CH}_{4}$ flux was $2.4 \pm 2.0$, which is in the range of typical $\mathrm{Q}_{10}$ values for biological processes. Analysis of ${ }^{13} \mathrm{C}$ values of emitted $\mathrm{CH}_{4}$ in the temperature experiments shows increasing depletion with cooler temperatures and lower flux. This indicates that not only does the magnitude of flux vary with temperature, but the actual dominant transport mechanism changes as well.

When the amount of $\mathrm{CH}_{4}$ leaving the root chamber was compared to the amount measured as flux in the canopy experiments, a significant amount of $\mathrm{CH}_{4}$ was "missing." Several experiments were conducted to account for this missing amount; evidence suggests $\mathrm{CH}_{4}$ is stored, at least temporarily, within the tree itself by an unknown mechanism. Transport efficiency was calculated and found to be relatively slow; that is, trees do not transport $\mathrm{CH}_{4}$ very efficiently. This has important ramifications for $\mathrm{CH}_{4}$ emission from trees, since increases in soil production of $\mathrm{CH}_{4}$ may not result in significantly higher $\mathrm{CH}_{4}$ flux from trees.

This work lays a foundation for understanding $\mathrm{CH}_{4}$ transport mechanisms, however these mechanisms will need to be more thoroughly defined in order to make accurate predictions about $\mathrm{CH}_{4}$ emission from trees and to describe how flux will change under altered climate conditions. 


\section{Acknowledgements}

Special thanks to Dawn Matarese for instruction on hydroponic growth apparatus construction and tree cultivation. Special thanks to GeoDesign, Inc of Tigard for extensive assistance in soil sampling. This work was funded by the Office of Science (BER), U.S. Department of Energy, grant number DE-FG02-08ER64515 and by NASA / Oregon Space Grant Consortium, grants NNG05GJ85H and NNX10AK68H. 


\title{
Table of Contents
}

\begin{abstract}
.................... i
Acknowledgements ....................... iii

List of Tables . . . . . . . . . . . . . . . vi

List of Figures . . . . . . . . . . . . . . . ix

$1 \quad$ Introduction . . . . . . . . . . . . . . . . . 1

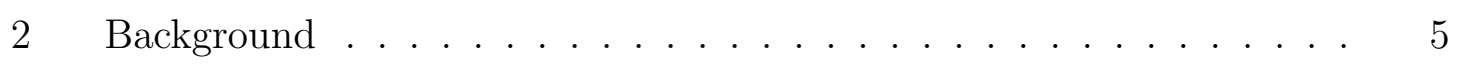

3 Experimental Methods . . . . . . . . . . . . . . . . 7

3.1 Canopy Flux Experiments $\ldots \ldots \ldots \ldots \ldots$

3.2 Temperature Experiments . . . . . . . . . . . . 15

$3.3 \quad$ Stem Experiments $\ldots \ldots \ldots \ldots \ldots$

3.4 Leak Tests, Canopy Flux Series Experiments and Full Chamber Experiments . . . . . . . . . . . . . . 17
\end{abstract}

$4 \quad$ Results........................... 24

$4.1 \quad$ Canopy Flux Experiments . . . . . . . . . . . . . . . 24

4.2 Temperature Experiments . . . . . . . . . . . 45

4.3 Stem Experiments . . . . . . . . . . . . 47

4.4 Canopy Flux Series Experiments and Full Chamber Experiments 49

$5 \quad$ Discussion . . . . . . . . . . . . . . . 57 
$5.1 \mathrm{CH}_{4}$ Transport Mechanisms . . . . . . . . . . . . . 57

5.2 Carbon Isotopic Composition . . . . . . . . . . . . 63

5.3 Temperature Influences on Transportation Mechanisms and $Q_{10} 66$

5.4 $\mathrm{CH}_{4}$ Partitioning .................. 74

6 Conclusion . . . . . . . . . . . . . . . . . . 77

References ........................ 79

Appendices

A Sandy River Delta Soil Experiment . . . . . . . . . . . . . . . 82

B Root Water Concentration . . . . . . . . . . . . . 88 


\section{List of Tables}

1 Correlations between measured parameters . . . . . . . . . 26

$2 \quad \delta^{13} \mathrm{C}$ Values for the canopy flux experiments $\ldots \ldots \ldots . \ldots 27$

$3 \quad \delta^{13} \mathrm{C}$ Values for the temperature canopy flux experiments $\ldots \ldots .27$

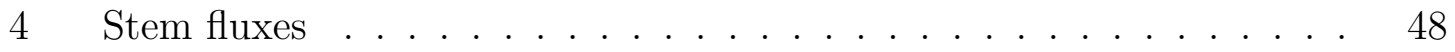

5 Canopy series experiment, $4-30-12 \ldots \ldots \ldots \ldots \ldots \ldots$

6 Canopy series experiment, $10-3-12 \ldots \ldots \ldots \ldots \ldots$

7 Canopy series experiment, $10-18-12 \ldots \ldots \ldots \ldots \ldots$

8 Summary of changes in the amount of $\mathrm{CH}_{4}$ in the experimental system

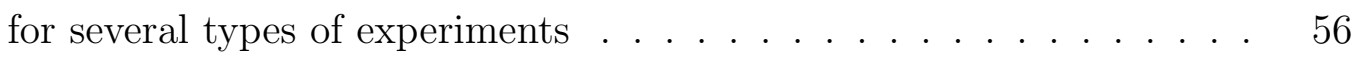




\section{List of Figures}

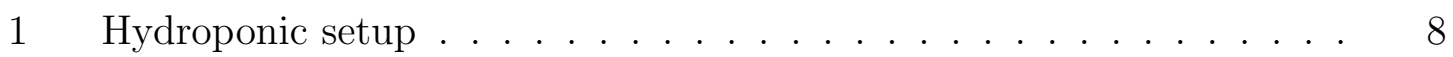

2 Canopy sampling experiment . . . . . . . . . . . . . . . . 10

3 Root chamber enclosure . . . . . . . . . . . . . . . . . 11

4 Experimental setup for canopy sampling . . . . . . . . . . . . . 12

5 Stem sampling experiment . . . . . . . . . . . . . . 18

6 Experimental setup for stem sampling . . . . . . . . . . . . . . . 19

$7 \quad$ Experimental setup for full-chamber sampling . . . . . . . . . 23

$8 \mathrm{CH}_{4}$ flux measured from the canopy versus leaf area, $2011 \ldots 28$

9 Transpiration versus leaf area, $\mathrm{n}=18,2011 \ldots \ldots \ldots \ldots$

10 Transpiration versus leaf area, $\mathrm{n}=15,2011 \ldots \ldots \ldots$

11 Leaf count versus tree weight, $2012 \ldots \ldots \ldots \ldots$

$12 \mathrm{CH}_{4}$ flux versus tree weight, $2012 \ldots \ldots \ldots \ldots \ldots$

$13 \mathrm{CH}_{4}$ flux versus ambient temperature, $2011 \ldots \ldots \ldots \ldots$

$14 \mathrm{CH}_{4}$ flux versus ambient temperature, $2012 \ldots \ldots \ldots \ldots \ldots$

$15 \mathrm{CH}_{4}$ flux versus leaf temperature, $2011 \ldots \ldots \ldots \ldots \ldots$

$16 \mathrm{CH}_{4}$ flux versus relative humidity, $2011 \ldots \ldots \ldots \ldots \ldots \ldots$

$17 \mathrm{CH}_{4}$ flux versus relative humidity, $2012 \ldots \ldots \ldots \ldots \ldots$

$18 \mathrm{CH}_{4}$ flux versus transpiration, $2011 \ldots \ldots \ldots \ldots \ldots$ 


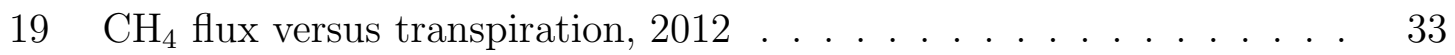

20 Transpiration versus leaf temperature, $2011 \quad \ldots . \ldots . \ldots 34$

21 Transpiration versus relative humidity, $2011 \ldots \ldots 34$

22 Transpiration versus relative humidity, $2012 \ldots \ldots$. . . . . . . . 35

23 Transpiration versus ambient temperature, $2011 \ldots . . \ldots 35$

24 Transpiration versus ambient temperature, $2012 \ldots \ldots$

25 Transpiration versus tree weight, $2012 \ldots \ldots$. . . . . . . . 36

26 Average $\mathrm{CH}_{4}$ flux by tree for 2010-2011 experiments . . . . . . . . . . 37

27 Average $\mathrm{CH}_{4}$ flux by tree for 2012 temperature series experiment . . 37

28 Average $\mathrm{CH}_{4}$ flux by average weekly temperature for 2012 temperature series experiment . . . . . . . . . . . . . . . . . 38

$29 \mathrm{CH}_{4}$ loss by flux versus $\mathrm{CH}_{4}$ emission estimated from root water loss, $2011 \ldots \ldots \ldots \ldots \ldots$

$30 \mathrm{CH}_{4}$ loss by flux versus $\mathrm{CH}_{4}$ emission estimated from root water loss, $2012 \ldots \ldots \ldots \ldots \ldots$

31 Logarithm of the ratio of $\mathrm{CH}_{4}$ loss by root water to $\mathrm{CH}_{4}$ loss by flux

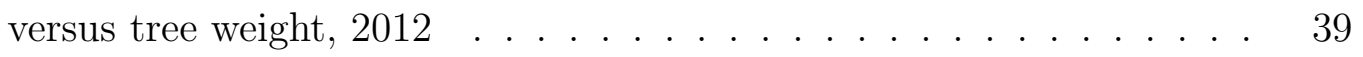

$32 \mathrm{CH}_{4}$ loss by root water versus tree weight, $2012 \ldots \ldots$. . . . . . . . 40

33 Ratio of $\mathrm{CH}_{4}$ loss by root water to $\mathrm{CH}_{4}$ loss by flux by tree, 2012 . . 40

$34 \delta{ }^{13} \mathrm{C}$ of $\mathrm{CH}_{4}$ emitted from the canopy versus $\mathrm{CH}_{4}$ flux, $\mathrm{n}=16,2011 \ldots 41$

$35 \delta{ }^{13} \mathrm{C}$ of $\mathrm{CH}_{4}$ emitted from the canopy versus $\mathrm{CH}_{4}$ flux, $\mathrm{n}=14,2011$. 41

$36 \quad \delta^{13} \mathrm{C}$ of $\mathrm{CH}_{4}$ emitted from the canopy versus $\mathrm{CH}_{4}$ flux, $2012 \ldots \ldots$

$37 \delta^{13} \mathrm{C}$ of total $\mathrm{CH}_{4}$ in the chamber (tedlar bag) versus $\mathrm{CH}_{4}$ flux, 2012.42

$38 \delta^{13} \mathrm{C}$ of $\mathrm{CH}_{4}$ emitted from the canopy versus temperature, $2012 \ldots 43$ 
39 Epsilon values for all trials in the temperature experiment versus $\mathrm{CH}_{4}$ flux, $2012 \ldots \ldots \ldots . \ldots \ldots$

40 Epsilon values for all trials in the temperature experiment versus temperature, $2012 \ldots \ldots \ldots 4$. . . . . . . . . . . . . . . . . 44

41 Keeling plot, $\delta^{13} \mathrm{C}$ of chamber $\mathrm{CH}_{4}$ for all data points, $2012 \ldots \ldots$

42 Keeling plot, $\delta^{13} \mathrm{C}$ of chamber $\mathrm{CH}_{4}$ for $17.1{ }^{\circ} \mathrm{C}$ trials, $2012 \ldots \ldots$

43 Keeling plot, $\delta^{13} \mathrm{C}$ of chamber $\mathrm{CH}_{4}$ for $22.3{ }^{\circ} \mathrm{C}$ trials, $2012 \ldots \ldots$

44 Keeling plot, $\delta^{13} \mathrm{C}$ of chamber $\mathrm{CH}_{4}$ for $25.2{ }^{\circ} \mathrm{C}$ trials, $2012 \ldots \ldots$ 


\section{Introduction}

The impetus behind this work has been to investigate the transport mechanisms of methane $\left(\mathrm{CH}_{4}\right)$ though trees, the exact processes of which are unknown. $\mathrm{CH}_{4}$ is a potent greenhouse gas 25 times more powerful molecule for molecule than carbon dioxide. Compared to a pre-industrial concentration of $650 \mathrm{ppb}$, the current atmospheric concentration of $\mathrm{CH}_{4}$ is around $1750 \mathrm{ppb}$. Although the rate of increase of $\mathrm{CH}_{4}$ in the atmosphere has slowed, atmospheric $\mathrm{CH}_{4}$ concentrations continue to rise. Uncertainties in emissions estimates persist, but the largest single source of $\mathrm{CH}_{4}$ emissions is natural wetlands. Upland soils are regarded as net $\mathrm{CH}_{4}$ sinks, and although possible emissions from these soils are still theorized [Megonigal and Guenther, 2008], some of the experimental work presented here bears on this issue. Understanding how $\mathrm{CH}_{4}$ is transported from the soil to the atmosphere through plants is important to quantifiying the overal global $\mathrm{CH}_{4}$ cycle.

Three different pathways are available to $\mathrm{CH}_{4}$ moving from wetland soil to the atmosphere: transport through the water layers separating soil and air, ebullition or bubbling from submerged soils through the water layer to the air, and plant transport [Chanton, 2005]. When vegetated areas were compared to adjacent non-vegetated areas, the presence of plants increased $\mathrm{CH}_{4}$ transport by 10 times compared to nonvegetated plots, and up to $90 \%$ of $\mathrm{CH}_{4}$ emission was observed to be through plants [Whiting and Chanton, 1992]. Several types of transport through wetland plants has been documented to date. Some plants form aerenchyma, hollow spaces in the cortex of stems and roots that allow $\mathrm{O}_{2}$ to move from the atmosphere to the rhizosphere. This is an adaptation of certain plants to inundation. $\mathrm{CH}_{4}$ and other gases produced 
in the rhizosphere can move to the atmosphere through these tissues. Aerenchyma have been shown to exist in the bark of black alder (Alnus glutinosa) through which nitrous oxide $\left(\mathrm{N}_{2} \mathrm{O}\right)$ and $\mathrm{CH}_{4}$ were transported [Rusch and Rennenberg, 1998]. Gas transport through aerenchyma is usually assumed to be diffusive [Chanton, 2005]. Alternatively, some wetland plants move $\mathrm{O}_{2}$ to flooded roots via convective (pressurized) gas flow. This occurs when a pressure gradient across hollow stems forces air flow through the system, allowing $\mathrm{O}_{2}$ to reach the root-stem interface. The following results demonstrate that stem transport dominates in the trees studied here. However, purely diffusional transport does not appear to be the dominant transport mechanism as has been suggested for rice or other wetland plants by experimental research. This has important consequences for modeling $\mathrm{CH}_{4}$ emissions from wetlands, as trees cannot be treated similarly to herbaceous species.

Although wetlands are the main source of $\mathrm{CH}_{4}$, Megonigal and Guenther [2008] have proposed that upland emission of $\mathrm{CH}_{4}$ from trees is possible. This is based on the observation that upland soils, though normally $\mathrm{CH}_{4}$ sinks, occasionally become $\mathrm{CH}_{4}$ sources. Also, soil $\mathrm{CH}_{4}$ concentration has been observed to peak near the water table at depths accessible by tree roots. The transport mechanism proposed by Megonigal and Guenther [2008] is the transpiration stream through xylem tissue. Based on the evidence presented in this work, such a transport mechanism appears to be unlikely. However, considering that one-third of Earth's land surface is forested, a small flux from upland areas could be significant and therefore the possibility merits investigation. Even if a $\mathrm{CH}_{4}$ transport mechanism by transpiration exists, $\mathrm{CH}_{4}$ may not leave the soil to enter the tree very quickly, as discussed in following sections. In spite of the promising presence of $\mathrm{CH}_{4}$ in upland soils, unless an alternative and 
efficient tree transport mechanism is defined and demonstrated, it is unlikely that a significant amount of this upland soil $\mathrm{CH}_{4}$ will be emitted by trees.

In general, models utilizing $\mathrm{CH}_{4}$ emissions from crops and wetlands estimate fluxes based on empirical data and not known mechanisms. Major emissions trends are the goal; consequently, known drivers of emission can be used in models without their connection to underlying mechanisms being clear. The influence of plant physiology on $\mathrm{CH}_{4}$ flux is overlooked because of its complications, many of which were encountered in this research. Based on this work, tree transport mechanisms differ significantly from those of other wetland plants such as reeds and herbaceous species. Accurate accounting of this difference in emission capability will lend itself to better wetland modeling and overall budgeting of $\mathrm{CH}_{4}$.

An additional area in need of attention is that of potential global warming feedbacks in transport mechanisms. As for wetlands, emissions are expected to increase in a warmer, wetter climate [Denman and Brasseur, 2007]. The effect of temperature on $\mathrm{CH}_{4}$ transport through trees was tested and is discussed. Although the mechanisms of transport are the focus of this investigation and have been experimentally isolated from the influence of soil processes, implications of the results cannot be interpreted without reconnection to soil processes. Faster transport of $\mathrm{CH}_{4}$ out of the soil leaves less time for its oxidation by methanotropic bacteria; likewise, a slower transport time means more $\mathrm{CH}_{4}$ will be oxidized in the soil and less will be emitted overall. How transport is affected by temperature changes and the overall augmentation or reduction of flux based on transport time is addressed below.

A set of $\mathrm{CH}_{4}$ flux sampling experiments was the first approach to exploring the problem of $\mathrm{CH}_{4}$ transport through trees, which provided some initial insights and 
relationships between $\mathrm{CH}_{4}$ flux from trees and physiological parameters. While these experiments do not themselves reveal the specific mechanisms of transport, these relationships set the backdrop for understanding how $\mathrm{CH}_{4}$ transport might be affected by ecological influences on plant physiology. Subsequent experimental work looked at the influence of temperature and focused on explaining unexpected features of the system suggested by the initial results. A good deal of previously unknown information on the problem of tree $\mathrm{CH}_{4}$ transport was gained, including some important observations of the physical nature of the system. The results of this work open doors into understanding a complex system, and while not elucidating the entirety of that system, the understanding of plant transport mechanisms with ramefications for plant physiology, ecology, and global change science is advanced. 


\section{Background}

The species studied in this work is Populus trichocarpa, a poplar species also known as black cottonwood. Native to the Pacific Northwest, it can be found in floodplains and areas where inundation occurs. This species also has importance as a potential landfill cover species [McBain et al., 2004]. Since it is flood-tolerant, it can be grown

hydroponically in order to isolate tree transport mechanism from the complications of plant-soil interactions. As a common species in wetland environments, it can be taken as representative of $\mathrm{CH}_{4}$-emitting trees. The assumption is made here that transport mechanisms in poplar will be similar to other flood-tolerant trees. Although experiments were conducted on trees grown in a hydroponic environment, the transport mechanisms themselves are assumed to be generally the same for trees in their natural environments.

Trees in upland, or drier, soils may not have adaptations suited to flooding and therefore may lack aerenchyma. The transport mechanism proposed by Megonigal and Guenther [2008] is the transpiration stream through xylem tissue for trees in these conditions. Black cottonwood also grows well under non-inundated conditions. Though not strictly an upland tree species, it serves as a model species for transport studies because of its versatility. It is expected that if $\mathrm{CH}_{4}$ transport occurs with transpiration, it will do so in black cottonwood.

The trees in the studies below were grown hydroponically for at least four months before canopy flux experiments commenced. Although reaching heights of a meter or more, they were immature compared to more established cottonwoods that can grow tens of meters high. $\mathrm{CH}_{4}$ emission was comparable to slightly more mature 
potted trees reaching over a meter in height as discussed below. It is expected that as certain physiological parameters change with maturity, for example, the stem area to leaf area ratio, the dominance of transport pathways associated with these parameters will also change. However, the specific $\mathrm{CH}_{4}$ transport mechanisms themselves are not expected to be altered by more mature tree growth. 


\section{Experimental Methods}

\subsection{Canopy Flux Experiments}

To isolate plant physiological gas flux controls from soil dynamics, black cottonwood was grown hydroponically, as it is a well-known wetland tree species that can be cultivated under such conditions. Cuttings from wild black cottonwood were taken from the Sandy River Delta floodplain in the Columbia River Gorge, Troutdale, Oregon. 7.5 liter plastic buckets with tight-fitting lids were filled to 5.7 liters with a modified Hoagland's solution and two $3 \mathrm{~cm}$ diameter holes were cut in the plastic lids, one on each half of the lid. A cut was made from each hole to the lid edge so the tree could be removed from the lid when needed for an experiment. One cutting was placed in each hole and held in place by a foam stopper, then the lid was secured to the bucket. The nutrient solution was changed every ten days. Every other day the $\mathrm{pH}$ was checked and sodium hydroxide added to the solution if the $\mathrm{pH}$ was found to be lower than 5.8. Eight saplings were cultivated for five months under greenhouse conditions with a photoperiod of 16 hours, as shown in Figure (1). Experimentation commenced after this growing period. Trees grew during the experimentation period and ranged in height from about $75 \mathrm{~cm}$ to 1 meter above the bucket lid level of $26 \mathrm{~cm}$. Leaf counts were made at the time of each experiment and leaf area was calculated as described below.

To perform an experiment, one tree was removed from the growing vessel and the tree's roots placed in an acrylic root chamber based on a design used by Rusch and Rennenberg [1998], as depicted in Figures (2), (3) and (4). The chamber was filled with deionized water through which natural gas had been bubbled until a high 


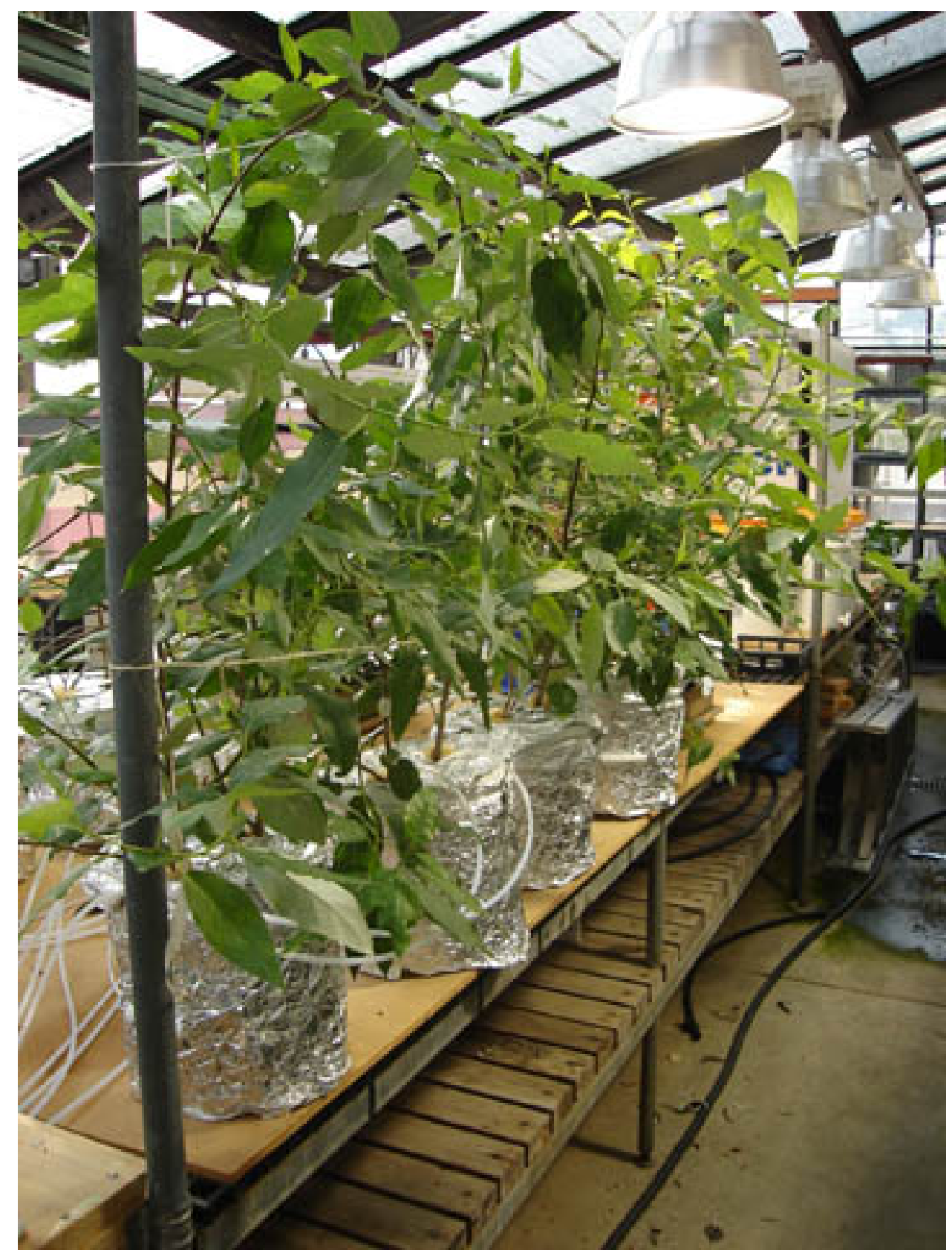

Figure 1: Depiction of hydroponic growth setup of black cottonwood cuttings. 
concentration of $\mathrm{CH}_{4}$ was reached. The root chamber was closed around the tree stem and sealed around the stem with modeling clay to separate the water and roots from the ambient air. Electrical tape was used to cover the seams of the root chamber lid. Aluminum foil covered the transparent root chamber to protect the roots from ambient light. After enclosing the tree in the root chamber, the system was left in the greenhouse for at least three hours before samples were taken in the afternoon or early evening.

The water level in the root chamber was marked once the tree roots were enclosed and the chamber sealed. Just before an experiment, the water level was refilled to the initial marked level. The amount of water used to refill the root chamber was taken as a measurement of water transpired by the tree. Just before the experiment, leaf temperature, ambient temperature and relative humidity were recorded. For sampling, a 100 liter tedlar bag was used to enclose the entire canopy of the tree. Since the bottom of the bag had been cut off and some of the bag material wrapped around the tree stem to seal the canopy, the net volume of the bag was approximately 90 liters. $20 \mathrm{~mL}$ of canopy air was sampled with a syringe from a septum on the tedlar bag every five minutes for a half hour, beginning as soon as the tedlar bag was closed around the base of the stem. $10 \mathrm{~mL}$ water samples were taken every ten minutes using a syringe from a sampling port on the root chamber. $20 \mathrm{~mL}$ ambient air samples were taken just after the bag was closed and just before it was removed. These samples were then run on a Agilent model 6890 gas chromatograph (GC) with a flame ionization detector (FID)[Khalil et al., 1998]. The rate of $\mathrm{CH}_{4}$ accumulation in the chamber was analyzed by linear regression to obtain the net $\mathrm{CH}_{4}$ flux. Water samples were mixed with $20 \mathrm{~mL} \mathrm{~N}_{2}$ and agitated by shaking for five minutes. The 


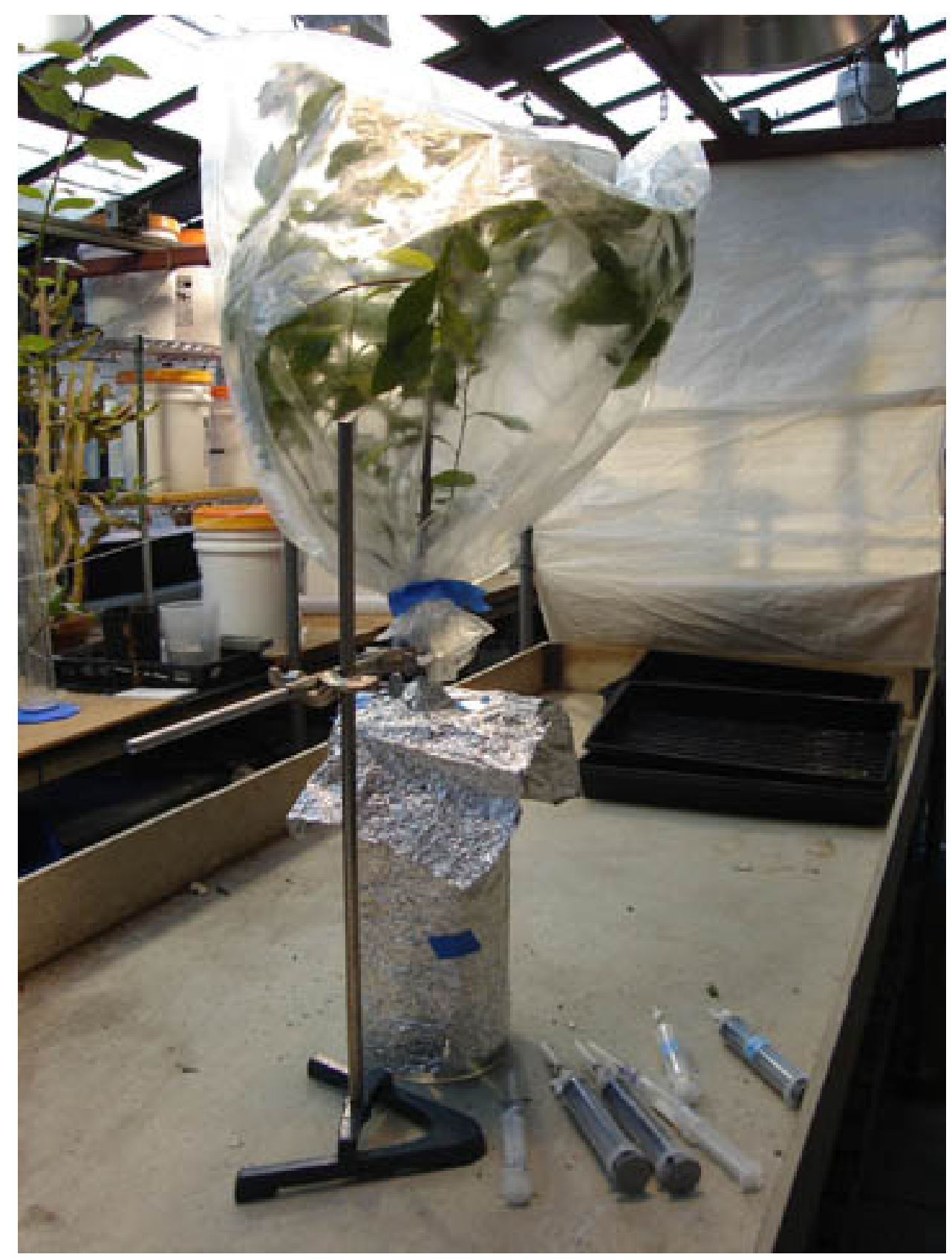

Figure 2: Depiction of experimental setup. During sampling, a tedlar bag is placed over the canopy and secured around the stem of the tree just above the top of the root chamber. 


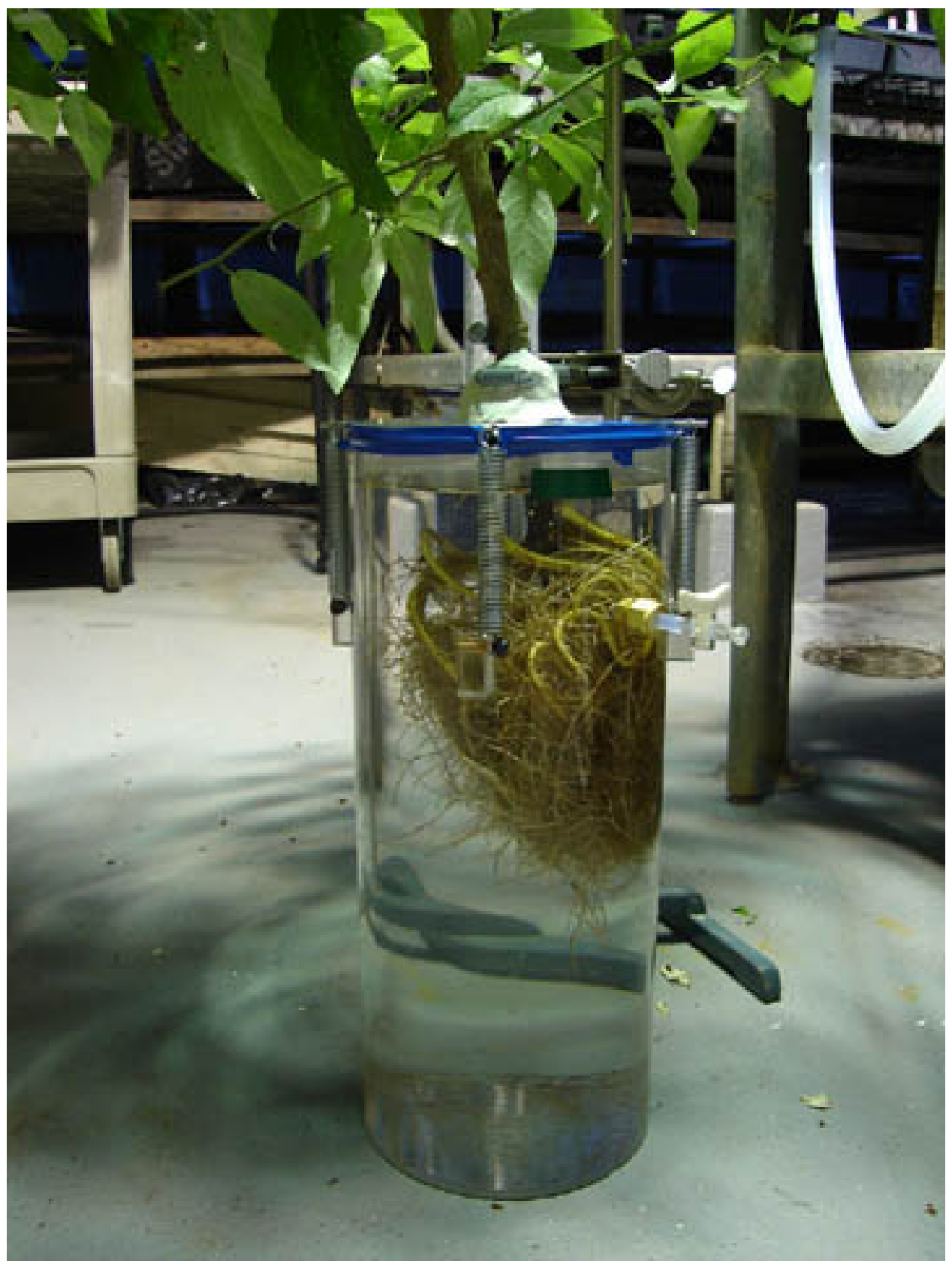

Figure 3: Depiction of experimental setup showing the tree roots enclosed and sealed in the root chamber. 


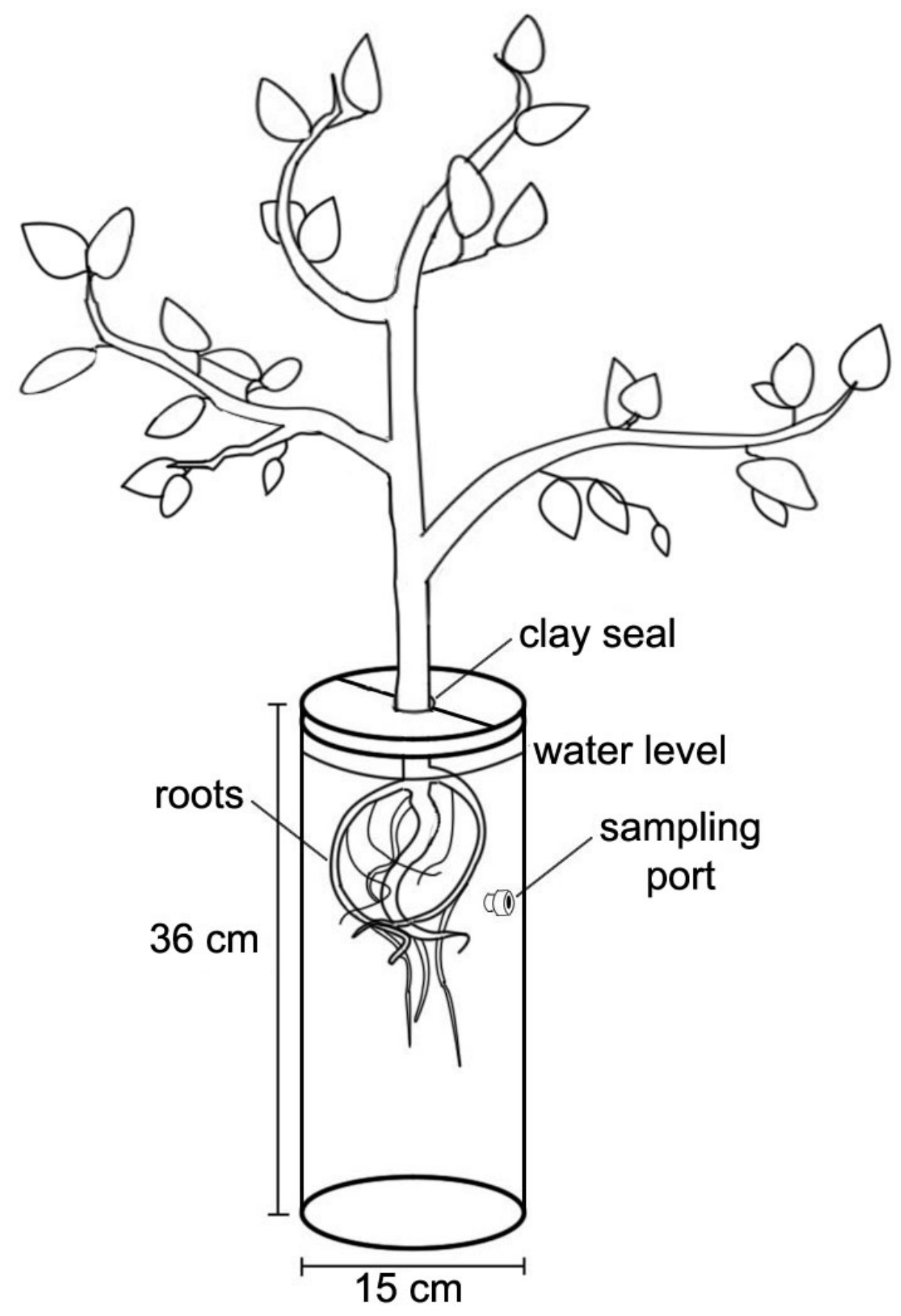

Figure 4: Depiction of experimental setup with dimensions. 
water was then expelled and the $\mathrm{CH}_{4}$ concentration determined by measurement on the GC-FID. The dissolved $\mathrm{CH}_{4}$ concentration of the water was calculated by the method described in Lu et al. [2000].

Samples were also taken at 30 minutes to measure the carbon isotopic composition, $\delta^{13} \mathrm{C}$ of $\mathrm{CH}_{4}$. Two $60 \mathrm{~mL}$ sample syringes were filled from the canopy bag, two from the ambient air, and $10 \mathrm{~mL}$ water was taken from the root chamber to be mixed with $50 \mathrm{~mL} \mathrm{~N} \mathrm{~N}_{2}$ and processed as described above. These samples were injected into stoppered $45 \mathrm{~mL}$ glass storage vials. Syringe samples from these vials were measured by continuous-flow gas chromatography-isotope ratio mass spectrometry on a Thermo Scientific Delta V Advantage IRMS using the method described in Rice et al. [2001]. Values for the canopy $\mathrm{CH}_{4}$ were corrected using the ambient greenhouse samples.

By convention the ratio of heavy to light isotopes of $\mathrm{CH}_{4}$ is expressed with the delta notation as

$$
\delta \%=\left[\frac{R_{\text {samp }}}{R_{\text {std }}}-1\right] * 1000
$$

where $R_{\text {samp }}={ }^{13} \mathrm{C} /{ }^{12} \mathrm{C}$ and $R_{\text {std }}$ is the known ratio of Vienna PeeDee belemnite limestone (VPDB) [Gonfiantini et al., 1995]. The values of $\delta^{13} \mathrm{C}$ found by the method described above are reported relative to the VPDB scale in equation (1).

Discrimination for or against ${ }^{13} \mathrm{C}$ in a particular process can be expressed by the ratio of ${ }^{13} \mathrm{C}$ to ${ }^{12} \mathrm{C}$ for the process, or

$$
\alpha=\frac{R_{A}}{R_{B}}
$$

where $R_{A}$ is the ${ }^{13} \mathrm{C} /{ }^{12} \mathrm{C}$ ratio prior to the process and $R_{B}$ is the ratio afterwards. 
The process may be a chemical reaction, dissolution from water into a gas phase, or diffusion along a gradient. $\alpha$ is known as the fractionation factor. Also convenient is the expression

$$
\epsilon=(\alpha-1) * 1000
$$

Using equation (1) this can be written as

$$
\epsilon=\left[\frac{\delta_{A}+1000}{\delta_{B}+1000}-1\right] * 1000
$$

It can be shown [Hoefs, 2004] that for small values of $\epsilon$,

$$
\epsilon \sim \delta_{A}-\delta_{B}
$$

Canopy $\mathrm{CH}_{4}$ flux from each of the eight trees was measured twice during November and December of 2010, and a third and fourth time on six of the original trees in March and April of 2011. Some growth occured between the fall and spring trials. Leaf area was measured between the 2010 and 2011 set of flux measurements and calculated non-destructively. Stem diameters were also recorded. The leaves of all eight trees were then photographed on a background with an area scale marker and the leaf area was found by pixel counting in Adobe Photoshop. All the leaves on one tree were traced on paper, cut out, and weighed. Leaf area was calculated using the area-to-mass ratio of the paper. A small difference was found between the two methods, the pixel-count method yielding $0.45 \mathrm{~m}^{2}$ and the paper method $0.46 \mathrm{~m}^{2}$. The pixel-calculated areas for the other seven trees were corrected using the factor by which the leaf tracing method and the pixel counting method differed on the first 
tree. Leaf areas ranged from $0.09 \mathrm{~m}^{2}$ to $0.49 \mathrm{~m}^{2}$ with an average of $0.34 \mathrm{~m}^{2}$. Leaf counts ranged from 125 to 424 leaves per tree with an average of 289 per tree. The correlation between leaf count and leaf area yielded a determination coefficient of $\mathrm{r}^{2}$ $=0.79$. Stem diameters were measured also. The diameter measurement was taken at $22 \mathrm{~cm}$ from the bottom of the original cutting, which was approximately the height where root growth from the cutting began. Stem diameters ranged from $0.010 \mathrm{~m}$ to $0.016 \mathrm{~m}$ with an average of $0.013 \mathrm{~m}$.

\subsection{Temperature Experiments}

As one of the most influential environmental parameters, temperature may have an effect on the magnitude of $\mathrm{CH}_{4}$ emissions. One of the goals of this study was to discover any relationship between temperature and $\mathrm{CH}_{4}$ flux from trees. Black cottonwood was grown hydroponically as previously described. The five trees used in the temperature experiment were taken as cuttings from one black cottonwood tree growing in the Sandy River Delta, Troutdale, Oregon, on September 19 $9^{\text {th }}$, 2011. Six cuttings were taken and rooted in three buckets containing a modified Hoagland solution. Daylength was set at a sixteen hour photoperiod. Solution was refreshed every ten days and solution $\mathrm{pH}$ maintained around the ideal of 5.8 for nutrient absorption.

Temperature experiments began on January $30^{\text {th }}, 2012$, and ran for just over three weeks. Each week, the trees were moved to a greenhouse room with a different temperature while other environmental factors such as day length were kept as constant as possible. Two trials during the third week were repeated the following week at the same temperature as the third week. The average day-time temperature was $22.3^{\circ} \mathrm{C}$ the first week, $25.2{ }^{\circ} \mathrm{C}$ the second week, and $17.1^{\circ} \mathrm{C}$ the third week. 
Natural gas was bubbled through deionized water in the root chamber for approximately 45 minutes before the start of each experiment. The root chamber was then placed on a scale (Mettler Toledo, New Classic MF, model MS1200 1L) in the greenhouse and weighed. After moving the tree from the growing container to the root chamber, the difference in weight was recorded as tree weight. Once secured in the sealed root chamber, the initial water level in the root chamber was marked and the total number of leaves counted before leaving the tree in greenhouse. After approximately three hours, the difference in water level was noted and water refilled through the root chamber water sampling port to the original level. The canopy experiment immediately followed, as outlined above for the 2010-2011 canopy experiments. Temperature and relative humidity were recorded once the tree was secured in the root chamber and during the experiment. Canopy samples, root water samples, and samples for the determination of isotopic composition were taken and processed in the same manner as previously described.

\subsection{Stem Experiments}

In the interest of separating stem emission from any potential emission occuring from the leaves, two acrylic cylindrical stem cuvettes $(20 \mathrm{~cm}$ in length, $5.8 \mathrm{~cm}$ radius) were used to measure flux exclusively emitted from the stem, based on a design used by Rusch and Rennenberg [1998] and depicted in Figures (5) and (6). These cuvettes can be attached around a section of stem $11.7 \mathrm{~cm}$ in length, or $0.23 \mathrm{~m}$ if both stem chambers are used. Following the overall procedure outlined above for experimental preparation, instead of the tedlar bag, the stem cuvettes were attached for a half hour around the tree stem while flux samples were taken every five minutes from 
each cuvette. Cuvettes were placed along the main stem of the tree, one above the other. Water concentration samples were taken as they were for the canopy flux experiments.

The first stem chamber trial was performed in April 2011; the later three trials took place in November and December of 2012. The second and third trials were done with the same tree. All three later trials also included samples from the headspace of the root chamber along with water concentration samples.

The main vertical tree stem in the first trial was measured to be 0.90 meters high, with the lower stem chamber approximately 0.30 meters above the top of the root chamber and the upper chamber directly on top of the lower chamber. The second and third trials used a tree extending $0.49 \mathrm{~m}$ above the root chamber (an additional $0.76 \mathrm{~m}$ of stem length grew out from the side of the tree's top, however this height was not included in calculations). In these trials, the lower chamber was about 0.03 $\mathrm{m}$ above the root chamber top, with the upper chamber about $0.02 \mathrm{~m}$ above the lower chamber. The fourth trial used a tree $1.62 \mathrm{~m}$ in height above the root chamber. In this final trial, the lower chamber was $0.04 \mathrm{~m}$ above the root chamber top and the upper chamber was $0.14 \mathrm{~m}$ above the lower chamber. Stem chamber heights are also summarized in the results below.

\subsection{Leak Tests, Canopy Flux Series Experiments and Full Chamber Ex- periments}

It was noticed during the canopy flux experiments that the amount of $\mathrm{CH}_{4}$ lost from the root chamber was significantly greater than the amount of $\mathrm{CH}_{4}$ leaving by canopy emission. Several experiments were conducted to test for leaks in the root chamber. 


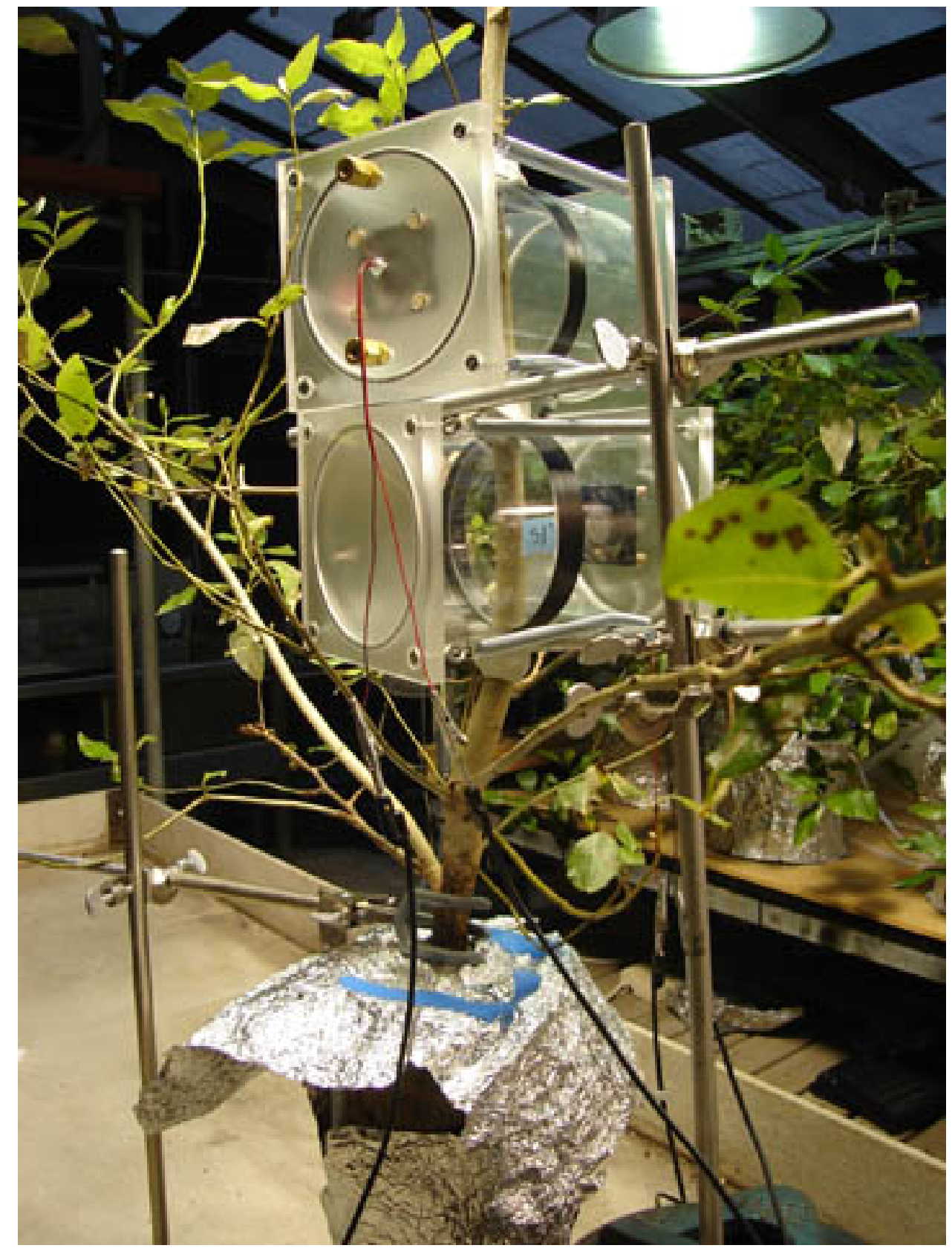

Figure 5: Depiction of experimental setup with stem chambers. 


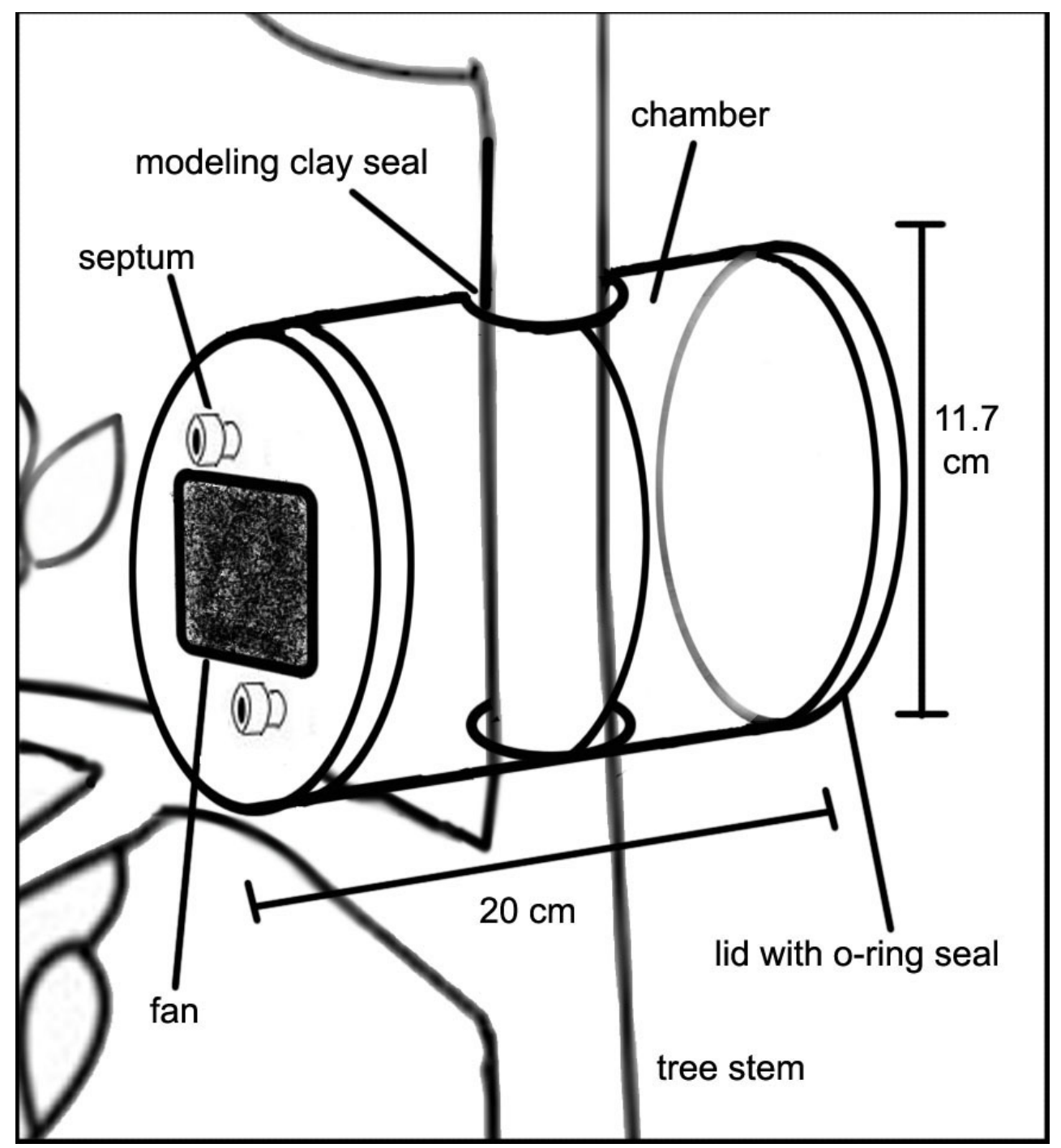

Figure 6: Depiction of stem chamber attached to tree. Stem chamber design is based on [Rusch and Rennenberg, 1998]. Actual lid pieces are square bases into which the cylindrical halves of the chamber fit, sealed with an o-ring. Not depicted are the four springs, one at each corner of the square lid base, that attach to the opposite lid piece and hold the chamber together by tension. Modeling clay is used to seal between the chamber and the tree stem; electrical tape is run along the middle seam of the chamber to prevent any leaking. Two wires running from the chamber fan and sealed through the lid with glue connect to a 12 -volt battery external to the chamber. 
Before any experimentation whatsoever in 2010, all three stem chambers and the root chamber were tested for leaks. This was done by injecting a known amount of $\mathrm{CH}_{4}$ into the chambers, sealing them, and taking samples every 15 minutes for one hour. No leaks were detected at this time. The experiment was repeated again for 120 minutes. A small leak was found in one stem chamber; this chamber was not subsequently used for any experiment. No other chambers were found to leak under these conditions.

A second type of leak test was performed in November of 2012, where the root chamber was sealed without a tree after bubbling $\mathrm{CH}_{4}$ through the water, and the top aperture closed with modeling clay. Headspace and water concentration samples were taken seven times over two days, with a final sample taken on day fifteen. A leak of approximately $1.5 \mu$ moles $\mathrm{CH}_{4} \mathrm{~min}^{-1}$ was detected over the first 220 minutes, falling to $0.95 \mu$ moles $\mathrm{CH}_{4} \min ^{-1}$ by the end of the second day. The magnitude of this leak in relation to flux will be discussed in the results section.

A set of series experiments were performed to investigate the partitioning of $\mathrm{CH}_{4}$ between the root water, root chamber headspace, tree, and that leaving by tree emission. The total amount of $\mathrm{CH}_{4}$ in the root chamber at the beginning of the experiment was known; therefore later measurements of $\mathrm{CH}_{4}$ concentration in the root chamber indicated the amount of $\mathrm{CH}_{4}$ that must have exited the root chamber water. Experimental setup and methods follow the design described above for the canopy flux experiments with the following modificaitons. Instead of one set of samples taken from the tedlar bag covering the canopy, the tree remained in the root chamber over a longer period of time and several half-hour samplings were conducted, the tedlar bag being removed between each half-hour sampling. Just before taking each set of 
samples, the water level in the root chamber was noted and refilled to the original level. Additionally, the headspace of the root chamber was sampled once before and after each canopy sampling. This was done by partly removing the clay seal and taking a $20 \mathrm{~mL}$ syringe sample from the headspace above the root chamber water level, quickly resealing the clay in place afterwards. Total amounts of $\mathrm{CH}_{4}$ in the root water, root chamber headspace, and that lost by $\mathrm{CH}_{4}$ flux could then be compared. Any amount not accounted for was assumed to remain in the tree itself.

The following methods describe how the values reported in the results tables presented below were derived. Canopy $\mathrm{CH}_{4}$ flux was measured over the usual halfhour sampling period. It was assumed that the measured flux is an average of the flux since the previous sampling period or time 0 in the case of the first sampling. This flux was multiplied by the time since the previous sampling to give the amount of $\mathrm{CH}_{4}$ that would have been lost from the canopy flux in that time. Transpiration rate was based on the amount of water lost since the previous sample period and not from time 0 except in the case of the first sampling. The headspace concentration of $\mathrm{CH}_{4}$ was measured just before the half-hour sampling period and the total amount of $\mathrm{CH}_{4}$ in the headspace calculated based on the volume of the headspace at the time of sampling. The volume of the root water was also measured at this time. Total $\mathrm{CH}_{4}$ in the root water was determined from this volume and the $\mathrm{CH}_{4}$ concentration in the root water samples taken during the half-hour sampling period. $\mathrm{CH}_{4}$ lost from the root chamber was calculated by subtracting the water and headspace concentrations at the time flux measurements were taken from the water and headspace concentrations at the time the tree was first sealed in the root chamber. This should not be confused with the $\mathrm{CH}_{4}$ lost only from the root water. 
An estimation of $\mathrm{CH}_{4}$ loss from the root chamber was made based on the loss of root water. At a given sampling period, the amount of water transpired out of the root chamber was measured. Root water concentration of $\mathrm{CH}_{4}$ was also measured at that time. Using this concentration and the amount of water lost, the total amount of $\mathrm{CH}_{4}$ lost from the root chamber could be estimated. In order to do this, the assumption had to be made that the measured concentration of $\mathrm{CH}_{4}$ in the root water was constant since the previous sampling or time 0 in the case of the first sampling. The $\mathrm{CH}_{4}$ concentration actually decreases over time, but the assumption is made for the sake of the estimation. As shown in the results, this amount is significantly less than the actual amount of $\mathrm{CH}_{4}$ lost from the root chamber. Finally, an estimation of $\mathrm{CH}_{4}$ loss from the leak found in the second leak test described above (approximately $1.5 \mu$ moles $\mathrm{CH}_{4} \mathrm{~min}^{-1}$ for the first 220 minutes, falling to $0.95 \mu$ moles $\mathrm{CH}_{4} \mathrm{~min}^{-1}$ by the end of the second day of the test) is made for each experiment in the results tables depending on the length of the experiment.

An additional type of test was conducted where the entire root chamber and tree were placed in a plastic tub with a trough around the outside upper edge to hold water, shown in Figure (7). A rectangular chamber constructed of PVC and plastic sheeting was then placed over the tub so that the lower edges of the chamber were held by the trough and sealed from air exchange by filling the trough with water. Flux samples were taken from the PVC chamber. These samples represent any flux from the canopy and actual leaks from the root chamber. Three trials were performed, one in November and two in December of 2012. The second and third trials were performed on the same tree. Results are described below. 


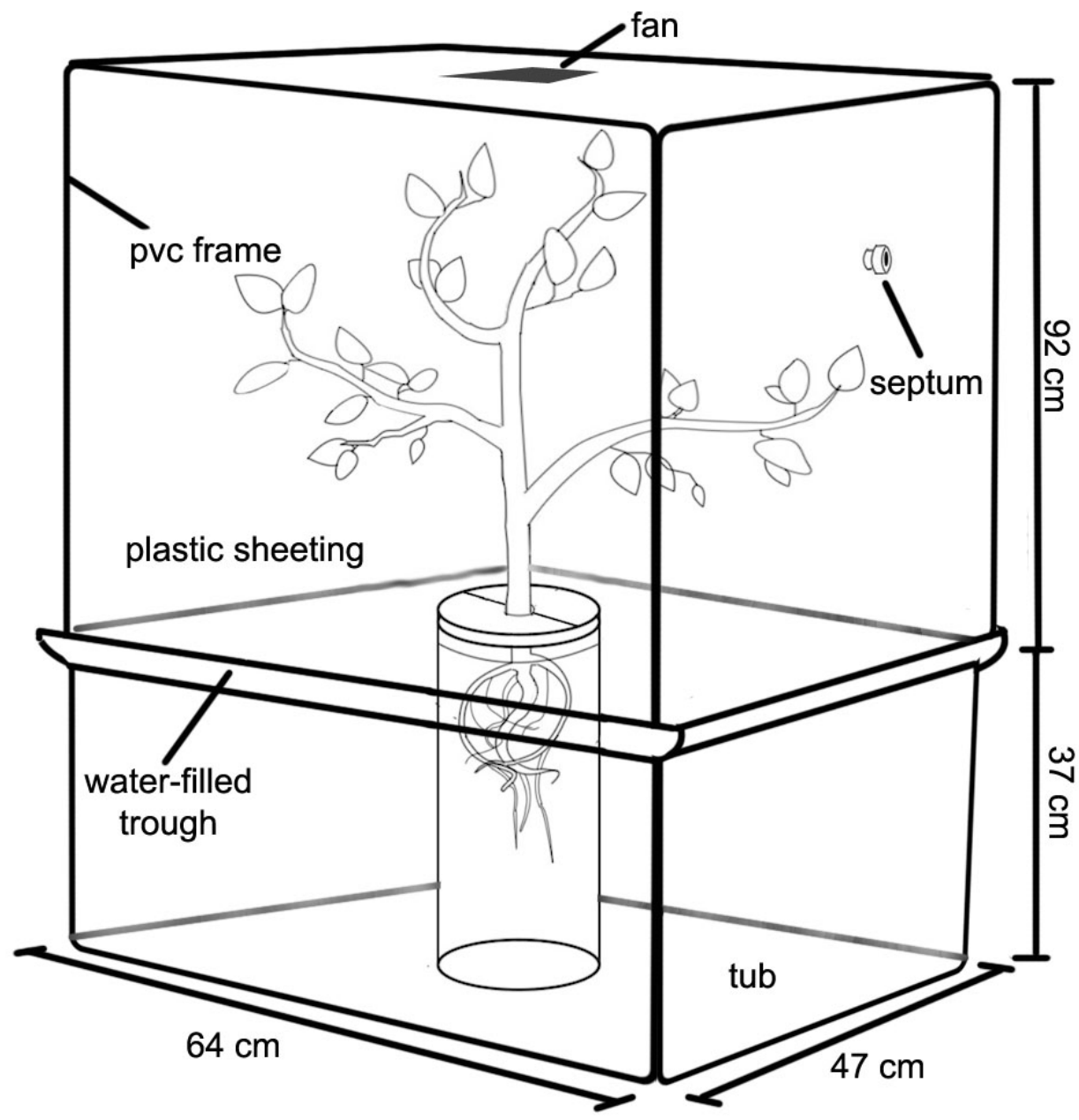

Figure 7: Experimental setup for the full-chamber leak test. After the tree is secured in the root chamber, the tree and root chamber are placed in a tub with a trough containing water. A PVC frame covered with plastic sheeting fits into the trough so that the water seals the interior from the outside. Samples are taken from the septum. Any leaks from the root chamber will be included in the overall $\mathrm{CH}_{4}$ concentration in the PVC chamber. 


\section{Results}

\subsection{Canopy Flux Experiments}

Significant relationships between environmental and physiological parameters found in the canopy flux experiments of 2010-2011 are reported in Table (1). Any of these relationships or variations of them that were tested in the 2012 temperature experiments are also reported in this table for comparison. The relationships are shown graphically in the figures following the table.

The amount of water refilled in the root chamber just before a trial and taken to represent the water transpired ranged from $30 \mathrm{~mL}$ to $500 \mathrm{~mL}$ with an average of 177 $\mathrm{mL}$ (the total initial volume of root chamber water was approximately $6000 \mathrm{~mL}$ ). In terms of water loss from the root chamber per time, the average was $0.82 \pm 0.59 \mathrm{mmol}$ water $\mathrm{s}^{-1}$. It should be noted that this rate may not represent the transpiration rate during the half-hour sampling period as conditions within the tedlar bag may have altered stomatal conductance. Some temperature variation occured from experiment to experiment due to greenhouse conditions. The average leaf temperature for a given trial was $20^{\circ} \mathrm{C}$, although it ranged from $16^{\circ} \mathrm{C}$ to $24^{\circ} \mathrm{C}$ with one trial at $34^{\circ} \mathrm{C}$. Root water concentration in all trials was relatively high at an average of $703 \pm 100 \mu \mathrm{mol}$ $\mathrm{CH}_{4} \mathrm{~L}^{-1}$ water, which is comparable to $\mathrm{CH}_{4}$ concentrations in potted, flooded soils without plants [Rice et al., 2010].

Concentration of $\mathrm{CH}_{4}$ in the tedlar bag versus time was graphed for the 28 canopy trials performed in the 2010-2011 canopy flux experiments. Of these 28 trials, 18 had an r-squared value over $0.95,3$ had an r-squared value between 0.9 and $0.95,3$ had an r-squared value between 0.75 and 0.9 , and for 4 trials the r-squared value was 
less than 0.75. This indicates that for the canopy, emissions are normally linear over the half-hour sampling period. Statistical analysis below will refer to the 18 trials with r-squared values over 0.95 , leaving out trials where inconsistent factors may have altered fluxes. The average flux for these 18 trials was $3.0 \pm 2.6 \mu \mathrm{g} \mathrm{CH}_{4} \mathrm{~min}^{-1}$. For comparison, the average flux during the 2012 temperature experiments was $2.5 \pm 1.6$ $\mu \mathrm{g} \mathrm{CH}_{4} \mathrm{~min}^{-1}$, although this value varied significantly with temperature as will be discussed in the section on the temperature experiments below.

Results from the canopy samples taken for isotopic composition analysis during the canopy flux experiments are reported in Table (2). These measurements were repeated during the 2012 temperature experiments and are reported in Table (3). A strong correlation exists between $\delta^{13} \mathrm{C}$ of the emitted $\mathrm{CH}_{4}$ and flux, as shown in Table (1), and Figures (34), (35), and (36). These correlations exist in spite of the fact that there are large corrections in the $\delta^{13} \mathrm{C}$ data. It is likely, therefore, that the $\delta^{13} \mathrm{C}$ is in fact capturing variations in the transport mechanisms; no matter what mechanism is at work, it is likely represented by the $\delta^{13} \mathrm{C}$ value. $\delta^{13} \mathrm{C}$ values for the canopy flux experiments are shown in Table (2). The average value for epsilon $(\epsilon)$, the amount by which the tree transport mechanisms discriminate against ${ }^{13} \mathrm{C}$, is $8.6 \pm 3.3 \%$. The value of epsilon varies with temperature and is discussed in the next section. 


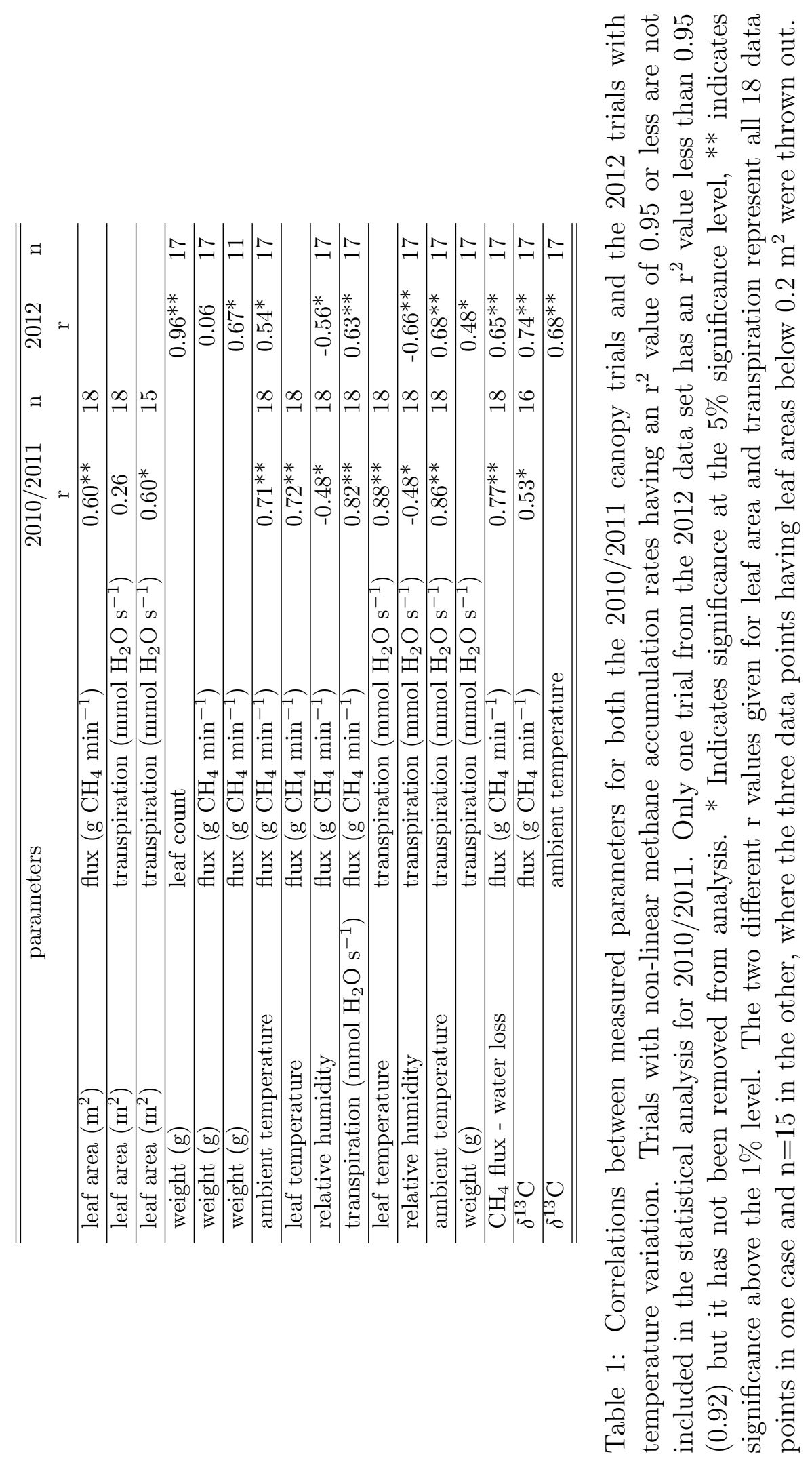



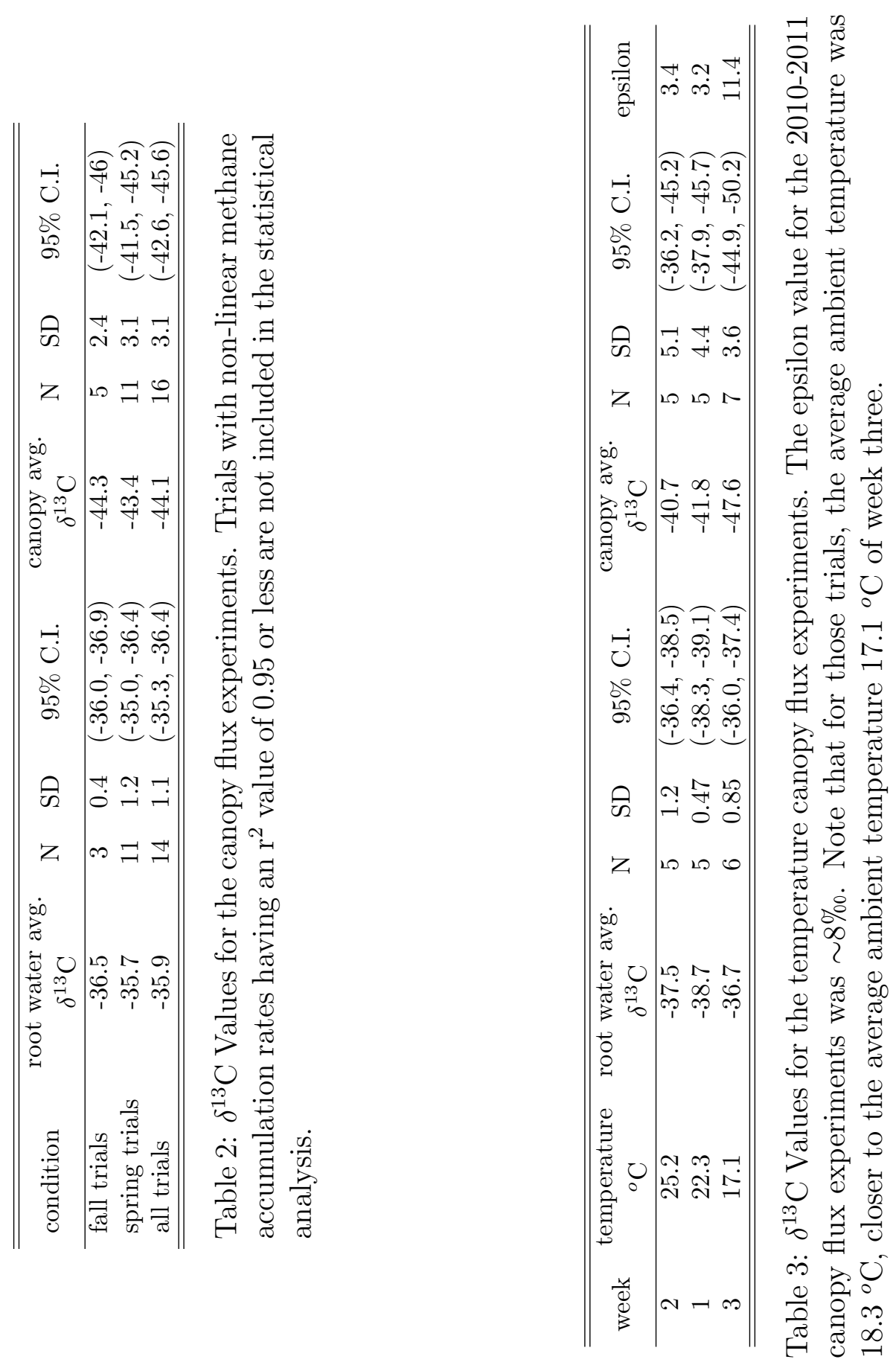


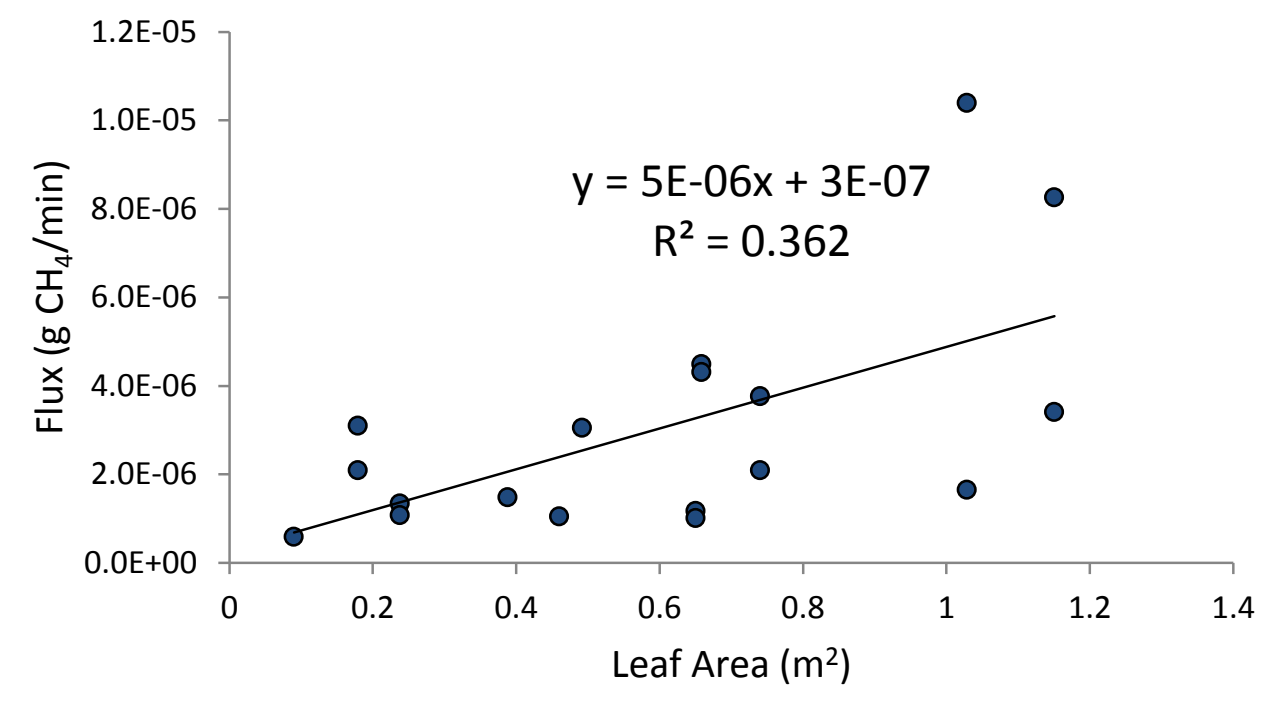

Figure 8: $\mathrm{CH}_{4}$ flux measured from the canopy versus leaf area, $\mathrm{n}=18.2011$ data.

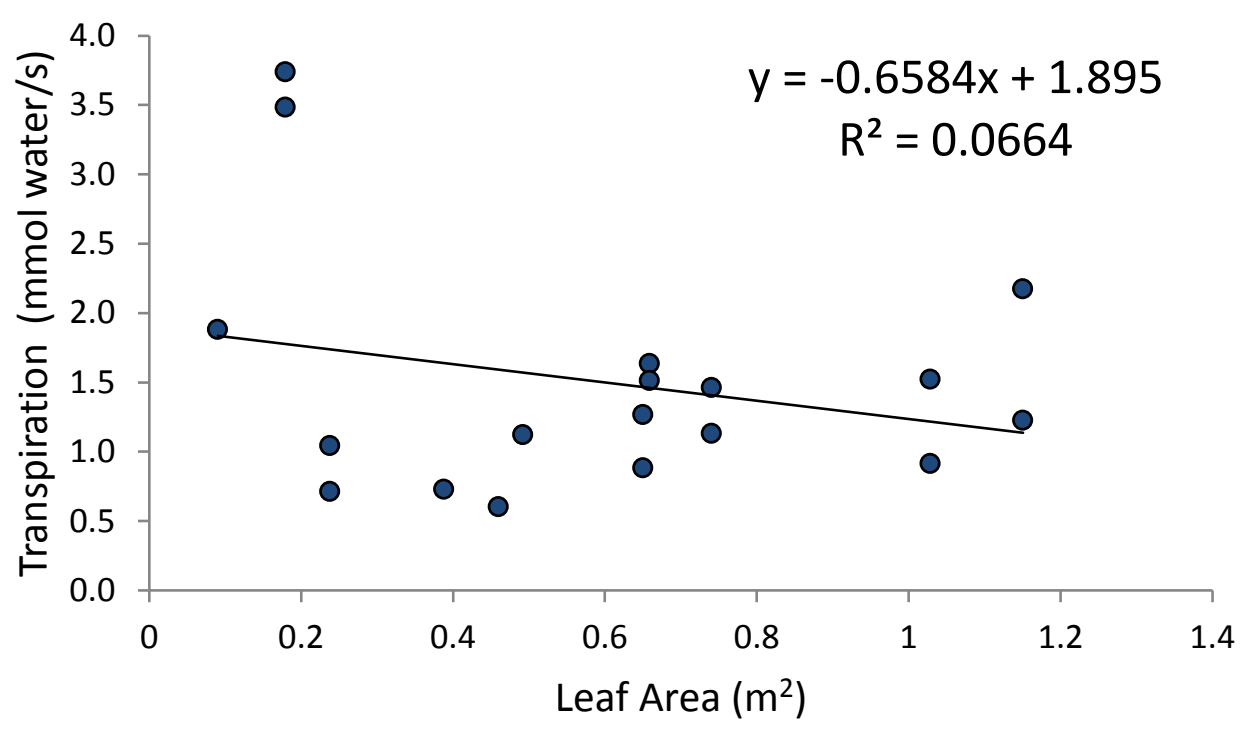

Figure 9: Transpiration versus leaf area, $n=18.2011$ data. 


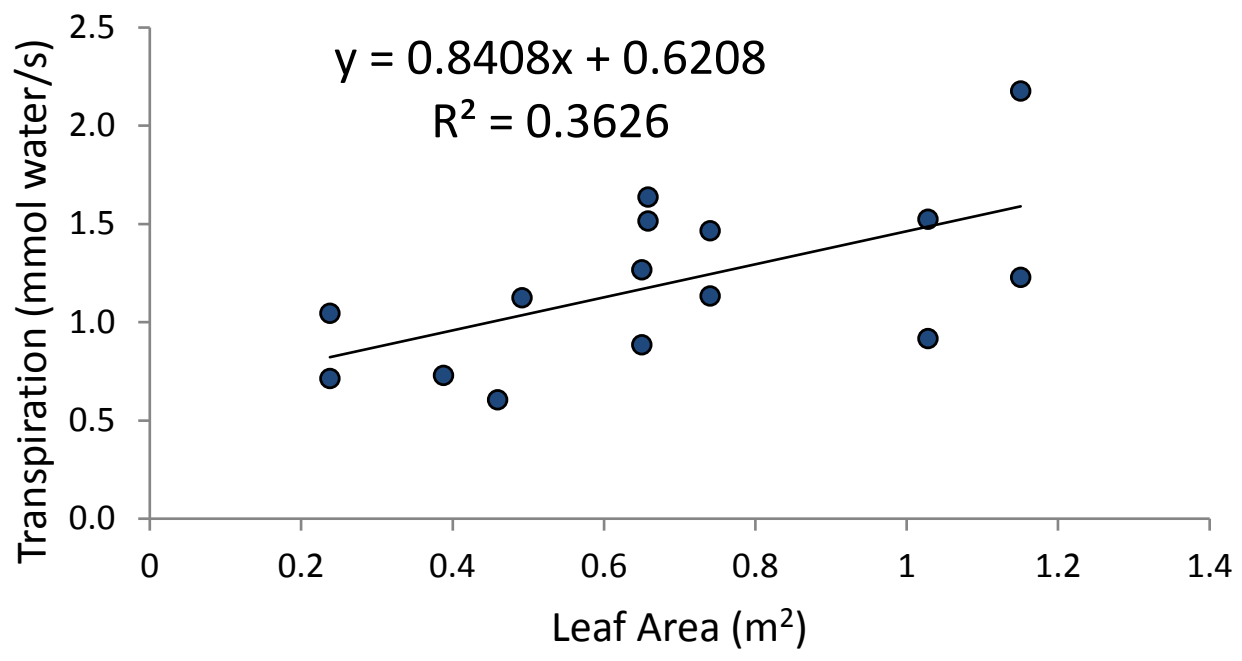

Figure 10: Transpiration versus leaf area without the three data points having leaf areas below $0.2 \mathrm{~m}^{2}, \mathrm{n}=15.2011$ data.

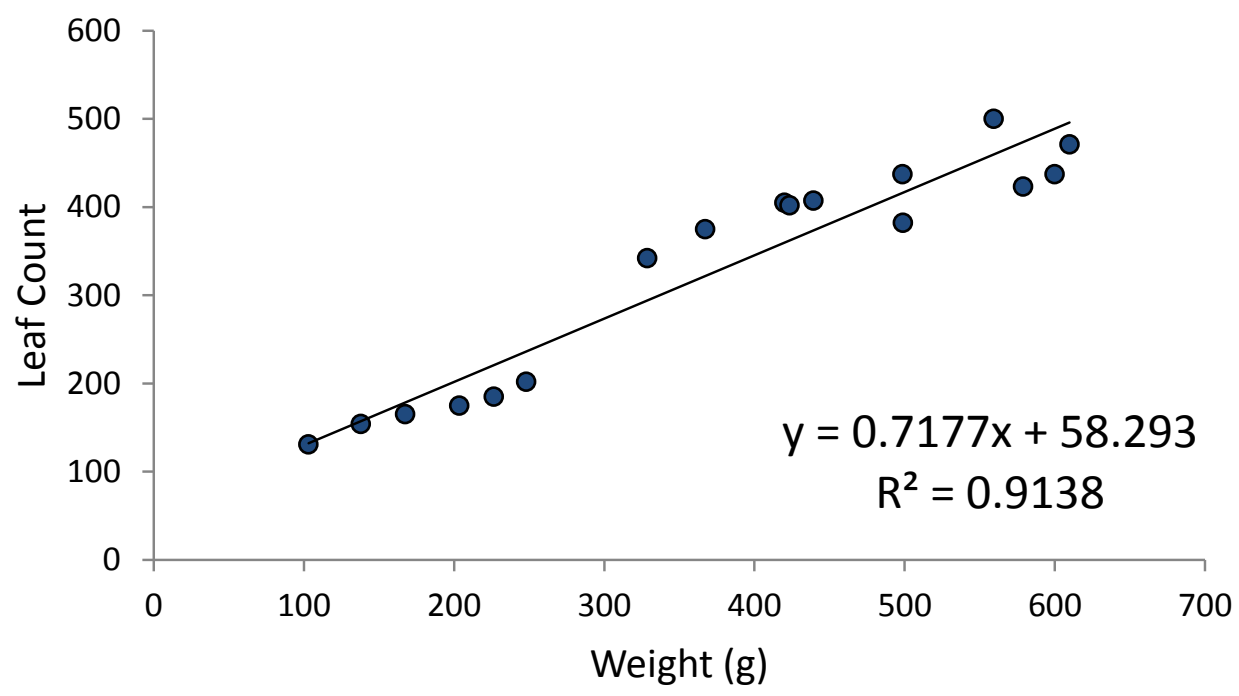

Figure 11: Leaf count versus tree weight, $n=17.2012$ data. 


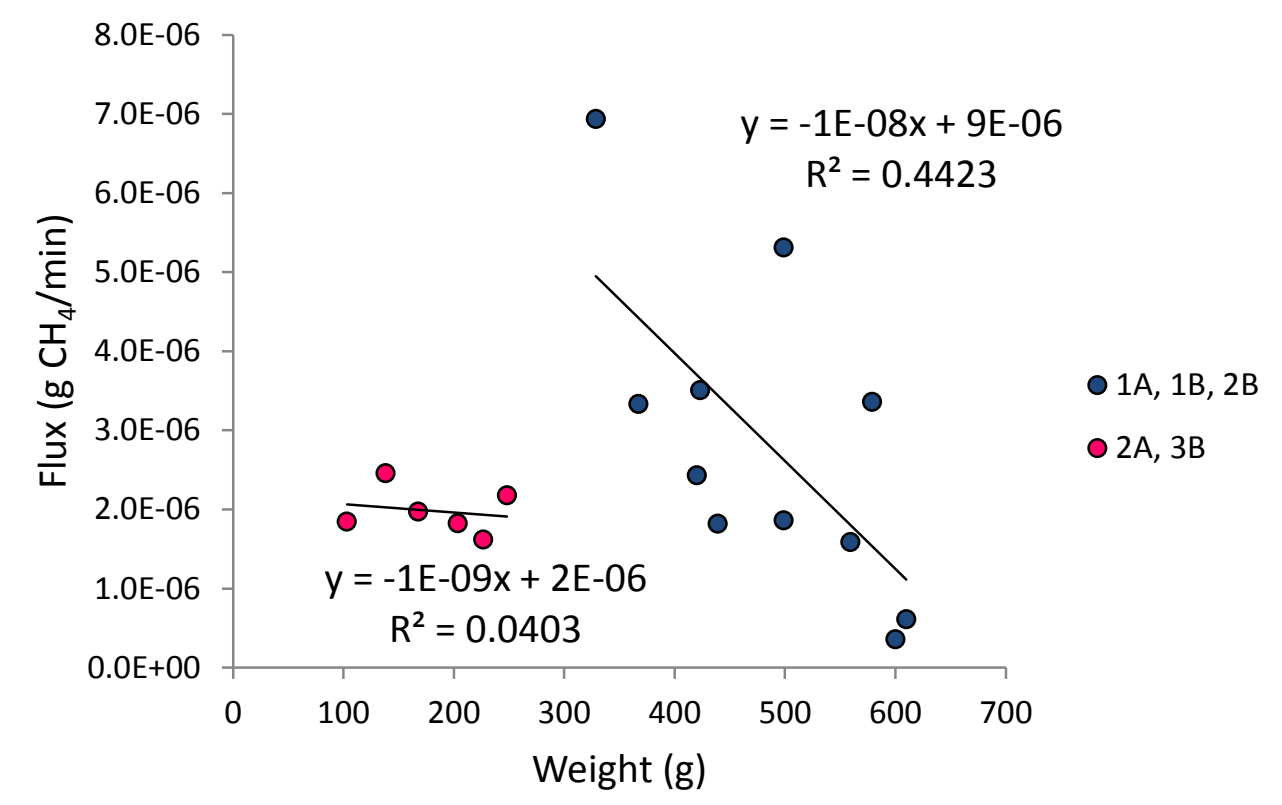

Figure 12: $\mathrm{CH}_{4}$ flux versus tree weight, $\mathrm{n}=17.2012$ data. The separation of the two groups of trees indicates there is some physiological difference in the transport capability of the trees. This may be represented by a difference in some internal barrier to $\mathrm{CH}_{4}$ transport.

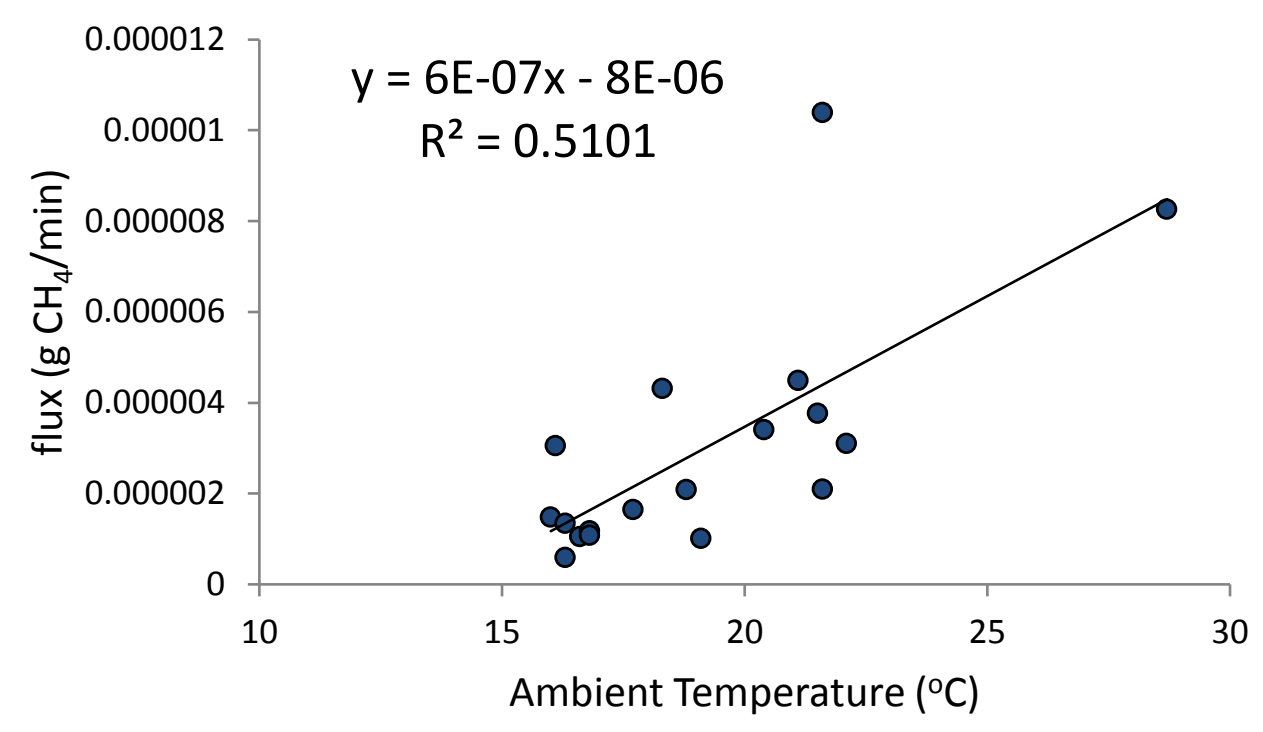

Figure 13: $\mathrm{CH}_{4}$ flux versus ambient temperature, $\mathrm{n}=18$. 2011 data. 


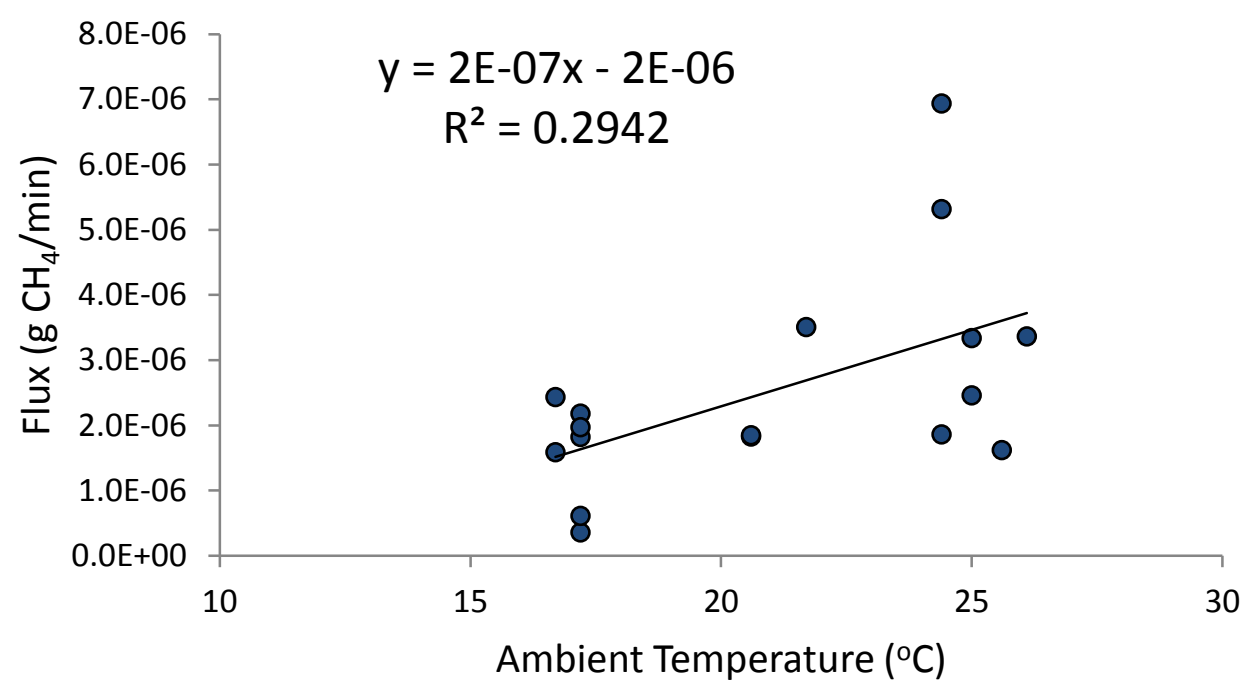

Figure 14: $\mathrm{CH}_{4}$ flux versus ambient temperature, $\mathrm{n}=17.2012$ data.

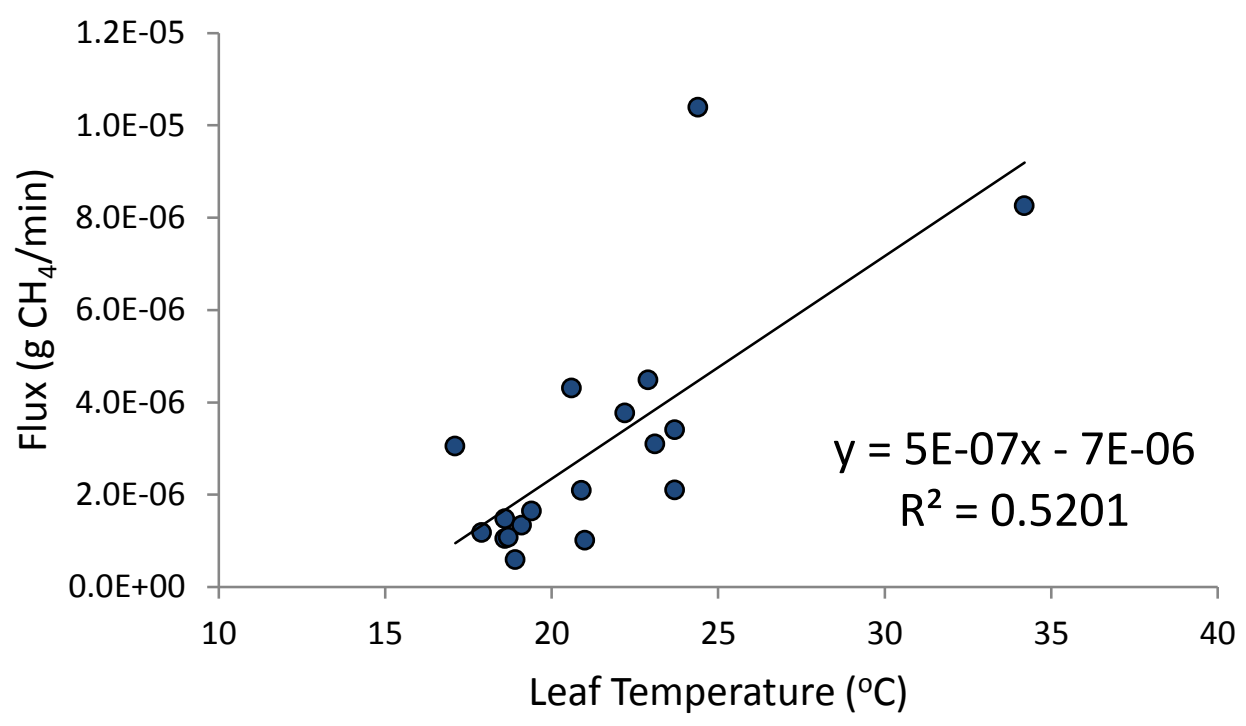

Figure 15: $\mathrm{CH}_{4}$ flux versus leaf temperature, $\mathrm{n}=18$. 2011 data. 


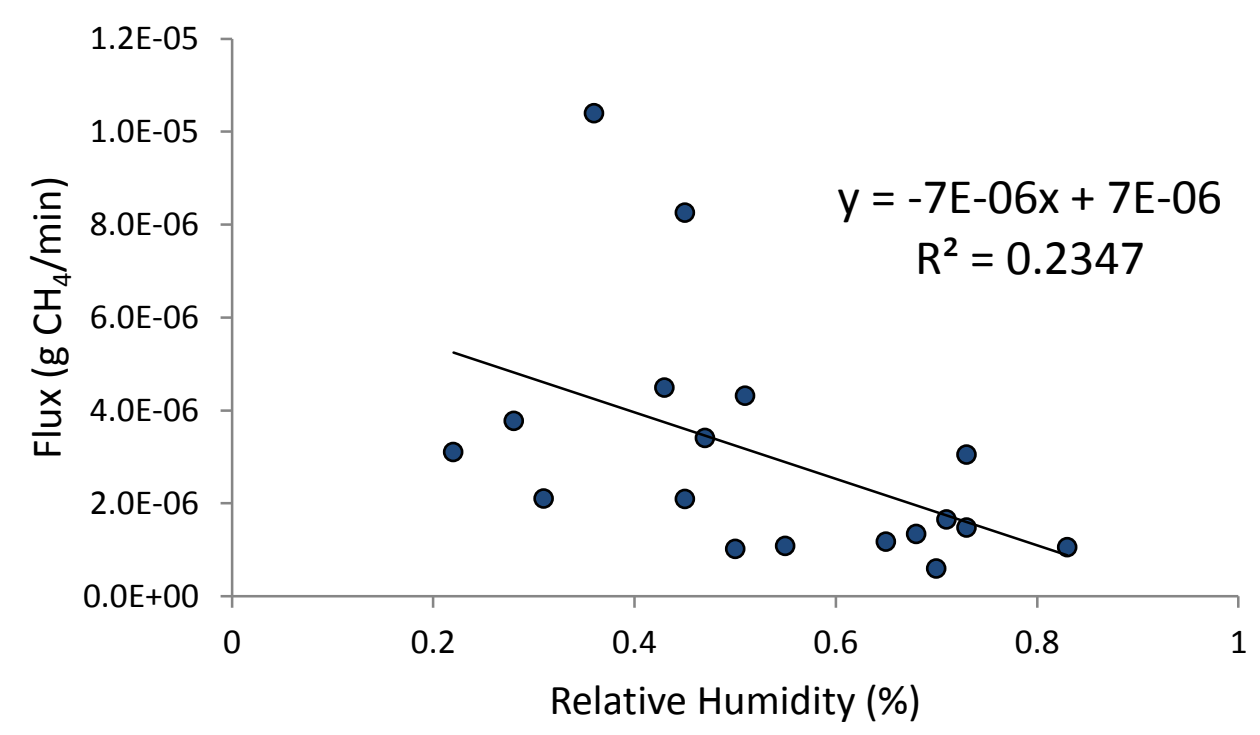

Figure 16: $\mathrm{CH}_{4}$ flux versus relative humidity, $\mathrm{n}=18$. 2011 data.

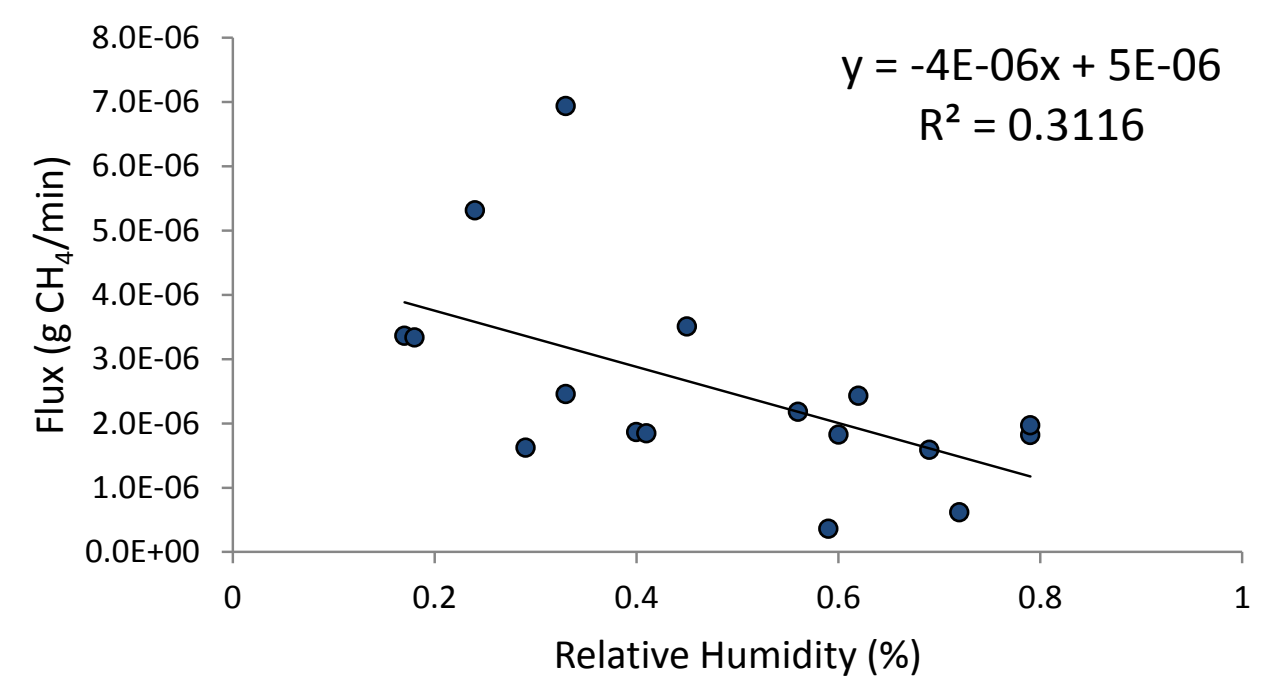

Figure 17: $\mathrm{CH}_{4}$ flux versus relative humidity, $\mathrm{n}=17.2012$ data. 


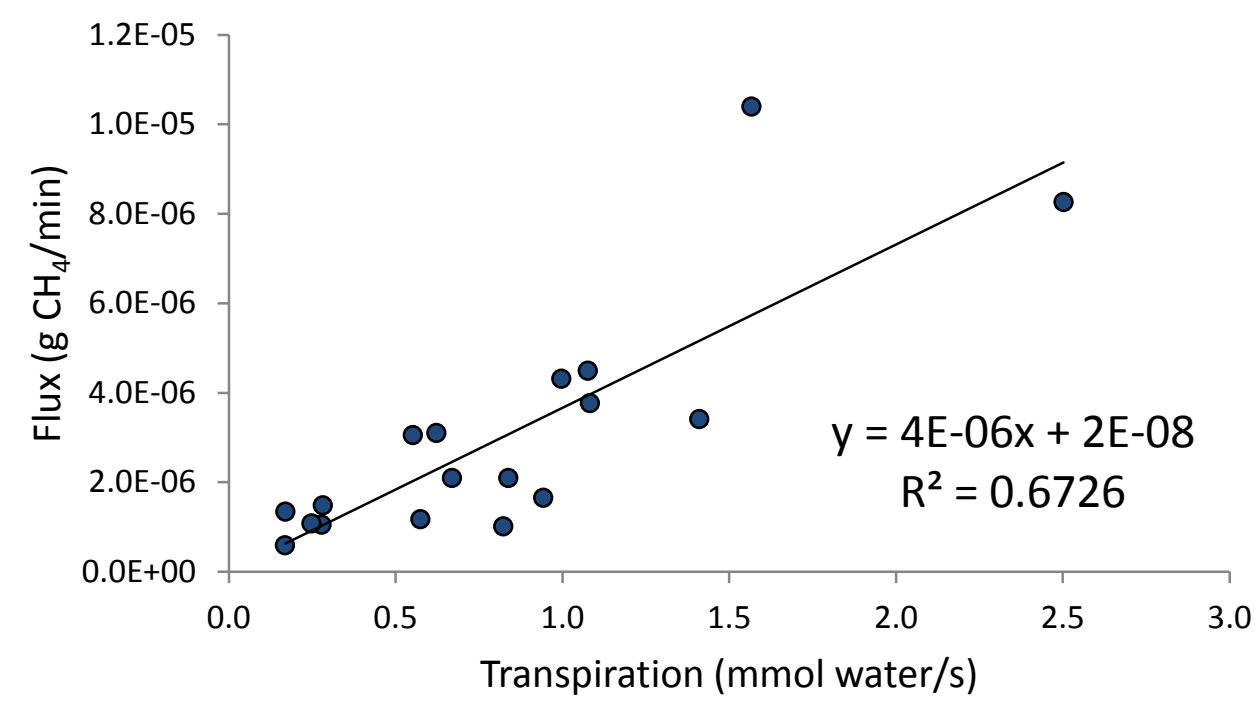

Figure 18: $\mathrm{CH}_{4}$ flux versus transpiration, $\mathrm{n}=18$. 2011 data.

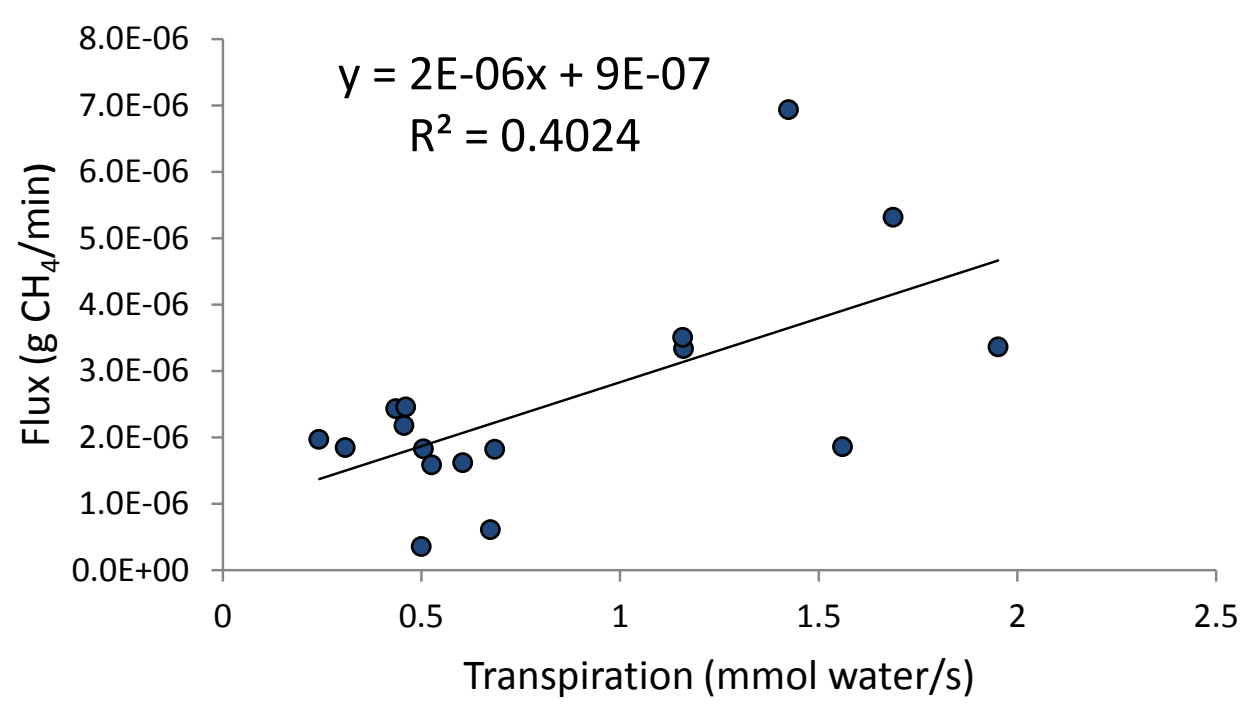

Figure 19: $\mathrm{CH}_{4}$ flux versus transpiration, $\mathrm{n}=17.2012$ data. 


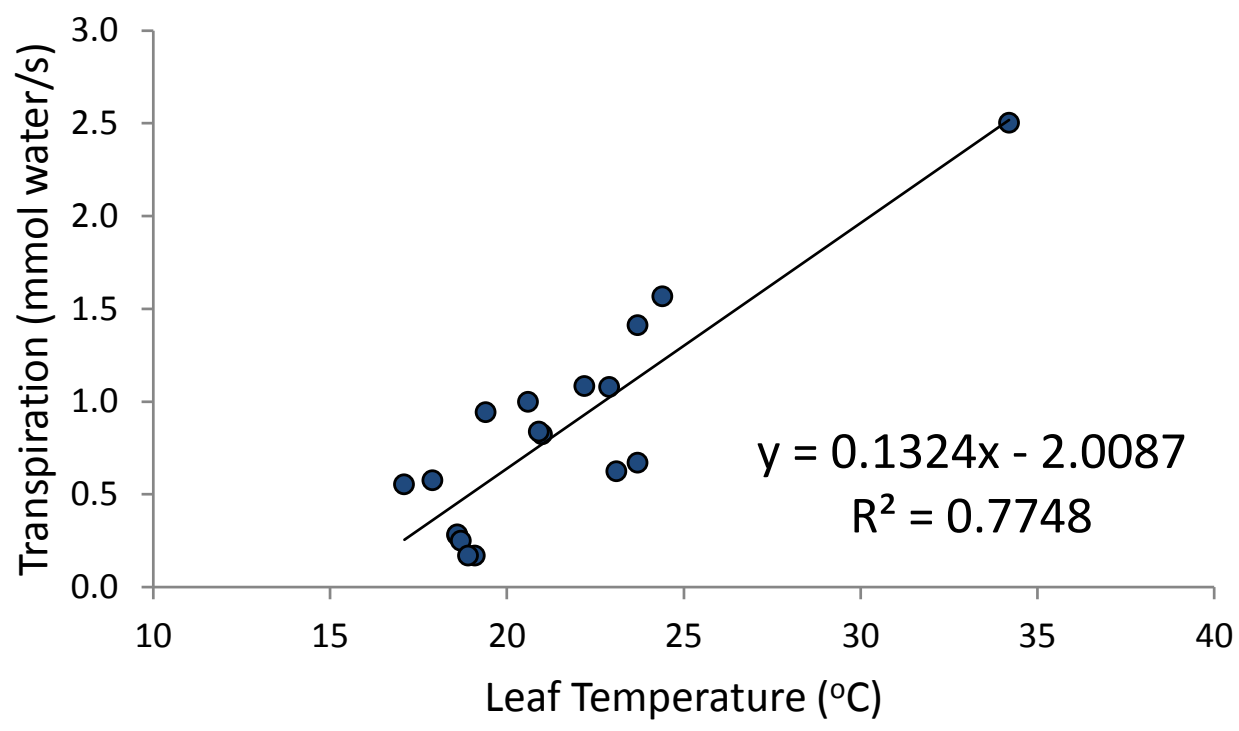

Figure 20: Transpiration versus leaf temperature, n=18. 2011 data.

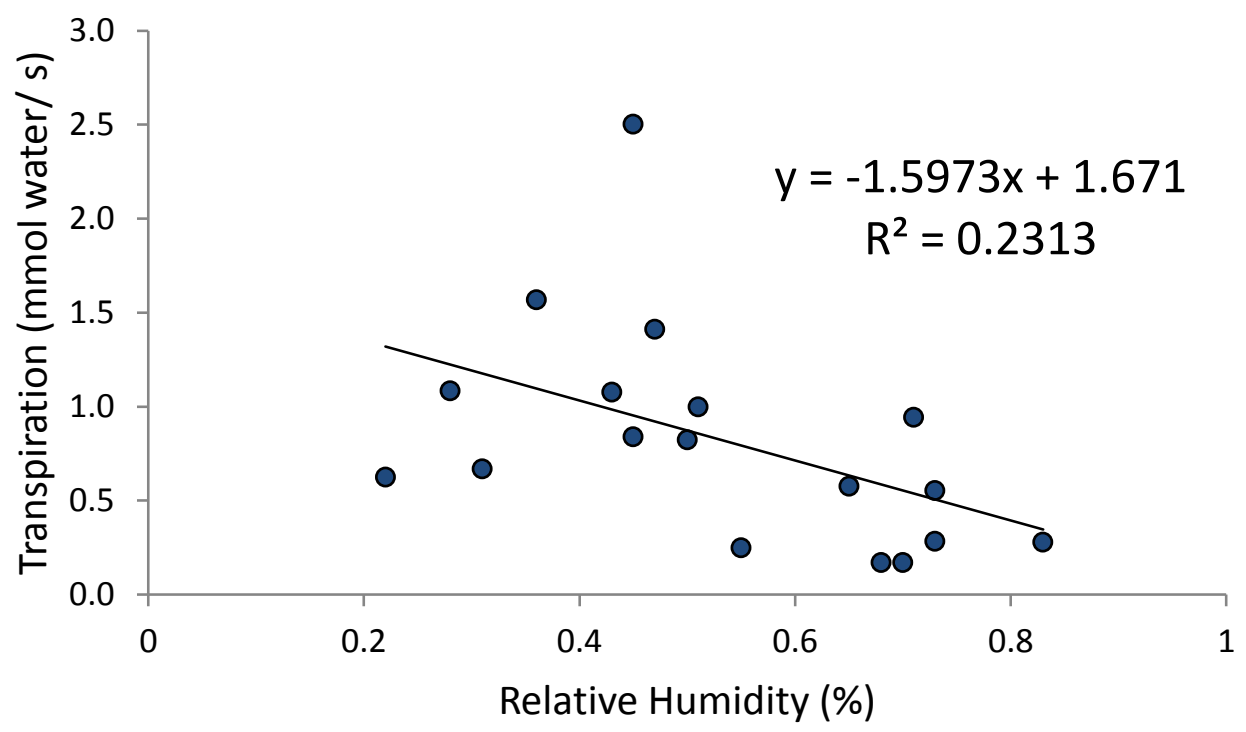

Figure 21: Transpiration versus relative humidity, n=18. 2011 data. 


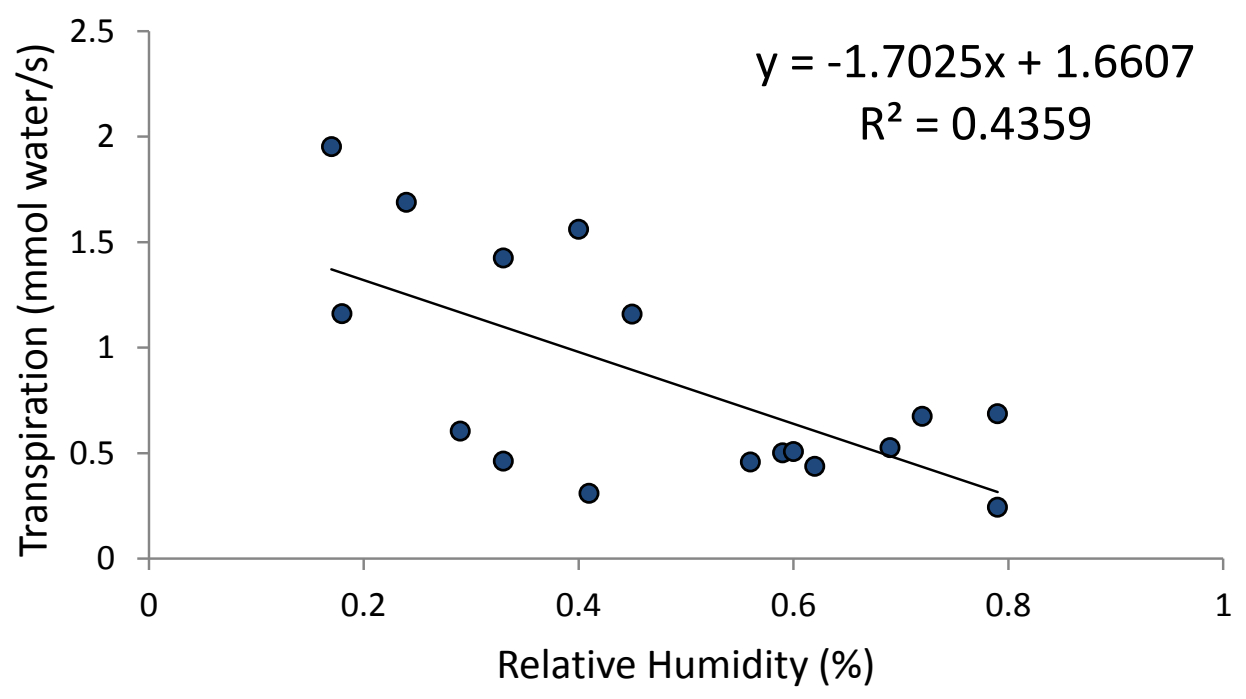

Figure 22: Transpiration versus relative humidity, n=17. 2012 data.

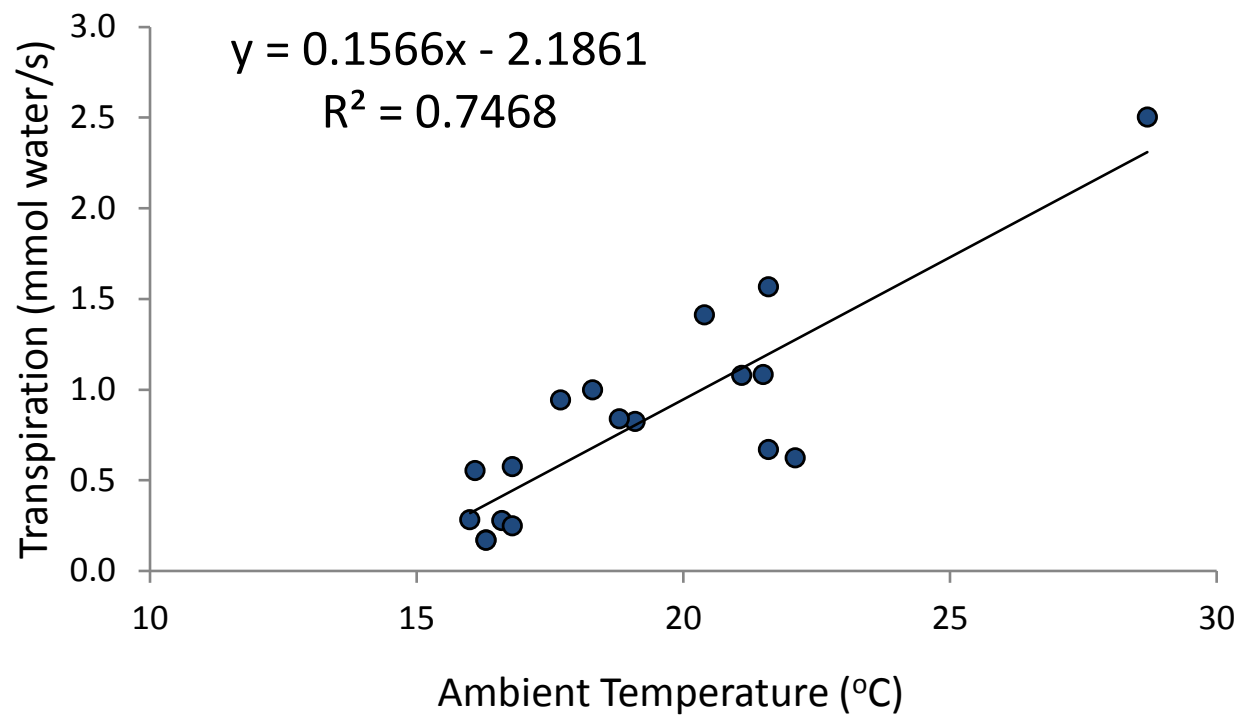

Figure 23: Transpiration versus ambient temperature, n=18. 2011 data. 


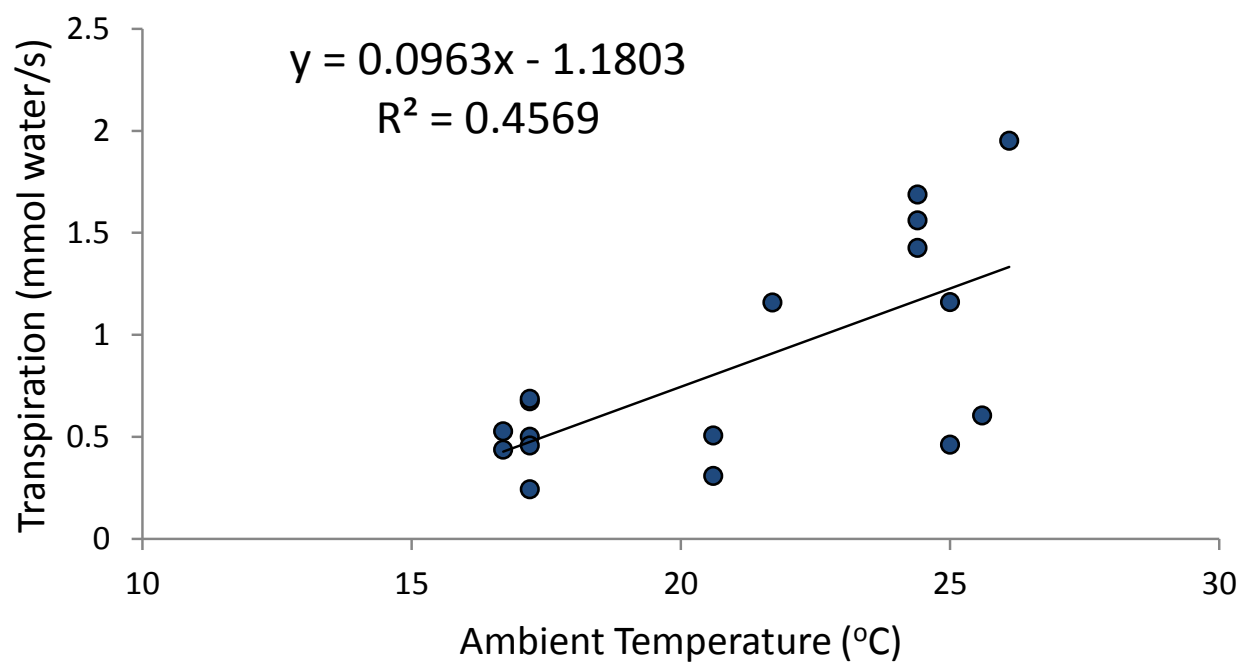

Figure 24: Transpiration versus ambient temperature, n=17. 2012 data.

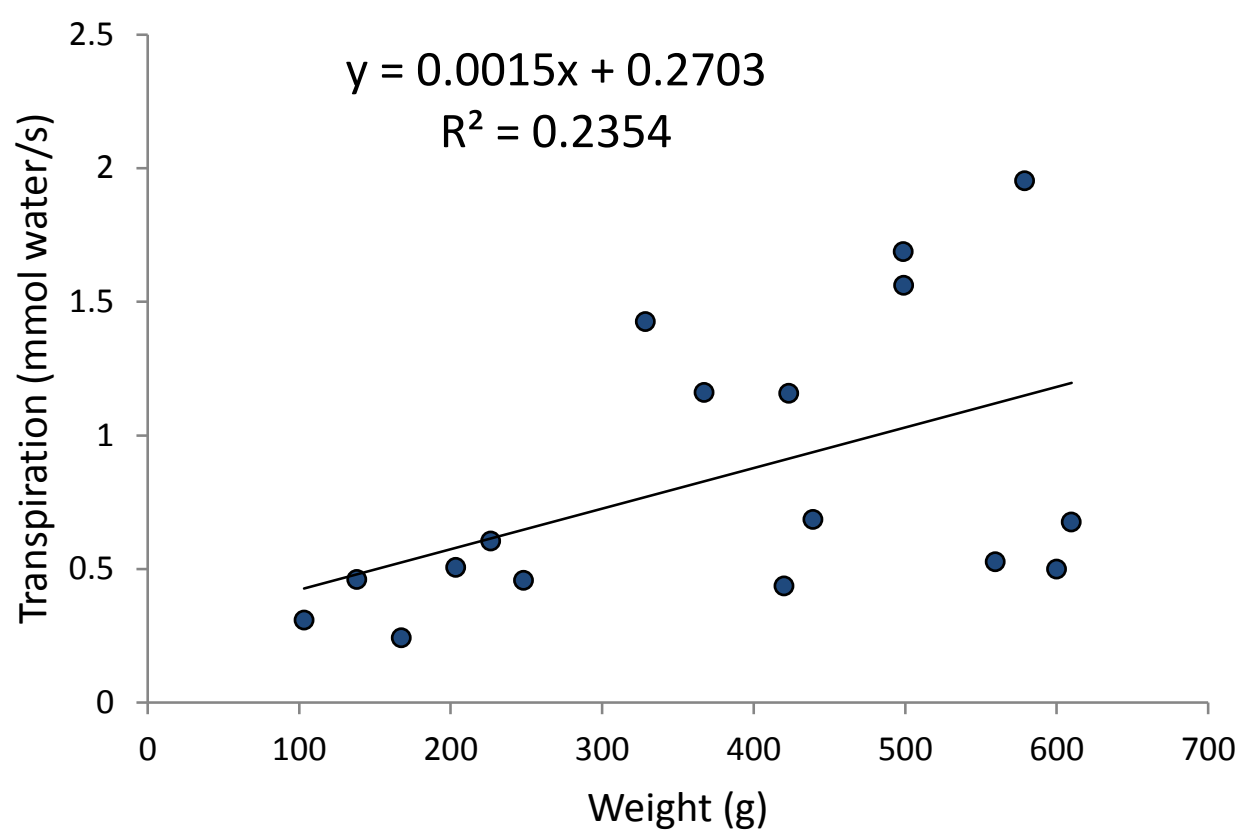

Figure 25: Transpiration versus tree weight, n=17. 2012 data. 


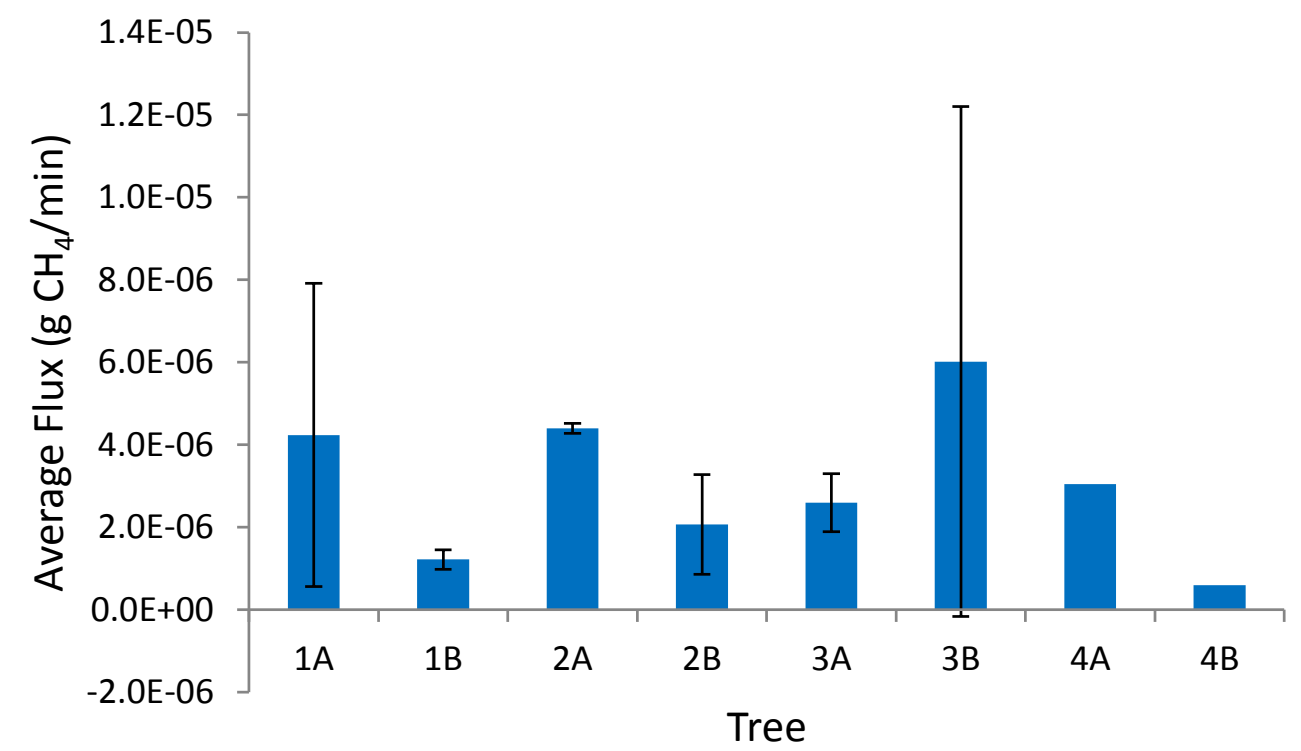

Figure 26: Average $\mathrm{CH}_{4}$ flux by tree for 2010-2011 experiments. Trees $4 \mathrm{~A}$ and 4B have only one data point each, the rest have two-four data points each.

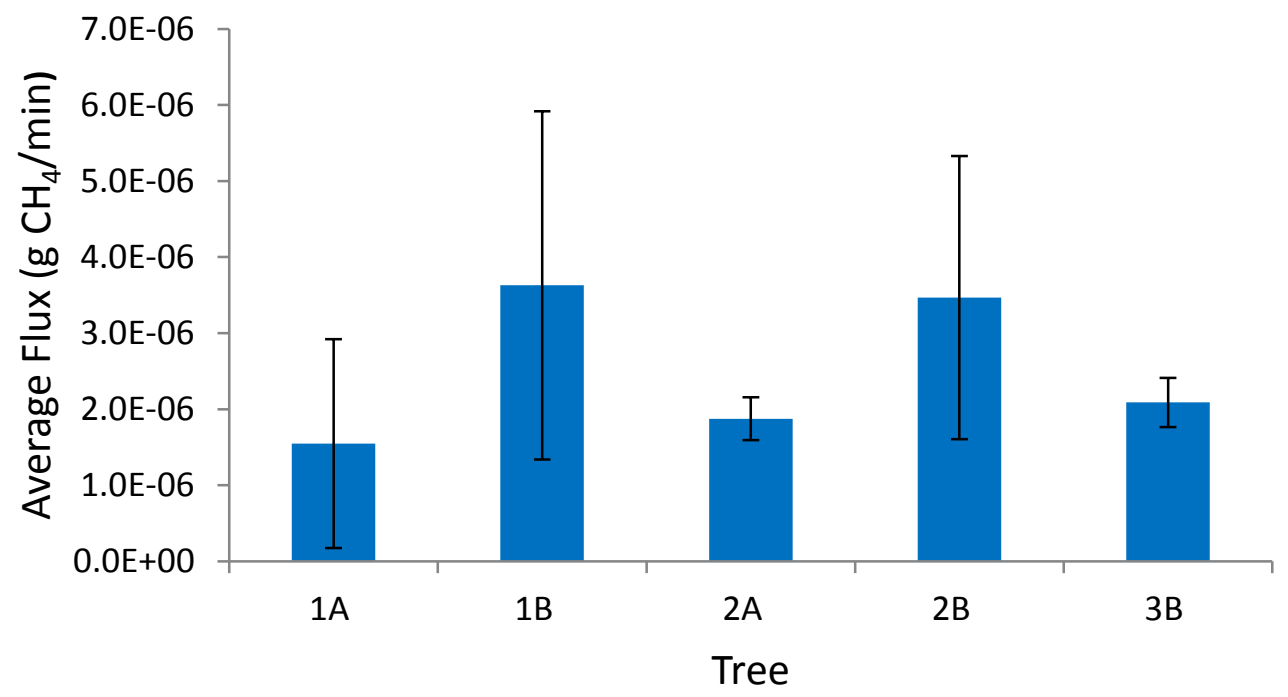

Figure 27: Average $\mathrm{CH}_{4}$ flux by tree for 2012 temperature series experiment. Trees $1 \mathrm{~A}$ and $1 \mathrm{~B}$ have four data points each, the rest have three data points each. 


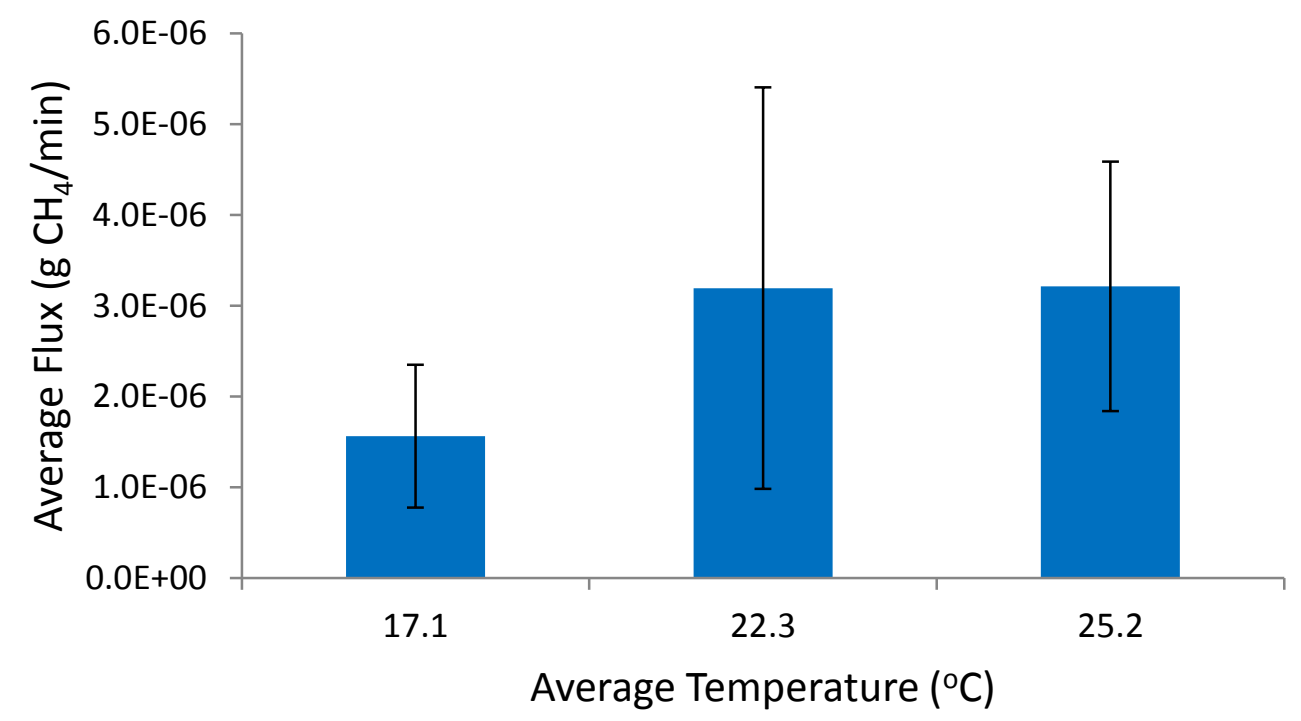

Figure 28: Average $\mathrm{CH}_{4}$ flux by average weekly temperature for 2012 temperature series experiment.

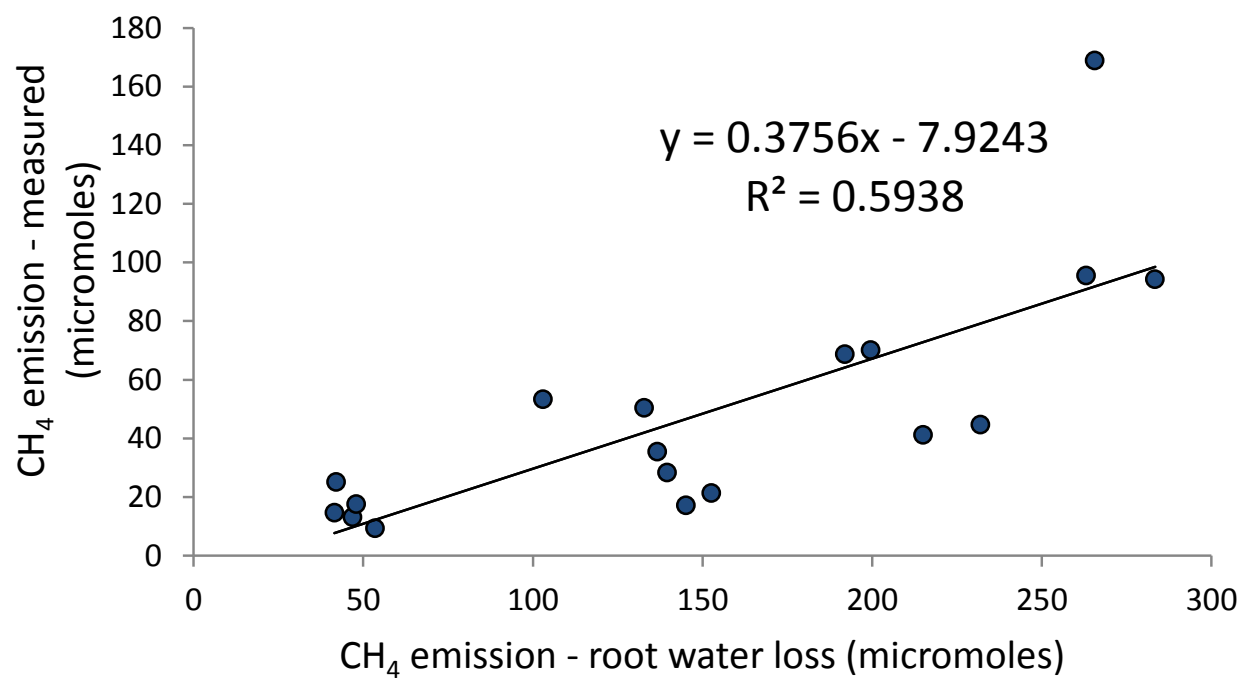

Figure 29: $\mathrm{CH}_{4}$ loss by flux versus $\mathrm{CH}_{4}$ emission estimated from root water loss, $\mathrm{n}=18.2011$ data. 


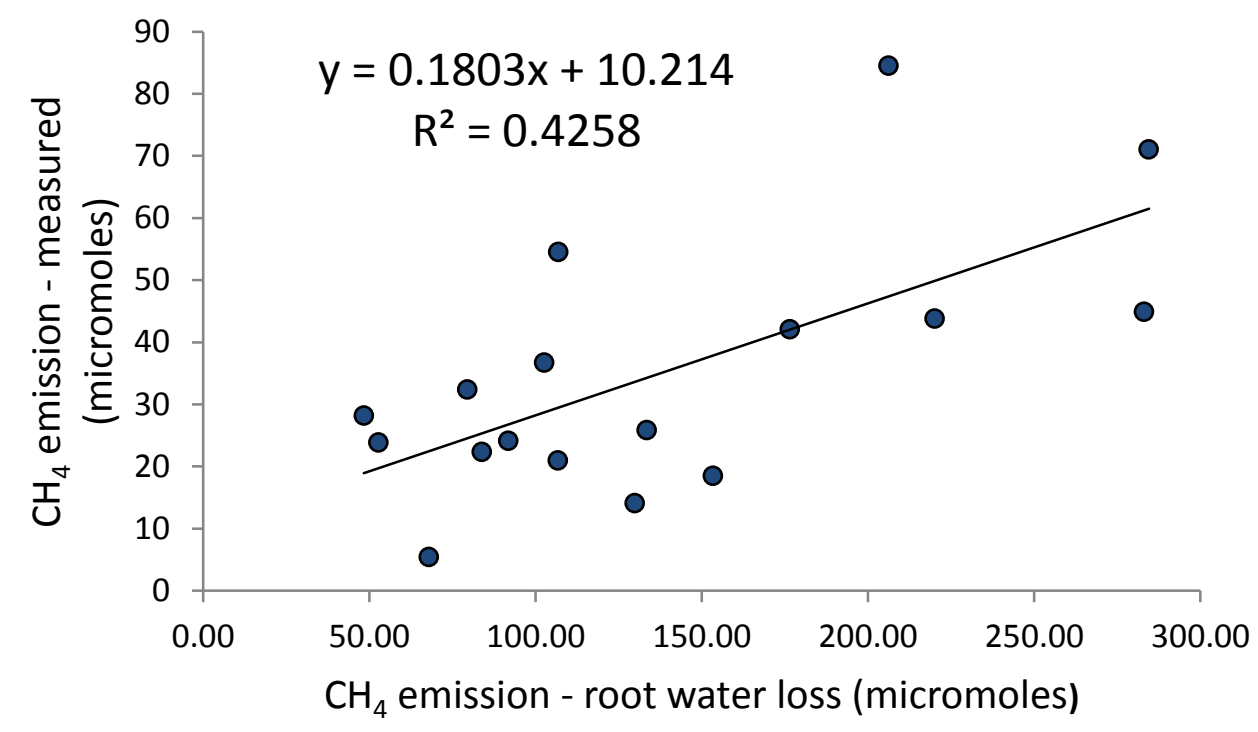

Figure 30: $\mathrm{CH}_{4}$ loss by flux versus $\mathrm{CH}_{4}$ emission estimated from root water loss, $\mathrm{n}=17.2012$ data.

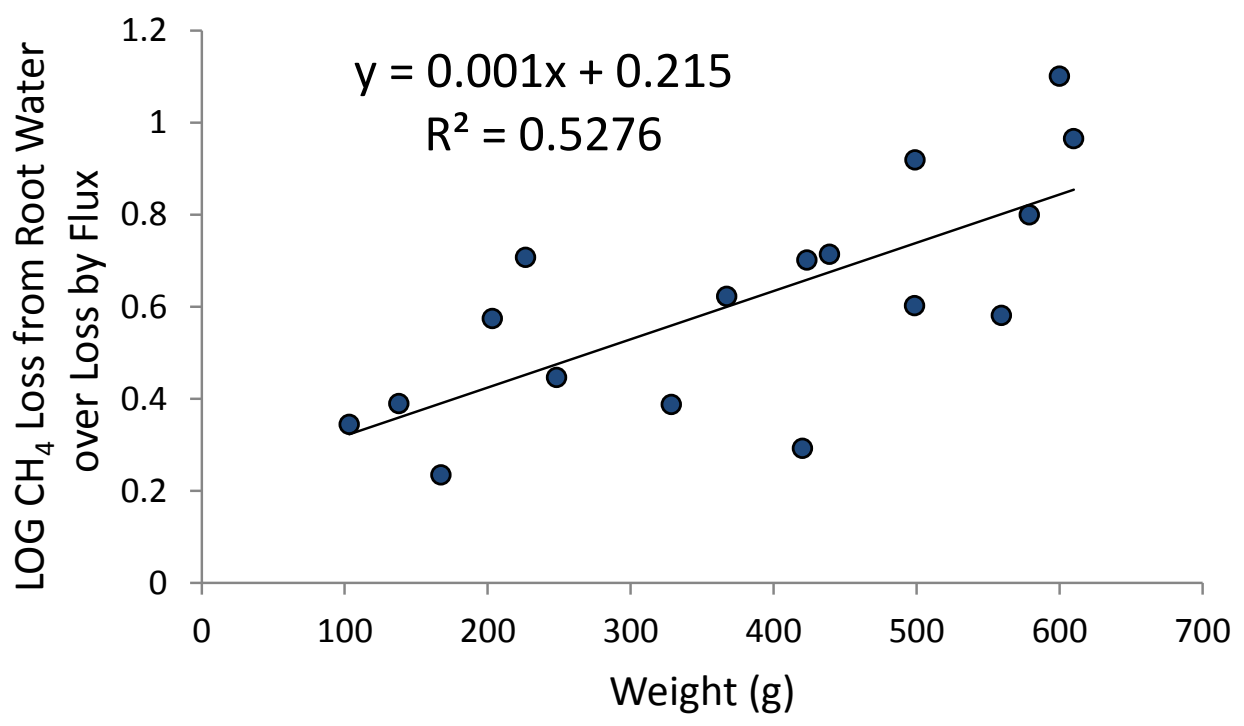

Figure 31: Logarithm of the ratio of $\mathrm{CH}_{4}$ loss by root water to $\mathrm{CH}_{4}$ loss by flux versus tree weight for 2012 temperature series experiment. The linear graph between these two variables yields an $\mathrm{r}^{2}$ of 0.46 ; a polynomial fit of the linear graph has an $\mathrm{r}^{2}$ value of 0.58 . The $1 \%$ level of significance falls at $\mathrm{r}^{2}=0.37$. 


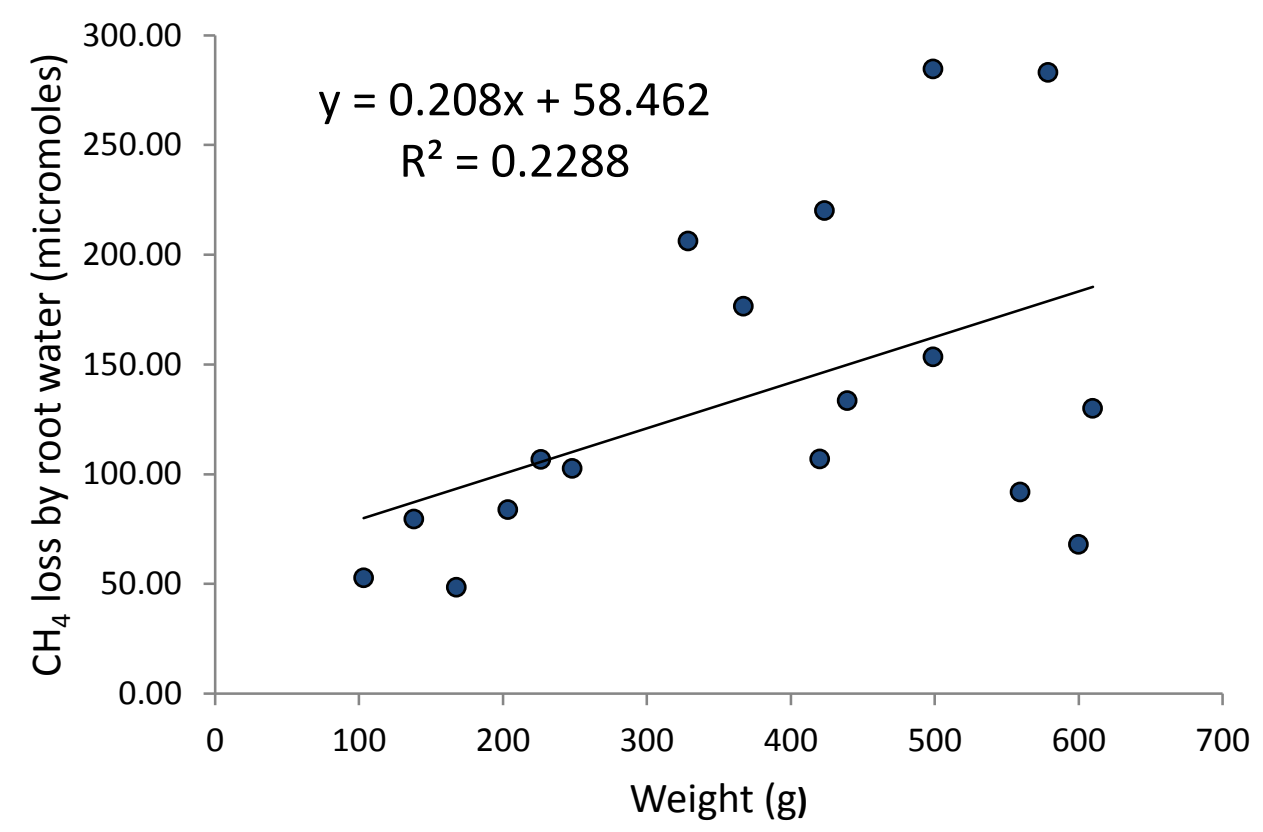

Figure 32: Although the relationship in figure (31) is significant, the relationship between $\mathrm{CH}_{4}$ loss by root water and weight is not statistically significant. There is no relationship between $\mathrm{CH}_{4}$ loss by flux and weight $\left(\mathrm{r}^{2}=0\right)$.

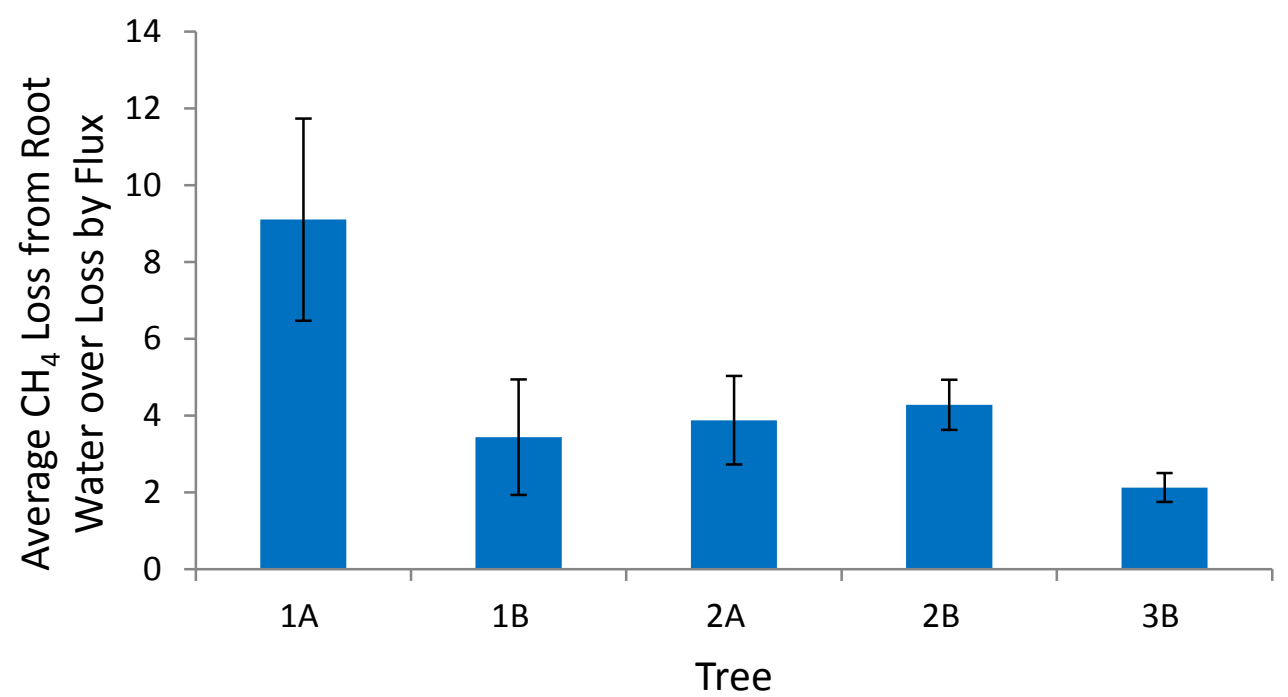

Figure 33: Ratio of $\mathrm{CH}_{4}$ loss by root water to $\mathrm{CH}_{4}$ loss by flux by tree for 2012 temperature series experiment. 


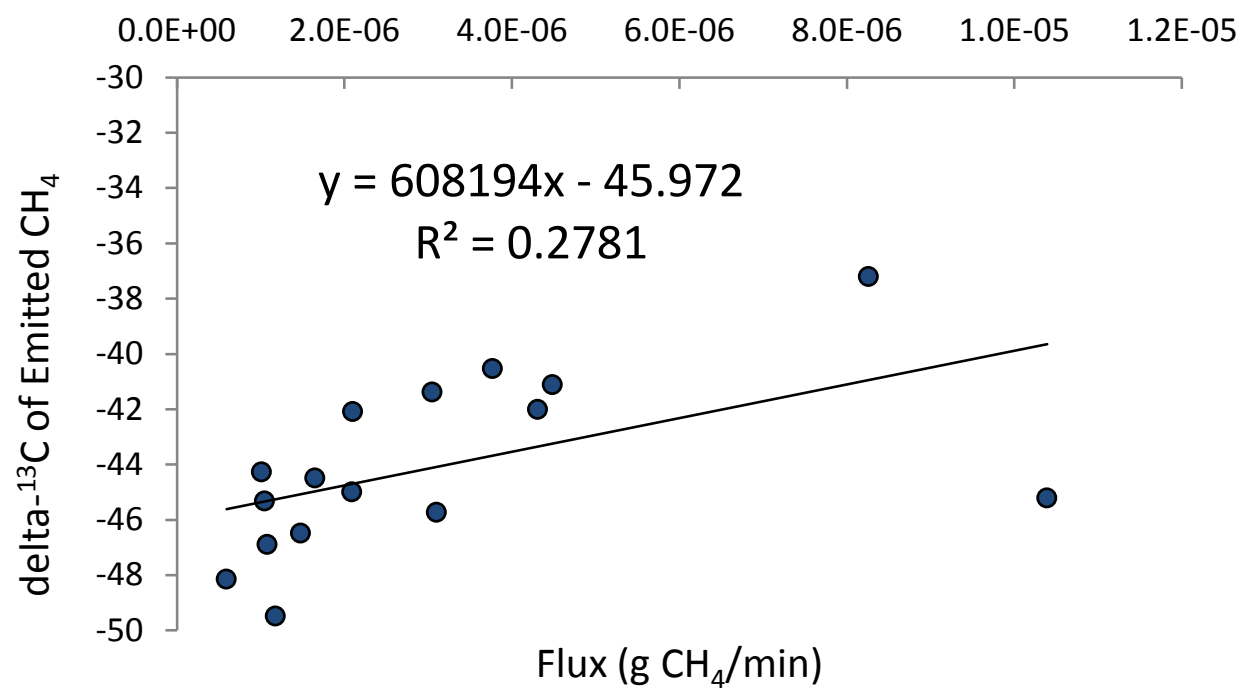

Figure 34: $\delta^{13} \mathrm{C}$ of $\mathrm{CH}_{4}$ emitted from the canopy versus $\mathrm{CH}_{4}$ flux, $\mathrm{n}=16.2011$ data.

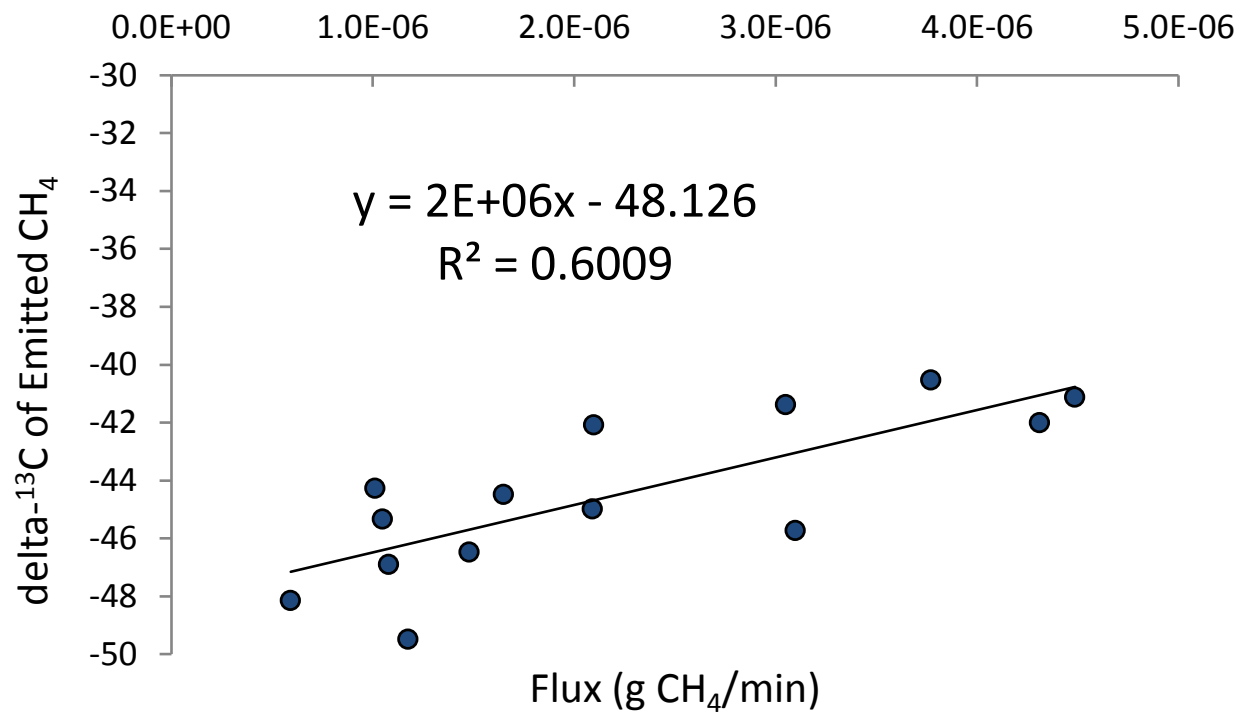

Figure 35: $\delta^{13} \mathrm{C}$ of $\mathrm{CH}_{4}$ emitted from the canopy versus $\mathrm{CH}_{4}$ flux, without the outliers, $\mathrm{n}=14.2011$ data. 


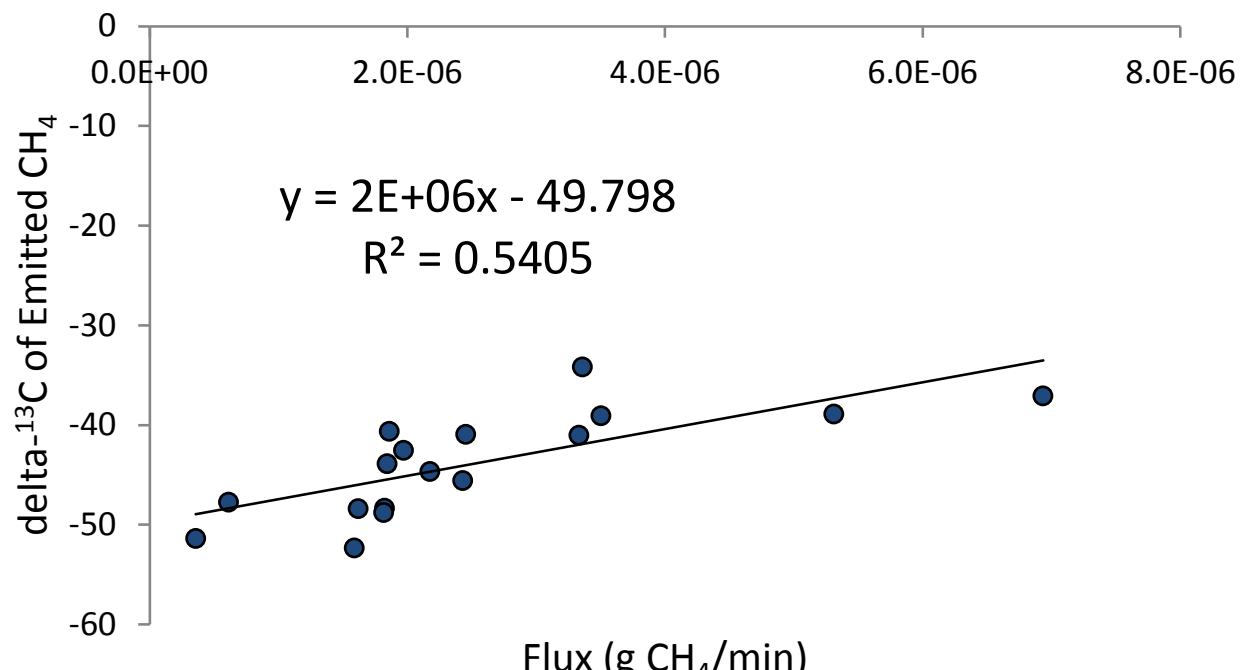

Figure 36: $\delta^{13} \mathrm{C}$ of $\mathrm{CH}_{4}$ emitted from the canopy versus $\mathrm{CH}_{4}$ flux, $\mathrm{n}=17.2012$ data.

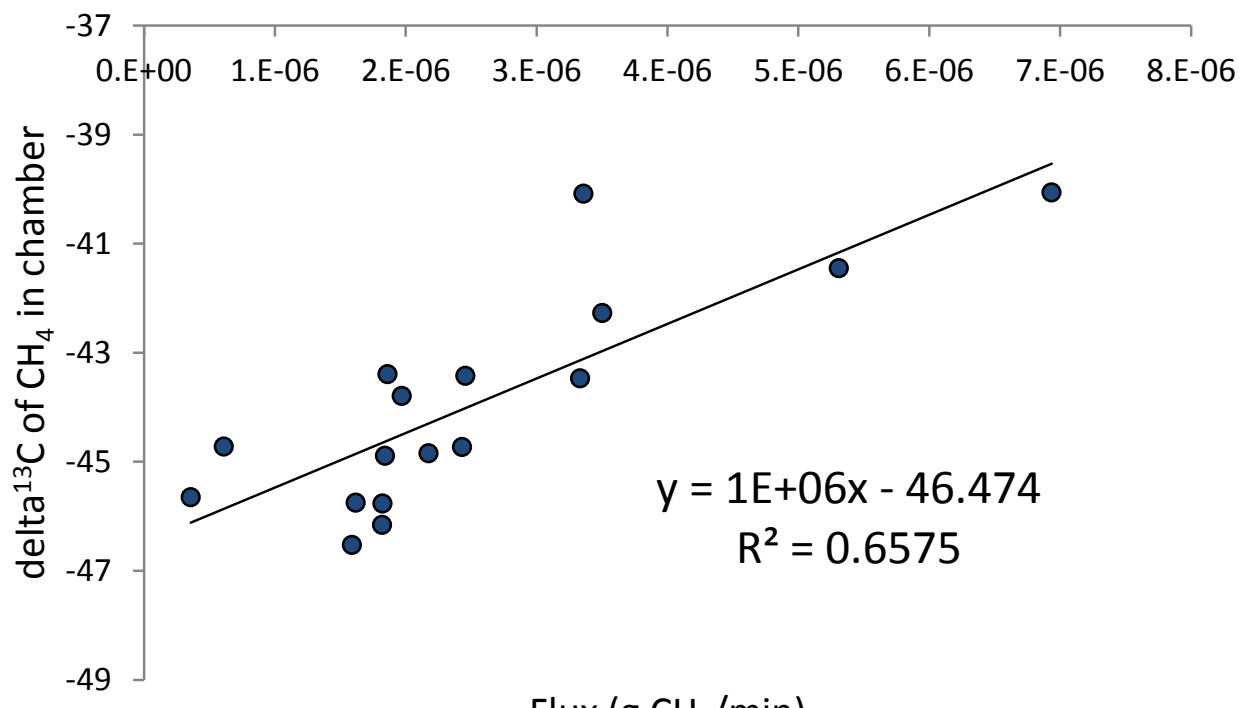

Figure 37: $\delta^{13} \mathrm{C}$ of total $\mathrm{CH}_{4}$ in the chamber (tedlar bag) versus $\mathrm{CH}_{4}$ flux, $\mathrm{n}=17$. 2012 data. 


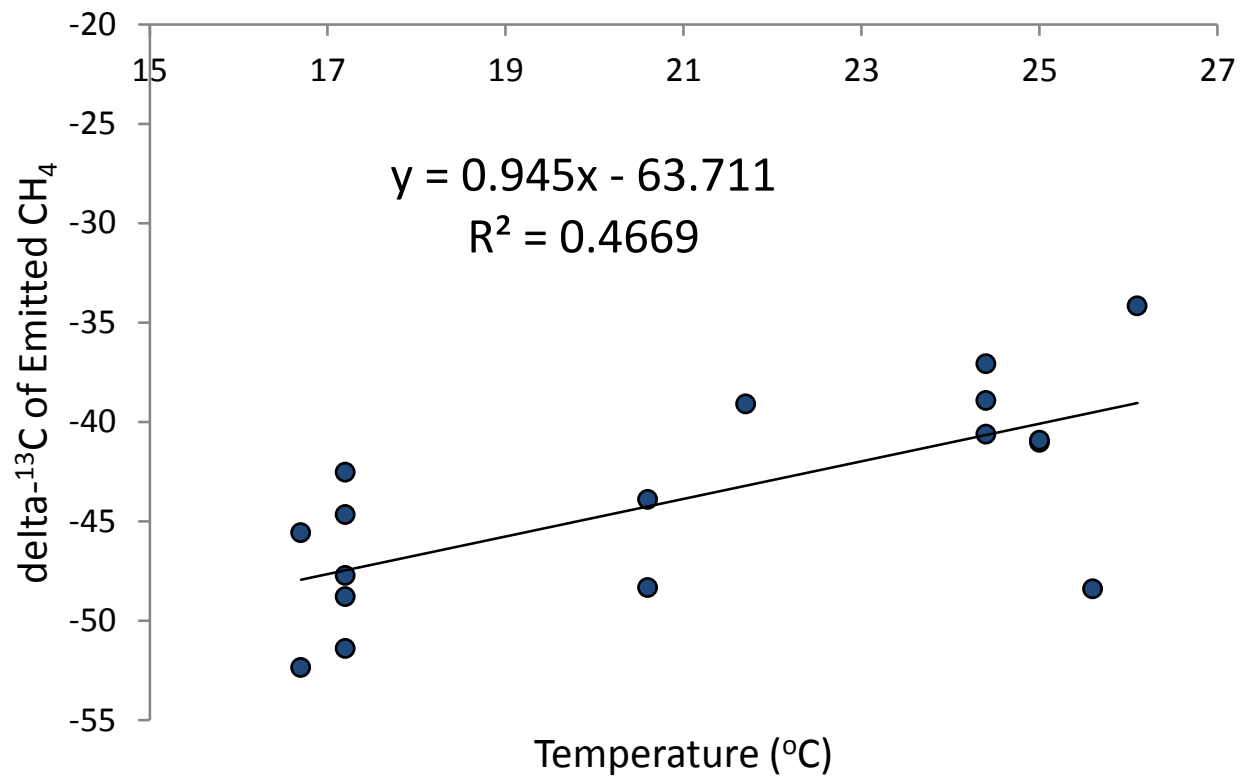

Figure 38: $\delta^{13} \mathrm{C}$ of $\mathrm{CH}_{4}$ emitted from the canopy versus temperature, $\mathrm{n}=17.2012$ data.

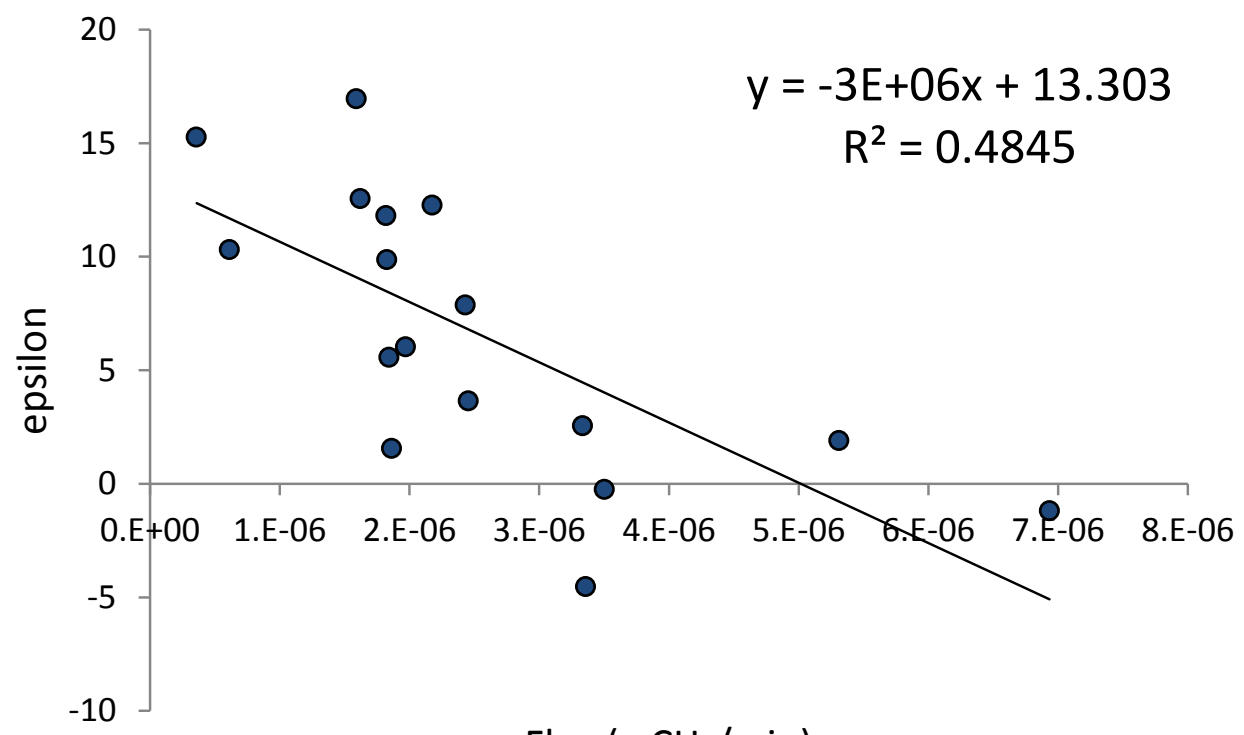

\section{Flux $\left(\mathrm{g} \mathrm{CH}_{4} / \mathrm{min}\right)$}

Figure 39: Epsilon values for all trials in the temperature experiment versus $\mathrm{CH}_{4}$ flux, $n=17.2012$ data. 


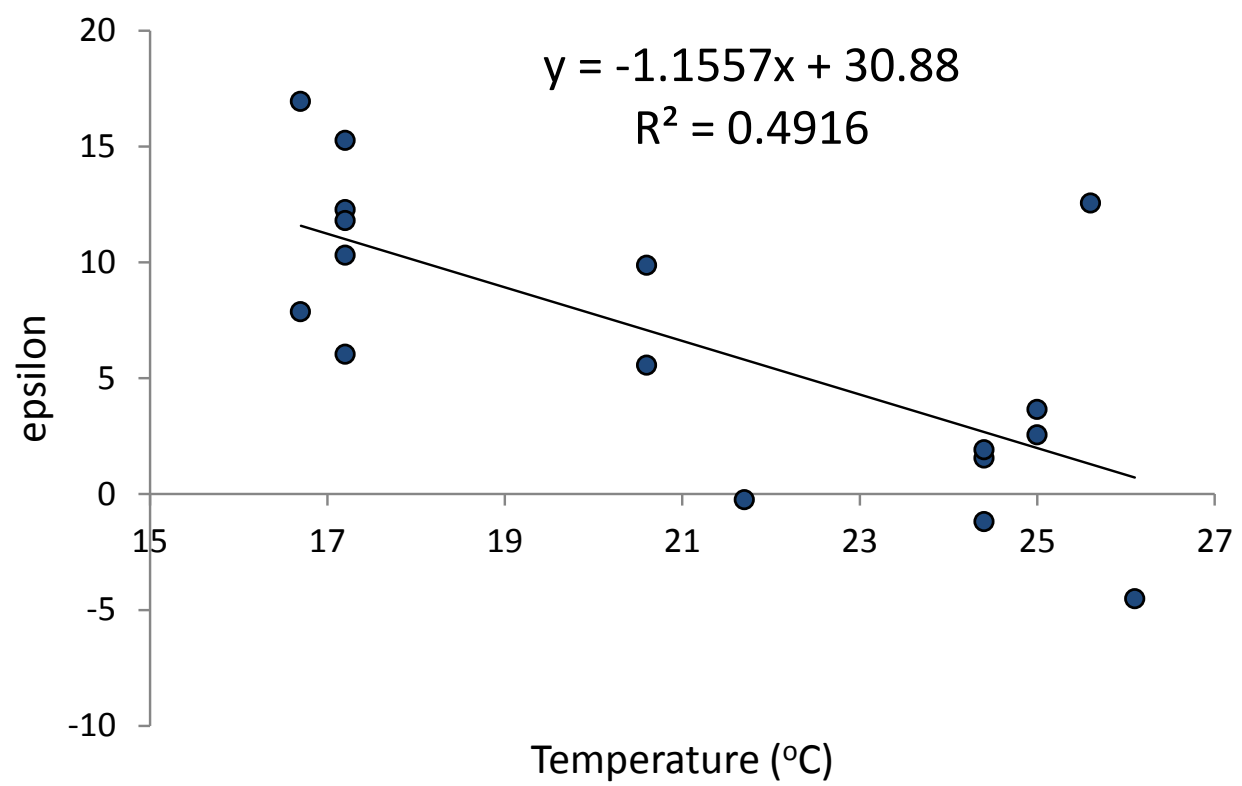

Figure 40: Epsilon values for all trials in the temperature experiment versus temperature, $n=17.2012$ data. 


\subsection{Temperature Experiments}

Significant relationships between environmental and physiological parameters found in the temperatuer experiments of 2012 are reported in Table (1). The relationships are shown graphically in the figures following the table. A strong correlation was found between leaf count and tree weight, as well as between tree weight and flux. Tree weight was recorded for the temperature experiments but had not been measured in the canopy flux experiments.

The amount of water refilled in the root chamber just before a trial and taken to represent the water transpired ranged from $60 \mathrm{~mL}$ to $450 \mathrm{~mL}$ with an average of 200 $\mathrm{mL}$ (the total initial volume of root chamber water was approximately $6000 \mathrm{~mL}$ ). In terms of water loss from the root chamber per time, the average was $0.84 \pm 0.53 \mathrm{mmol}$ water $\mathrm{s}^{-1}$. It should be noted that this rate may not represent the transpiration rate during the half-hour sampling period as conditions within the tedlar bag may have altered stomatal conductance. These values for transpiration and water loss are very similar to those reported in the previous section for the canopy flux experiments. In spite of physiological differences between trees due to uncontrollable influences (e.g., some variation in leaf count, stem diameter, overall size), overall transpiration rates remain similar. Average daytime temperature the first week was $22.3^{\circ} \mathrm{C}, 25.2{ }^{\circ} \mathrm{C}$ the second week, and $17.1^{\circ} \mathrm{C}$ the third week (this includes the two trials conducted during the fourth week). Root water concentration in all trials was relatively high at

an average of $704 \pm 110 \mu \mathrm{mol} \mathrm{CH}_{4} \mathrm{~L}^{-1}$ water, nearly identical on average to those for the canopy flux experiments described above.

Concentration of $\mathrm{CH}_{4}$ in the tedlar bag increased linearly with time for the 17 
canopy trials of the temperature experiement. Of these 17 trials, 12 had an r-squared value of 0.99 , three had an r-squared value between 0.97 and 0.98 , one had an rsquared value of 0.99 with one sample removed and 0.94 overal, and one trial had an r-squared value of 0.92 . Statistical analysis below for the temperature experiments will include all 17 trials unless otherwise specified. The three canopy trials of the time series experiment had r-squared values of $0.95,0.99$, and 0.96 respectively with increasing time. The average flux during the temperature experiments was $2.5 \pm 1.6$ $\mu \mathrm{g} \mathrm{CH}_{4} \min ^{-1}$. The average flux for the warmest temperature, $25.2{ }^{\circ} \mathrm{C}$, was $3.2 \pm$ $1.4 \mu \mathrm{g} \mathrm{CH} \mathrm{Cmin}^{-1}$; the average flux at the next highest temperature, $22.3^{\circ} \mathrm{C}$, was 3.2 $\pm 2.2 \mu \mathrm{g} \mathrm{CH} \mathrm{min}^{-1}$; at the coolest temperature of $17.1^{\circ} \mathrm{C}$, the average flux was 1.6 $\pm 0.8 \mu \mathrm{g} \mathrm{CH} \mathrm{min}^{-1}$. A t-test shows that the flux at the coolest average temperature $\left(17.1^{\circ} \mathrm{C}\right)$ is significantly different ( $p$-value less than 0.02$)$ than the flux at the warmest average temperature $\left(25 \cdot 2^{\circ} \mathrm{C}\right)$.

Results from the canopy samples taken for isotopic composition analysis during the canopy flux experiments are reported in Table (3). The epsilon value did vary with temperature. For the warmest week $\left(25.2^{\circ} \mathrm{C}\right)$, epsilon was found to be $3.4 \pm$ $5.2 \%$; for the week at $22.3{ }^{\circ} \mathrm{C}$, epsilon was $3.2 \pm 4.4 \%$; at the coolest $\left(17.1{ }^{\circ} \mathrm{C}\right)$, epsilon was $11.4 \pm 3.7 \%$. A significant correlation between $\delta^{13} \mathrm{C}$ of the emitted $\mathrm{CH}_{4}$ and ambient temperature was found, as reported in Table (1) and Figure (38). The significant relationship between $\delta^{13} \mathrm{C}$ of the emitted $\mathrm{CH}_{4}$ flux found in the canopy flux experiments was also found in the temperature experiments to an even stronger extent, $\mathrm{r}=0.53$ for the former and $\mathrm{r}=0.74$ for the latter. This relationship is shown graphically in Figure (36). $\delta^{13} \mathrm{C}$ of the total $\mathrm{CH}_{4}$ in the chamber (tedlar bag), which includes the atmospheric background $\mathrm{CH}_{4}$, has been graphed against flux as well and 
is shown in Figure (37). For the temperature experiments, the value of epsilon, or the difference between the root water $\delta^{13} \mathrm{C}$ and the emitted $\delta^{13} \mathrm{C}$, has been graphed against $\mathrm{CH}_{4}$ flux and temperature as well. These graphs are shown in Figures (39) and (40). The relevance of this data will be examined in the discussion section.

\subsection{Stem Experiments}

Results from the stem chamber experiments are summarized in Table (4). The lower stem chamber is referred to as S1 and the upper chamber as S3. In this table, "time" refers to how long the tree has been secured in the root chamber. The flux is given from each stem chamber, and again per area of stem. The estimated total stem flux is calculated by dividing the total main stem length by the length enclosed by the two stem chambers, then multiplying by the sum of the two stem chamber fluxes. It is notable that the estimated flux is of the same magnitude as the whole-canopy fluxes reported in the other tables. Transpiration, based on water loss from the root chamber, is also reported.

As mentioned above, the first stem chamber trial was performed in April 2011; the later three trials took place in November and December of 2012. The second and third trials were done with the same tree. Table (8) reports the results of the three stem trials from the fall of 2012 where samples of the headspace of the root chamber were also taken. The lower stem chamber in the first of the November trials may have had a high flux due to a leak from the root chamber that was just below the stem chamber seal. This problem was amended in later trials by leaving a few milimeters of stem space between the root chamber seal and the lower stem chamber seal. 


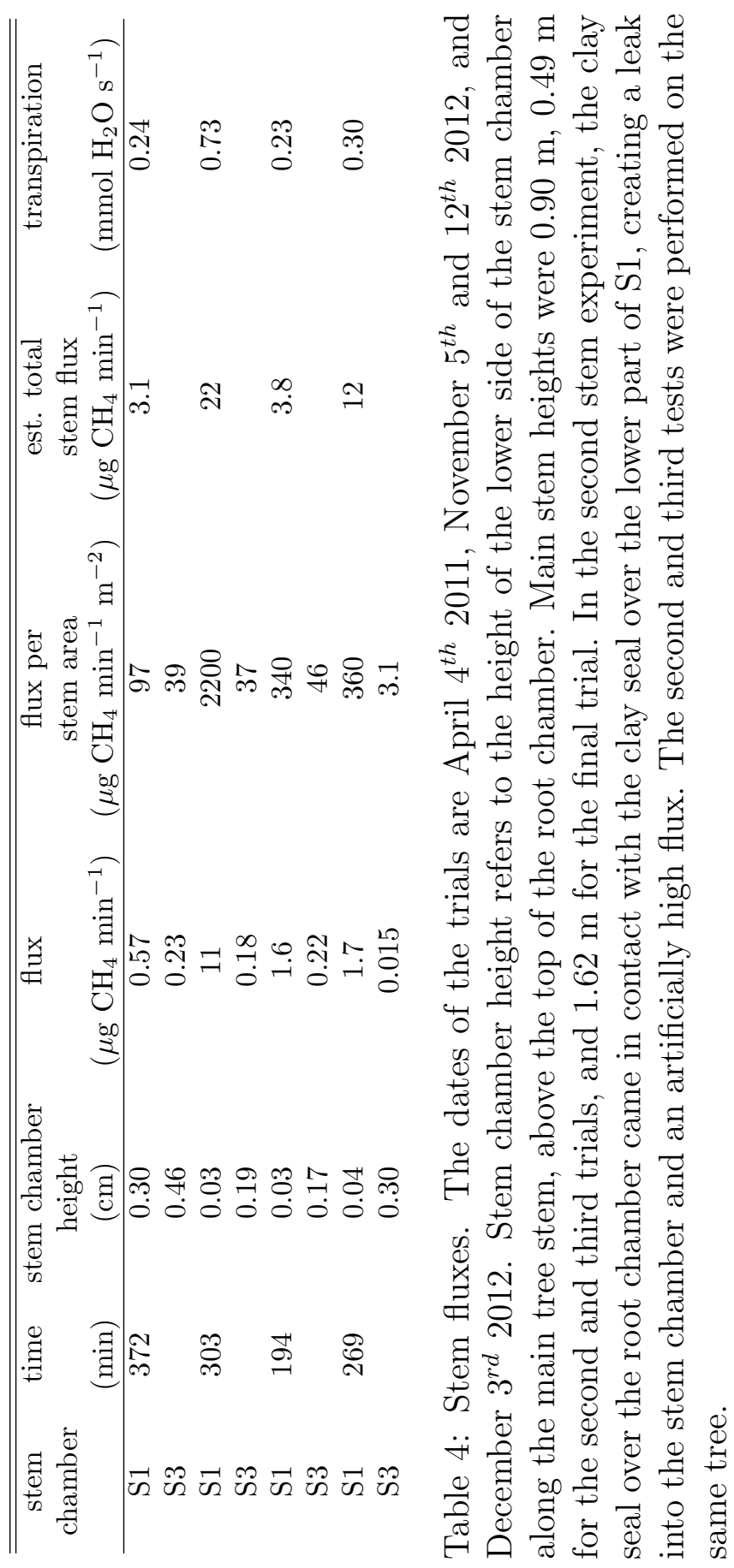




\subsection{Canopy Flux Series Experiments and Full Chamber Experiments}

The first of the series experiments was conducted in April 2012. After sealing the tree in the root chamber, the first half-hour set of flux samples was taken at 75 minutes, the second at 165 minutes, and the third at 260 minutes. Results for this experiment are shown in Table (5). The time recorded in the first column is the total time after the tree is first sealed in the root chamber. Flux is the measured value of canopy emission over the half-hour sampling period. Canopy fluxes for the first series experiment reported in Table (5) are as follows: $1.09 \mu \mathrm{g} \mathrm{CH}_{4} \mathrm{~min}^{-1}$ at 75 minutes, $1.96 \mu \mathrm{g} \mathrm{CH}_{4} \mathrm{~min}^{-1}$ at 165 minutes, and $1.79 \mu \mathrm{g} \mathrm{CH} \mathrm{min}^{-1}$ at 260 minutes. Transpiration monotonically decreased during this period, and since flux did not, this is an indication that $\mathrm{CH}_{4}$ is not emitted through leaves by the transpiration stream.

The second experiment of this type was conducted on October $3^{\text {rd }}$ of 2012. In this experiment reported in Table(6), a tedlar bag sampling was performed once before the tree was moved from water with $\mathrm{CH}_{4}$ to water without it. At that time the flux went from $3.11 \mu \mathrm{g} \mathrm{CH} \mathrm{CH}_{4}^{-1}$ after 302 minutes of being in the original water to $2.19 \mu \mathrm{g} \mathrm{CH} \mathrm{CH}_{4}^{-1}$ approximately 15 minutes after the tree was secured in the $\mathrm{CH}_{4}$ free water. Root water $\mathrm{CH}_{4}$ concentration was at $637 \mu$ moles $\mathrm{CH}_{4} \mathrm{~L}^{-1}$ water when the first canopy measurements were taken. When the second set was taken, water concentration was measured at $23 \mu$ moles $\mathrm{CH}_{4} \mathrm{~L}^{-1}$ water. This indicates that $\mathrm{CH}_{4}$ was leaving the tree through the roots into the $\mathrm{CH}_{4}$-free water, following the concentration gradient.

From October $18^{\text {th }}$ to October $26^{\text {th }}$ a third series type experiment was performed on the same tree as the second series experiment. This time, one set of flux measure- 
ments was taken once every day beginning on the first day and ending on the fourth day after first sealing the tree in the chamber. On day five, the tree was removed from the root chamber and resealed once the chamber had been cleaned out and refilled with methane-free water. A set of flux measurements was then taken on day seven and day nine. Table (7) reports the data from this series experiment. Although at first the flux increases, it drops over the next several days. In all three series experiments, the total $\mathrm{CH}_{4}$ loss by flux is less than the estimated $\mathrm{CH}_{4}$ loss predicted from the total amount of root water loss and root water concentration at time of sampling. Again, $\mathrm{CH}_{4}$ is not leaving the tree system at the same rate as water loss through the leaves.

Table (8) summarizes the results of the series experiments. The three stem experiments and the three full chamber experiments where $\mathrm{CH}_{4}$ concentration in the root water and the headspace were measured as well as the canopy or stem chamber flux are also summarized in that table. Series experiments were performed on trees $3 \mathrm{~B}$, $2 \mathrm{~B}$, and $2 \mathrm{~B}$, stem experiments were performed on trees $2 \mathrm{~A}, 2 \mathrm{~A}$, and $3 \mathrm{~B}$ (a cutting of the tree $3 \mathrm{~B}$ from the first series experiment), and all three full chamber leak test experiments were performed on tree $2 \mathrm{~B}$. In the second full chamber experiment, there was a probable leak from the rectangular chamber that likely affected the overall flux results. The results from this test are therefore not reliable but are reported here for the sake of completeness.

The $\mathrm{CH}_{4}$ loss rate is calculated as the loss from the root chamber over the time the tree has spent in the root chamber up to that point. Total $\mathrm{CH}_{4}$ emissions are calculated by summing the various flux measurements that have been made from extending each half-hour flux value to the previous sampling time. $\mathrm{CH}_{4}$ recovered is 
the amount of $\mathrm{CH}_{4}$ measured in the root water and headspace after the tree has been placed in $\mathrm{CH}_{4}$-free water after a flux experiment. This type of experiment was done twice and is described above. The loss estimated column in the table assumes the leak of $1.5 \mu$ moles $\mathrm{CH}_{4} \mathrm{~min}^{-1}$ as measured in the root chamber leak test described in the methods section is constant over the total time of the given experiment. This column represents the amount of $\mathrm{CH}_{4}$ that would be lost from the system given the constant leak.

For the first six rows of the column (series and stems experiments), the loss estimated by the leak added to the total emissions represent the total $\mathrm{CH}_{4}$ released from the root chamber-tree system. In other words, the $\mathrm{CH}_{4}$ loss from the root chamber is the total $\mathrm{CH}_{4}$ that has entered tree or leaked from the root chamber. The difference between the loss from the root chamber, and the $\mathrm{CH}_{4}$ emission plus the estimated leak, is the $\mathrm{CH}_{4}$ assumed to be remaining in some manner within the tree itself. In the three full chamber experiments in the table, the entire tree and root chamber system were enclosed. Therefore, the total emissions includes canopy flux and any actual leak that may have been present from the root chamber. In this case, the amount of $\mathrm{CH}_{4}$ remaining in the tree is the difference between the $\mathrm{CH}_{4}$ loss from the root chamber and the total $\mathrm{CH}_{4}$ emissions.

A pertinent observation from this data is that the amount of $\mathrm{CH}_{4}$ lost from the root chamber, which includes both the root water and headspace loss, can be much higher than the $\mathrm{CH}_{4}$ lost from emissions (flux) and chamber leak. Among the six series and full chamber experiments, four did not have larger than normal leaks from the system (the 10-3-12 series experiment appears to have had a larger than average $\mathrm{CH}_{4}$ loss from the root chamber and the 12-9-12 full chamber experiment involved a 
suspected leak from the chamber over the tub). In the third series experiment ending on 10-26-12, the estimated leak was considerably larger than the actual amount of $\mathrm{CH}_{4}$ lost from the root chamber because of the long duration of the experiment and must be disregarded. The remaining three experiments (series on 4-30-12, chamber on 11-27-12, and chamber on 12-12-12) can be used to get an average of the difference between the $\mathrm{CH}_{4}$ lost from the root chamber and that lost by canopy emissions and leaking, which comes out to be $980 \mu$ moles $\mathrm{CH}_{4}$. This missing $\mathrm{CH}_{4}$ is an average of three times higher than that accounted for by flux and leaking (again note that for the full chamber experiments the total $\mathrm{CH}_{4}$ emissions include any leak from the root chamber). 


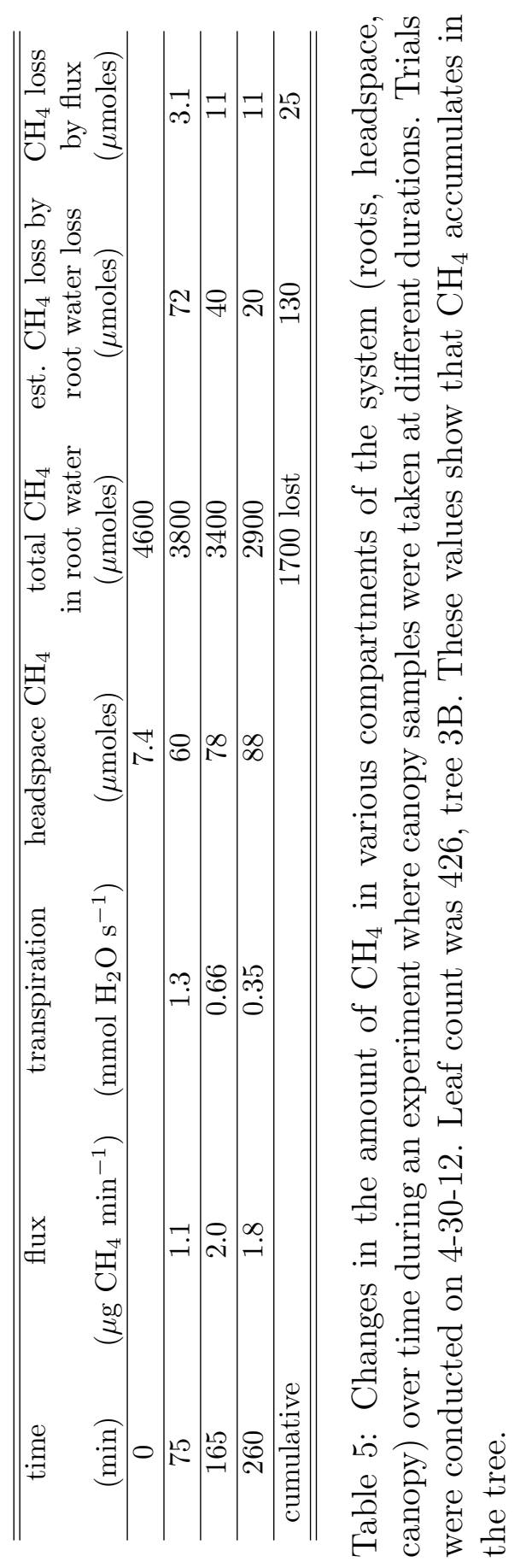




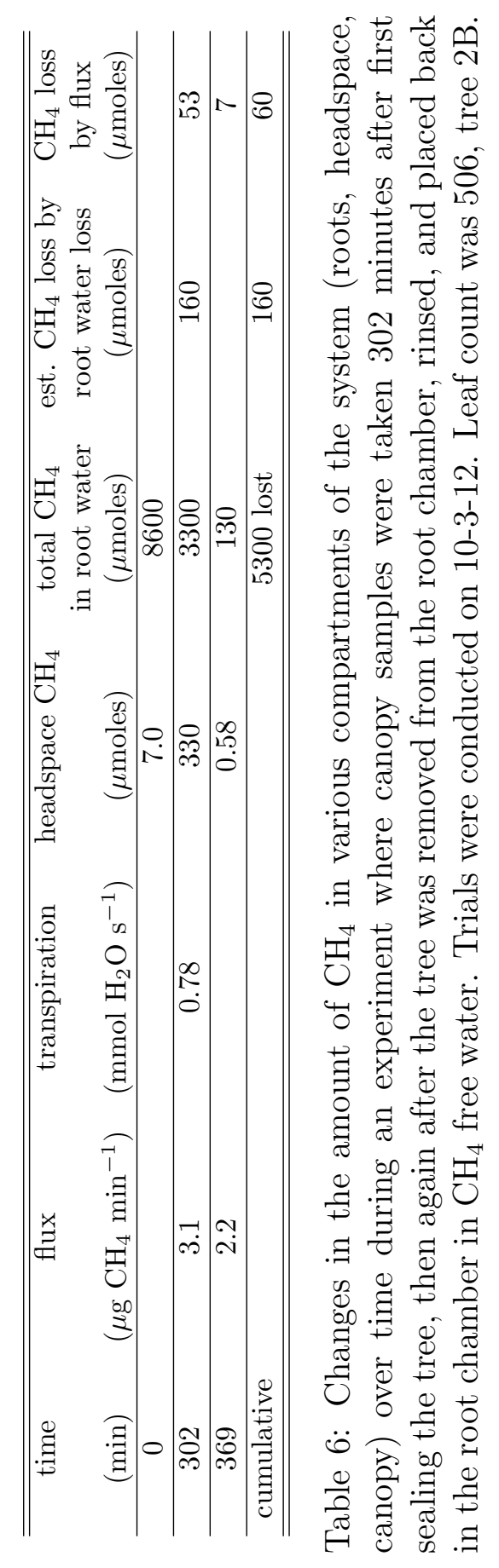




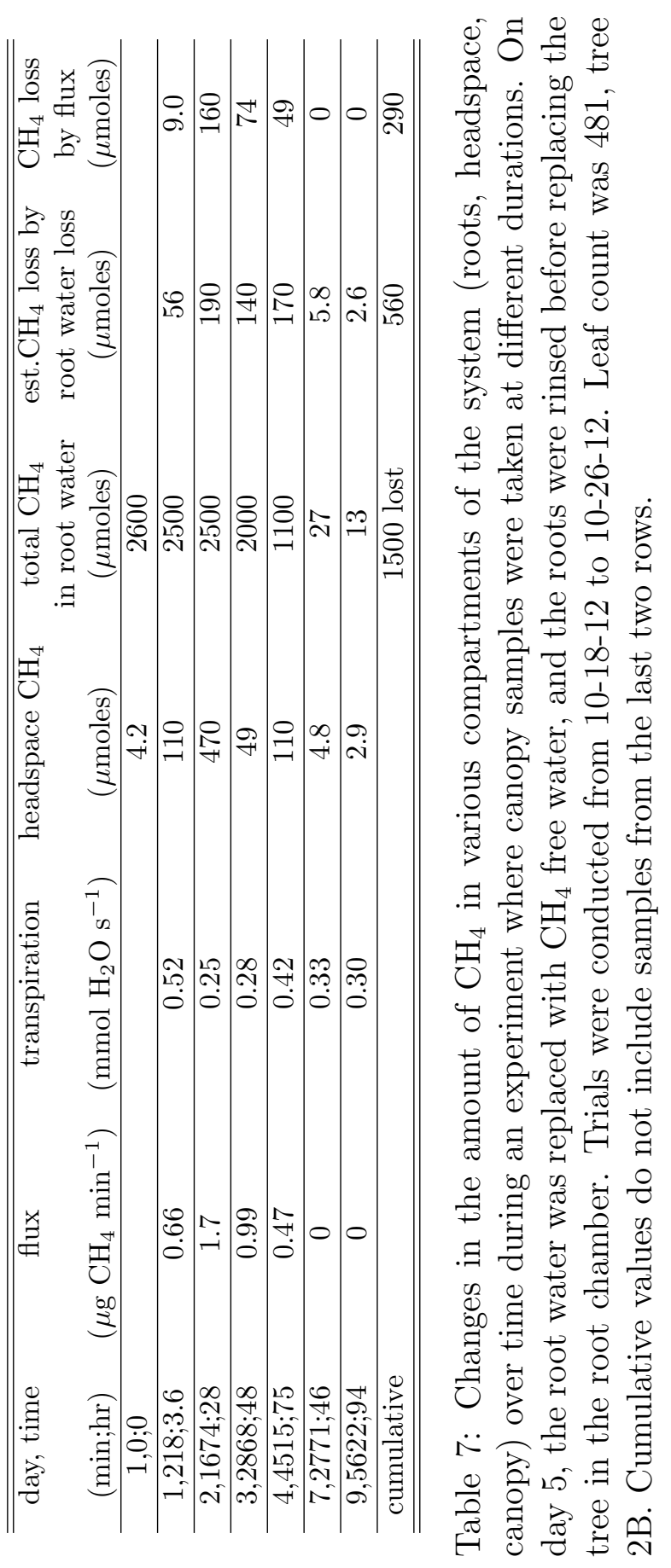




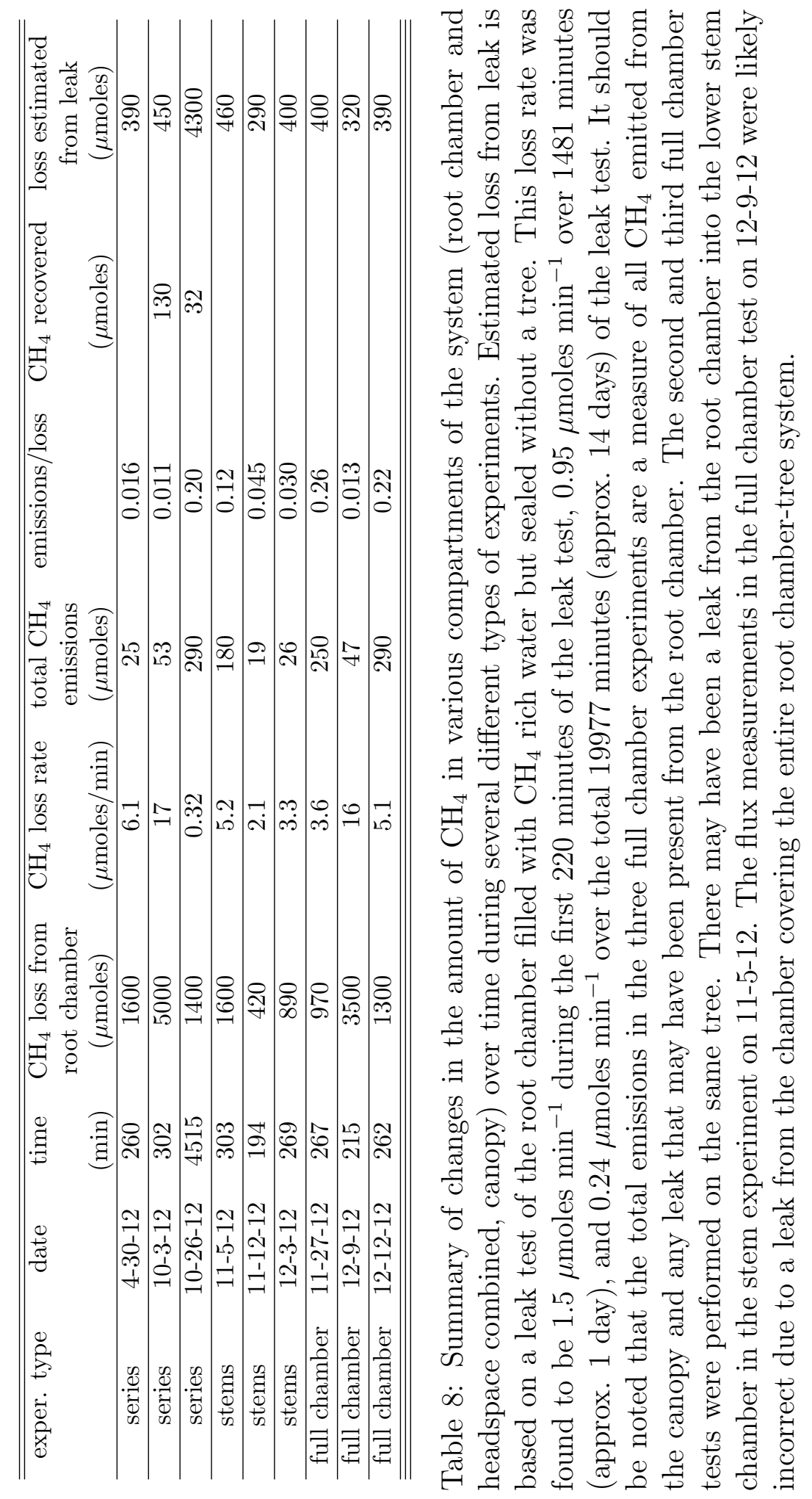




\section{Discussion}

\section{1 $\mathrm{CH}_{4}$ Transport Mechanisms}

One of the important outcomes of this work is the demonstration that trees having the capability of moving $\mathrm{CH}_{4}$ from the soil to the atmosphere will do so when $\mathrm{CH}_{4}$ is present in the root zone. Although previous work has measured the emission of $\mathrm{CH}_{4}$ from certain tree species in flooded field conditions [Gauci et al., 2010, Terazawa et al., 2007], there is debate over whether trees will emit $\mathrm{CH}_{4}$ under other conditions, such as transporting $\mathrm{CH}_{4}$ from saturated zones deeper in the soil [Megonigal and Guenther, 2008]. These experiments demonstrate that for black cottonwood, in all cases that $\mathrm{CH}_{4}$ was present in the root zone, flux was measured from the canopy. The remaining question, then, is whether or not upland or drier soils produce enough $\mathrm{CH}_{4}$ that will escape oxidation long enough to enter the tree roots. The transport efficiency of the tree will bear upon this issue, as a high transport efficiency will increase the likelihood that $\mathrm{CH}_{4}$ will move rapidly into and through the tree.

The purpose of the following discussion is to interpret the data from the first set of flux experiments performed in 2010-2011, as well as the relevant data from the 2012 temperature experiments, where canopy flux measurements were made and several environmental and physiological parameters measured from ambient temperature and humidity to leaf count and transpiration. The relationships between these parameters suggest some insights about $\mathrm{CH}_{4}$ transport. While no definitive statements about transport mechanisms can be made based on this data, it lays a foundation of work in an area where still little is known. As for the more thoroughly studied rice plant, correlations between morphophysiological and anatomical characteristics of rice plants 
and $\mathrm{CH}_{4}$ emission exist [Nouchi et al., 1990, Das and Baruah, 2008]. Although a large amount of $\mathrm{CH}_{4}$ has been shown to come through emergent wetland plants [Shannon et al., 1996], physiological correlations for tree emission of $\mathrm{CH}_{4}$ have been studied very little and the role that woody vegetation has in wetland emission of $\mathrm{CH}_{4}$ is still very poorly understood [Vann and Megonigal, 2003, Terazawa et al., 2007]. Therefore, the physiological relationships to $\mathrm{CH}_{4}$ emission discussed below are inroads to delineating which relationships are most important and to pointing out on what future research should focus.

A number of implications can be drawn from the physiological relationships summarized in Table (1) and the related figures showing the relationships graphically. It appears that the significant relationship between $\mathrm{CH}_{4}$ flux and leaf area found in the 2010-2011 data, shown in Figure (8) was in actuality representative of a general relationship between the capability of a tree to emit $\mathrm{CH}_{4}$ and biomass, not an indication of leaf flux. This is first of all supported by the fact that little other evidence was found to indicate leaf flux in general. Estimated stem flux from Table (4), which represents the flux from the length of the main tree stem, is of the same order of magnitude as fluxes measured for the full canopy. This indicates that most of the $\mathrm{CH}_{4}$ is in fact being emitted from the stems of the trees. Secondly, there is a very high correlation between leaf count and weight (see Figure (11)), as well as a relationship between $\mathrm{CH}_{4}$ flux and weight, although it is not linear (see figure (12); note that the correlation shown in Table (1) shows both a correlation for all flux data points and weight, which is not significant, and the correlation for the flux from just three of the trees and weight, which is significant). Therefore, leaf area is likely a proxy for tree weight or overall tree biomass, meaning that the actual correlation is between flux 
and biomass. Such a relationship between the overall size of a plant and $\mathrm{CH}_{4}$ flux has also been observed for rice [Yao et al., 2000].

There is a correlation between transpiration rate and flux, which was not found with rice [Lee et al., 1981, Seiler et al., 1984]. The correlation between these two parameters shown in Table (1) and Figures (18) and (19) may be due to other factors having the same effect on both $\mathrm{CH}_{4}$ emission and water flux, such as temperature or relative humidity as shown in other figures. Since leaf temperature and transpiration are correlated and leaf temperature and flux also correlate (see Table (1) and Figures (15), (13) and (14)), temperature may be the driving factor affecting both transpiration and $\mathrm{CH}_{4}$ flux. There is also a possible relationship between leaf area and transpiration (see Table (1) and Figures (9) and (10)), possibly representing a link between transpiration and biomass. This could be similar to the connection between $\mathrm{CH}_{4}$ flux and biomass, biomass therefore being the link between transpiration and flux.

Garnet et al. [2005] looked at $\mathrm{CH}_{4}$ emission from three wetland plant species and one tree. Experiments were conducted with the plants potted in soil. The tree species Taxodium distichum had a statistically significant positive correlation between $\mathrm{CH}_{4}$ emission and stomatal conductance, as well as a positive relationship between $\mathrm{CH}_{4}$ emission and temperature, but the effects of stomatal conductance and temperature were found to be independent. This could be interpreted as evidence for leaf emission of $\mathrm{CH}_{4}$, since temperature would not be the factor influencing both stomatal conductance and $\mathrm{CH}_{4}$ flux independently. Here, $\mathrm{CH}_{4}$ flux and temperature do share a correlation, as noted above. Transpiration, which can be taken as representative of stomatal conductance, and temperature in all experiments are correlated as well, as 
shown in Table (1) and Figures (20), (23) and (24). The transpiration-temperature correlation in the experiments here explains the connection between $\mathrm{CH}_{4}$ flux and transpiration. If leaf emission of $\mathrm{CH}_{4}$ is not significant, then Garnet et al. [2005] found a relationship between $\mathrm{CH}_{4}$ emission and stomatal conductance that must be explained by a third factor that affected both variables.

Evidence from this work supports the conclusion that leaf emission of $\mathrm{CH}_{4}$ is in fact not significant. $\mathrm{CH}_{4}$ emission measured in the stem experiment and scaled to an estimated stem area for the tree yields a value in the range of measured fluxes for the entire canopy. The average flux for the 18 canopy emission trials in 2010-2011 was $3.0 \pm 2.6 \mu \mathrm{g} \mathrm{CH}_{4} \mathrm{~min}^{-1}$; the overall average flux for all temperature trials was $2.5 \pm 1.6 \mu \mathrm{g} \mathrm{CH}_{4} \mathrm{~min}^{-1}$. From Table (4), the estimated total stem fluxes from the main stem of the tree were $3.1,3.8$, and $12 \mu \mathrm{g} \mathrm{CH}_{4} \min ^{-1}$. Therefore, a considerable amount of the total $\mathrm{CH}_{4}$ emitted exits from stems after traveling through the tree, possibly via air-filled aerenchyma tissue. A decrease in flux was observed with height of the stem chamber along the stem. Rusch and Rennenberg [1998] also found this to be true in their experiments. Along with the flux from the canopy varying linearly with the mixing ratio of $\mathrm{CH}_{4}$ in the root zone, this was taken as evidence for the major transport of $\mathrm{CH}_{4}$ to be by diffusion. While the stem pathway does appear to dominate, the exact mechanisms of transport may or may not include diffusion as will be discussed below.

Other experiments in this work demonstrate the unlikeliness of $\mathrm{CH}_{4}$ emission by transpiration. In the results of the first series experiment given in Table (5), transpiration monotonically decreased during the experimental period. Since flux did not, this is an indication that $\mathrm{CH}_{4}$ is not emitted through leaves by the transpiration 
stream. In all three series experiments, the total $\mathrm{CH}_{4}$ loss by flux is less than the estimated $\mathrm{CH}_{4}$ loss predicted from the total amount of root water loss and root water concentration at time of sampling. The conclusion, then, is that $\mathrm{CH}_{4}$ is not leaving the tree system at the same rate as water loss through the leaves.

The correlation between weight and flux where the values can be grouped by tree as in Figure (12) may point to something other than mere dependence of flux capacity on mechanism, but rather to developmental differences in the individual trees. Perhaps as weight and leaf count increase, the overall volume of tissues able to carry $\mathrm{CH}_{4}$ decreases. However, some developmental characteristic may become important. There is no obvious single factor that fits as an explanation, and in fact a number of factors could play a role, for example, an increased suberized layer at the endodermis of the root in some trees and not others. No other work to date has investigated physiological developmental differences in trees and changes in $\mathrm{CH}_{4}$ emission.

The average $\mathrm{CH}_{4}$ emission by tree for the 2010-2011 canopy flux experiments and the 2012 temperature experiment is shown in Figures (26) and (27). A significant amount of variation in flux exists from tree to tree. Physiological differences between trees, such as total biomass, therefore have an effect on emitted $\mathrm{CH}_{4}$. What is yet unknown in whether other differences, such as the relative amount of aerenchyma in each tree, have an effect on this flux. These results, though a topical survey of the effect of tree physiology on $\mathrm{CH}_{4}$ flux, reveal the specific questions that need to be answered to form a complete understanding of $\mathrm{CH}_{4}$ movement through trees.

Figures (29) and (30) show $\mathrm{CH}_{4}$ loss by flux versus the $\mathrm{CH}_{4}$ emission estimated from root water loss. $\mathrm{CH}_{4}$ loss by flux is calculated by taking the flux measured at 
the time of the half-hour tedlar bag canopy sampling and assuming that flux as being representative of the entire time the tree has been sealed in the root chamber. The total $\mathrm{CH}_{4}$ lost due to flux can then be calculated using this flux and total time in the root chamber. Emission estimated from root water loss is calculated by first measuring the total water lost from the root chamber during the time the tree has been sealed in the chamber. This amount of water is considered the total amount of water transpired by the tree. At the time of canopy sampling, the root water concentration of $\mathrm{CH}_{4}$ is measured. This concentration is lower than the concentration measured when the tree is first sealed in the root chamber; nonetheless, the root water concentration at canopy sampling is multiplied by the total amount of water lost to obtain an estimate for $\mathrm{CH}_{4}$ loss from the root chamber. This assumes that $\mathrm{CH}_{4}$ enters and leaves the tree at the same rate as water, and as discussed above there is evidence that such an assumption is incorrect. However, this assumption is used to examine the relationship between actual $\mathrm{CH}_{4}$ flux rates and water movement. As shown in Figures (29) and (30) $\mathrm{CH}_{4}$ loss estimated from the root water is at a higher rate than $\mathrm{CH}_{4}$ loss due to flux in both the 2010-2011 canopy flux measurements and the 2012 temperature experiments. It may be that $\mathrm{CH}_{4}$ flux decreases when the tedlar bag measurements are being made. Were $\mathrm{CH}_{4}$ emission from the leaves, this would be reasonable to assume since stomatal closure is likely to occur in a static chamber environment. However, as it appears that the bulk of the flux is from the stems, a static chamber should not interfere with this type of emission. This data may alternatively be pointing to $\mathrm{CH}_{4}$ storage as discussed in a later section. The assumption that $\mathrm{CH}_{4}$ moves into and through the tree at the same rate as water does appear incorrect. In any case, there is a statistically significant relationship between $\mathrm{CH}_{4}$ loss by flux and that estimated 
to be lost from the root water that merits further study.

A connection between $\mathrm{CH}_{4}$ loss by flux and root water and physiological parameters may exist. While $\mathrm{CH}_{4}$ loss by flux did not have a significant correlation to tree weight, nor did $\mathrm{CH}_{4}$ loss estimated from root water (Figure (32)), the ratio between the two did and is shown in Figure (31). The logarithm of the ratio is shown since the linear relationship was less significant $\left(\mathrm{r}^{2}=0.49\right.$ versus 0.53 for the logarithm plot); a polynomial fit of the linear graph has an $\mathrm{r}^{2}$ value of 0.58 (the $1 \%$ level of significance falls at $\left.\mathrm{r}^{2}=0.37\right)$. Why these two variables independently have no significant correlation to tree weight, yet the ratio of the two does, may have some bearing on the physiological mechanisms of $\mathrm{CH}_{4}$ movement into and through the tree. The ratio of the two variables also appears to vary by tree as shown in Figure (33).

\subsection{Carbon Isotopic Composition}

An analysis of the possible physical pathways of $\mathrm{CH}_{4}$ through the tree is helpful in interpreting the isotopic fractionation of $\mathrm{CH}_{4}$ observed from canopy measurements. $\mathrm{CH}_{4}$ entering the root system with water can move apoplastically, or without traversing cellular membranes. A membrane barrier at the root endodermis must be crossed before the xylem tissue is entered, which is the main bulk-flow water transport system through roots and stems of trees [Taiz and Zeiger, 2006]. This xylem pathway is driven by a hydrostatic pressure gradient, as opposed to the water potential that moves water from cell to cell across membrane barriers [Taiz and Zeiger, 2006]. The bulk flow of water causes no isotopic fractionation of its own. Therefore, $\mathrm{CH}_{4}$ transported by transpiration would show an isotopic fractionation due to dissolution from water to gas and from the crossing of two cell membrane barriers at the root endoder- 
mis. Transfer of $\mathrm{CH}_{4}$ from water to air leads to an isotopic fractionation on the order of $-0.8 \%$ [Knox et al., 1992], an order of magnitude smaller than the fractionation measured here. Experimentation is needed to know the isotopic fractionation due to membrane transport.

Alternatively, $\mathrm{CH}_{4}$ may enter the roots without ever being drawn into the xylem tissue, instead entering air-filled aerenchyma tissue connected to lenticels along the tree's stems. This pathway is believed to be the dominant pathway for $\mathrm{CH}_{4}$ flux from rice and some wetland plants [Denier Van Der Gon and Van Breemen, 1993, Chanton, 2005]. Isotopic fractionation would occur due to dissolution from water to gas and from any concentration-gradient driven diffusion between the root zone and the atmosphere. Molecular diffusion is described by Fick's first law, where molecules move along a concentration gradient by random collisions:

$$
J=D \frac{d C}{d z}
$$

$J$ is the flux in mass per area per time, $D$ is the diffusion coefficient in length ${ }^{2}$ per time, $C$ is the concentration and $z$ is distance, and $\mathrm{d} C / \mathrm{d} z$ is the concentration gradient. For a gas moving along a concentration gradient through air, the diffusion coefficient is related to the molecular weights of the constituents:

$$
D_{12} \propto\left[\frac{\left(M_{1}+M_{2}\right)}{M_{1} M_{2}}\right]^{1 / 2}
$$

where $M_{1}$ can be taken to be the molecular weight of air and $M_{2}$ for the molecular weight of $\mathrm{CH}_{4}$ [Mason and Marrero, 1970]. The expected fractionation for $\mathrm{CH}_{4}$ dif- 
fusing in air is found from the ratio of the diffusion constants for ${ }^{12} \mathrm{CH}_{4}$ and ${ }^{13} \mathrm{CH}_{4}$. Using equation (7) and taking the molecular weight of air to be $28.9 \mathrm{~g} \mathrm{~mol}^{-1}$, the $\alpha$ for diffusion is 1.019. The resulting isotopic fractionation due to molecular diffusion, therefore, is expected to be $-19 \%$ [ [Chanton, 2005].

The $\delta^{13} \mathrm{C}$ value of $8 \%$ indicates that $\mathrm{CH}_{4}$ transported through the tree follows neither a purely bulk flow pathway nor a purely diffusional one. The value can be interpreted to indicate two or more mechanisms of transport, possibly some combination of movement through membrane barriers, bulk flow, and diffusion. It may not be true that a particular pathway is dominated by only one mechanism; that is, stem transport may not represent a pathway dominated by bulk flow or diffusion alone but instead involve other mechanisms. Isotopic composition measurements of emitted $\mathrm{CH}_{4}$ can discriminate between mechanisms, but not transport pathways per se. This leads to an important implication of this work, that tree transport mechanisms cannot be separated into particular pathways through the tree. A diffusional mechanism, for example, may not be associated with transport through stem aerenchyma alone, but also with any pathway involving membrane crossings. An indication of diffusional transport in the isotopic data could mean that diffusion takes place along any number of transport pathways.

The significant relationship between $\delta^{13} \mathrm{C}$ of the emitted $\mathrm{CH}_{4}$ flux found in the canopy flux experiments and in the temperature experiments was unexpected (Figures (34) and (36). One explanation is that different transport mechanisms dominate depending on the amount of $\mathrm{CH}_{4}$ emitted. A low flux may occur given any amount of $\mathrm{CH}_{4}$ in the root zone that is dominated by a particular transport mechanism or mechanisms with a certain isotopic signature. When various ecophysiological param- 
eters, such as temperature, combine to result in a high flux, more $\mathrm{CH}_{4}$ is emitted by a different transport mechanism or mechanisms with a correspondingly different isotopic signature. $\delta^{13} \mathrm{C}$ of the total $\mathrm{CH}_{4}$ in the chamber (tedlar bag), which includes the atmospheric background $\mathrm{CH}_{4}$, is shown in Figure (37) graphed against flux. The y-intercept for this graph is $-46.5 \%$ ( $95 \%$ C. I. $\pm 1.2 \%$ ), not far from the $-44.8 \%$ of the background ambient $\mathrm{CH}_{4}$. This means that when the flux is 0 , the $\delta^{13} \mathrm{C}$ value is near background as expected.

It should be noted as well that on the April $4^{\text {th }}, 2011$ stem flux trial, one sample from each stem chamber was taken to measure $\delta^{13} \mathrm{C}$. The $\delta^{13} \mathrm{C}$ values of these stem samples were $-53.7 \%$ and $-50.3 \%$ for the upper and lower chambers, respectively. The mechanisms involved in stem emission of $\mathrm{CH}_{4}$ therefore cause greater discrimination with distance traveled along the stem. This would not be expected with pure diffusion, since the fractionation factor $\alpha$ depends not on distance or length but on the masses of the constituent particles. A fractionating process that continues with distance traveled along the tree stem would be indicated by these numbers. However, only one experiment of this type was performed and further testing would be needed to verify this conclusion.

\subsection{Temperature Influences on Transportation Mechanisms and $\mathrm{Q}_{10}$}

The temperature coefficient, or $\mathrm{Q}_{10}$, is the rate of change in a system, usually biological, with a temperature change of $10{ }^{\circ} \mathrm{C}$. The temperature experiments described above were conducted to find the $\mathrm{Q}_{10}$ of $\mathrm{CH}_{4}$ transport through trees. $\mathrm{Q}_{10}$ can be calculated or measured for soil production or oxidation of $\mathrm{CH}_{4}$, then combined with the $\mathrm{Q}_{10}$ transport to find an overall $\mathrm{Q}_{10}$ for the soil-plant-atmosphere system of $\mathrm{CH}_{4}$ 
production and transport to the atmosphere.

Mathematically $\mathrm{Q}_{10}$ is defined as

$$
Q_{10}=\frac{F(T+10)}{F(T)}
$$

where $F$ is a rate, specifically flux in this case, and $T$ is temperature. Since the temperature experiment took place at three different temperatures and the specific span of $10{ }^{\circ} \mathrm{C}$ was not possible to control, another equation is derived from the definition of $\mathrm{Q}_{10}$ to find its value using the temperatures and fluxes that were actually measured. The type of relationship between flux and temperature, such as linear or exponential, must be assumed. Since an exponential relationship describes the $Q_{10}$ of many microbial systems, systems obeying the Arrhenius equation, and many biological systems in general, it will be assumed here. An exponential relationship had lower statistical significance than the linear relationship found between flux and temperature shown in Figures (15), (13) and (14); however this may be because of the small temperature range sampled $\left(17^{\circ} \mathrm{C}\right.$ to $\left.25^{\circ} \mathrm{C}\right)$.

Assuming the exponential relationship $F(T)=F_{o} e^{\alpha T}$, where $\alpha$ is a rate constant, the value of $\alpha$ can be shown to be

$$
\alpha=\frac{1}{T_{1}-T_{2}} \ln \frac{F\left(T_{1}\right)}{F\left(T_{2}\right)}
$$

where $T_{1}$ and $T_{2}$ are two different temperatures and $F_{1}$ and $F_{2}$ are the fluxes measured at those temperatures (note that this $\alpha$ should not be confused with $\alpha$ in the equation for isotopic ratios as shown in Equation (2)). This equation for $\alpha$ is then used to find 
the $\mathrm{Q}_{10}$ by the relationship $Q_{10}=e^{10 \alpha}$.

Flux values measured at the coolest average temperature $\left(17.1^{\circ} \mathrm{C}\right)$ and the warmest average temperature $\left(25.2^{\circ} \mathrm{C}\right)$ were used to calculate a transport $\mathrm{Q}_{10}$. The $\mathrm{Q}_{10}$ for these two different temperatures is $2.4 \pm 2.0$, calculated using the equations for $\alpha$ and $\mathrm{Q}_{10}$. The average temperatures during the warmest and coolest weeks and the average flux for each of those weeks were used in the calculation. This value of 2.4 is reasonable given that many biological systems are characterized by a $Q_{10}$ in this range [Davidson and Janssens, 2006]. (The standard deviation of $\mathrm{Q}_{10}$ was found using the error propagation formula

$$
\sigma_{Q_{10}}=\sqrt{\left(\frac{\partial Q_{10}}{\partial T_{1}}\right)^{2} \sigma_{T_{1}}^{2}+\left(\frac{\partial Q_{10}}{\partial T_{2}}\right)^{2} \sigma_{T_{2}}^{2}+\left(\frac{\partial Q_{10}}{\partial F_{1}}\right)^{2} \sigma_{F_{1}}^{2}+\left(\frac{\partial Q_{10}}{\partial F_{2}}\right)^{2} \sigma_{F_{2}}^{2}}
$$

The assumption needed to use this formula is that the standard deviations of each variable are small in comparison to the partial derivatives, which was not strictly true in this case. No other suitable error estimation has been made at this time.)

The average $\mathrm{CH}_{4}$ flux by temperature is shown in Figure (28). As outlined in the results, there was a significant decrease in $\mathrm{CH}_{4}$ flux with temperature, although an insignificantl difference was seen between flux at the two warmer temperatures. A similar trend is seen in the $\delta^{13} \mathrm{C}$ values in Table (3). The epsilon values for the two higher temperature weeks are $3.2 \%$ and $3.4 \%$; however, the coolest week yielded an epsilon of $11.4 \%$ (small fluxes measured during the lowest temperature week will pull canopy $\delta^{13} \mathrm{C}$ values farther away from raw values when corrected, and this might emphasize the overall difference). It should be noted that the epsilon value for the 2010-2011 flux experiments shown in Table (2) is approximately 8\%, with the average 
temperature for these trials being $18.3^{\circ} \mathrm{C}$. In all, as temperature decreases there is a monotonic increase in the epsilon value. Additionally, there is a significant relationship between $\delta^{13} \mathrm{C}$ and flux mentioned above, as well as a significant relationship between $\delta^{13} \mathrm{C}$ and temperature shown in Table (1) and Figure (38).

The value of epsilon has been graphed against $\mathrm{CH}_{4}$ flux and temperature as well. These graphs are shown in Figures (39) and (40). In the epsilon versus flux graph, the data crosses the flux axis so that an epsilon of 0 corresponds to a particular flux. This would mean that a bulk-flow type transport mechanism that does not create a fractionation dominates when the flux is around that magnitude. The relationship here corresponds to that in the epsilon verus temperature graph. In other words, this data shows that at higher temperatures, the $\delta^{13} \mathrm{C}$ values are enriched and there is a higher flux, while at lower temperatures $\delta^{13} \mathrm{C}$ values are depleted and there is a lower flux. A model where one transport mechanism dominates when the temperature is higher while a different mechanism prevails when temperatures are cooler is supported by these findings. For example, if one of the primary mechanisms of transport is diffusion, the greater depletion of ${ }^{13} \mathrm{C}$ at lower temperatures would indicate that diffusion dominates at those temperatures since the predicted isotopic fractionation due to molecular diffusion is $-19 \%$, a greater fractionation value than those observed in the tested temperature range.

A Keeling Plot is useful to investigate fractionation due to different processes. This approach was developed by Charles Keeling who found a relationship between the carbon isotope abundance and the inverse of $\mathrm{CO}_{2}$ concentrations [Keeling, 1961]. This relationship can be used to parse out atmospheric $\mathrm{CO}_{2}$ sources behind the changes in the atmospheric $\delta^{13} \mathrm{C}$ values [Pataki et al., 2003]. Concentrations of a particular gas 
in the atmosphere are the sum of background concentrations and any sources of the gas,

$$
c_{a}=c_{b}+c_{s}
$$

where $c_{a}$ is the concentration of the gas in the atmosphere, $c_{b}$ is the background concentration of the gas and $c_{s}$ is the concentration of the gas due to some source. The conservation of mass is used to give an expression involving the carbon isotope ratios of each component,

$$
\delta^{13} C_{a} c_{a}=\delta^{13} C_{b} c_{b}+\delta^{13} C_{s} c_{s}
$$

These two equations can be combined to yield [Pataki et al., 2003]

$$
\delta^{13} C_{a}=c_{b}\left(\delta^{13} C_{b}-\delta^{13} C_{s}\right)\left(1 / c_{a}\right)+\delta^{13} C_{s}
$$

If the concentration $\mathrm{c}_{a}$ and $\delta^{13} \mathrm{C}_{a}$ have been measured, then a plot of the two variables will be linear with the y-intercept representing the carbon isotope ratio of the source.

When the tedlar bag is over the tree and samples are being taken, the air in the bag is a mix of background $\mathrm{CH}_{4}$ and emitted $\mathrm{CH}_{4}$. If one transport mechanism dominates at lower temperatures and another transport mechanism dominates at higher temperatures, a Keeling Plot of the chamber $\mathrm{CH}_{4}$ for the lowest and highest temperatures should show the $\delta^{13} \mathrm{C}$ of the process that dominates at that temperature. These plots are shown in Figures (41), (42), (43) and (44). The values of $\delta^{13} \mathrm{C}$ taken from the $y$-intercepts are $-32.8 \%$ (95\% C. I. of $\pm 14.7 \%)$ for the week averaging $25.2^{\circ} \mathrm{C}$ in temperature, $-34.0 \%$ (95\% C. I. of $\pm 5.1 \%$ ) for the week averaging $22.3^{\circ} \mathrm{C}$ 
in temperature, and $-44.1 \%$ (95\% C. I. of $\pm 6.9 \%)$ for the week averaging $17.1^{\circ} \mathrm{C}$ in temperature (the $95 \%$ C. I. for the Keeling plot including all values of flux at all temperatures is $\pm 3.4 \%$ ). There is no proposed transport mechanism that would explain the enrichment of $\delta^{13} \mathrm{C}$ over the root water value of $\sim-37 \%$, therefore these plots are not assumed to yield the actual fractionation due to a particular process. However, the overall trend of increasing depletion with cooler temperatures is evident. 


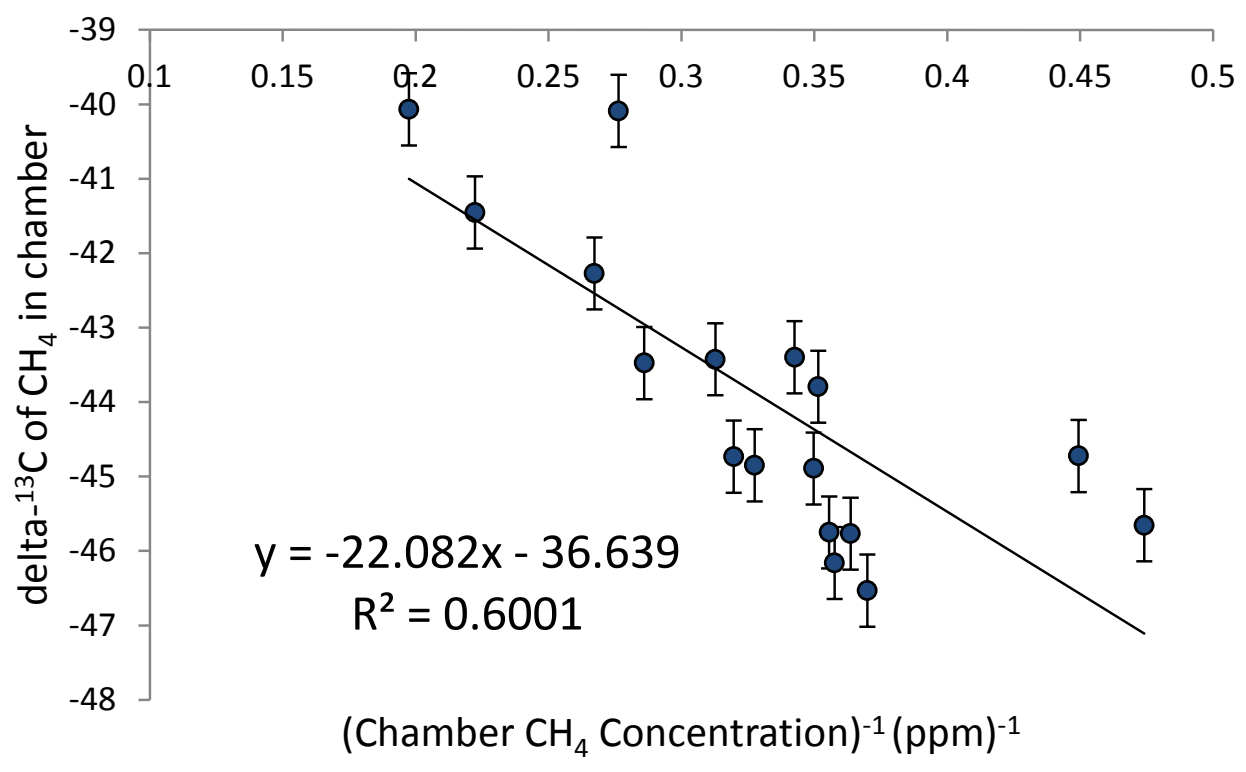

Figure 41: Keeling plot showing the $\delta^{13} \mathrm{C}$ of chamber $\mathrm{CH}_{4}$ for all data points in the temperature experiment, $\mathrm{n}=17$. Error bars show standard error. 2012 data.

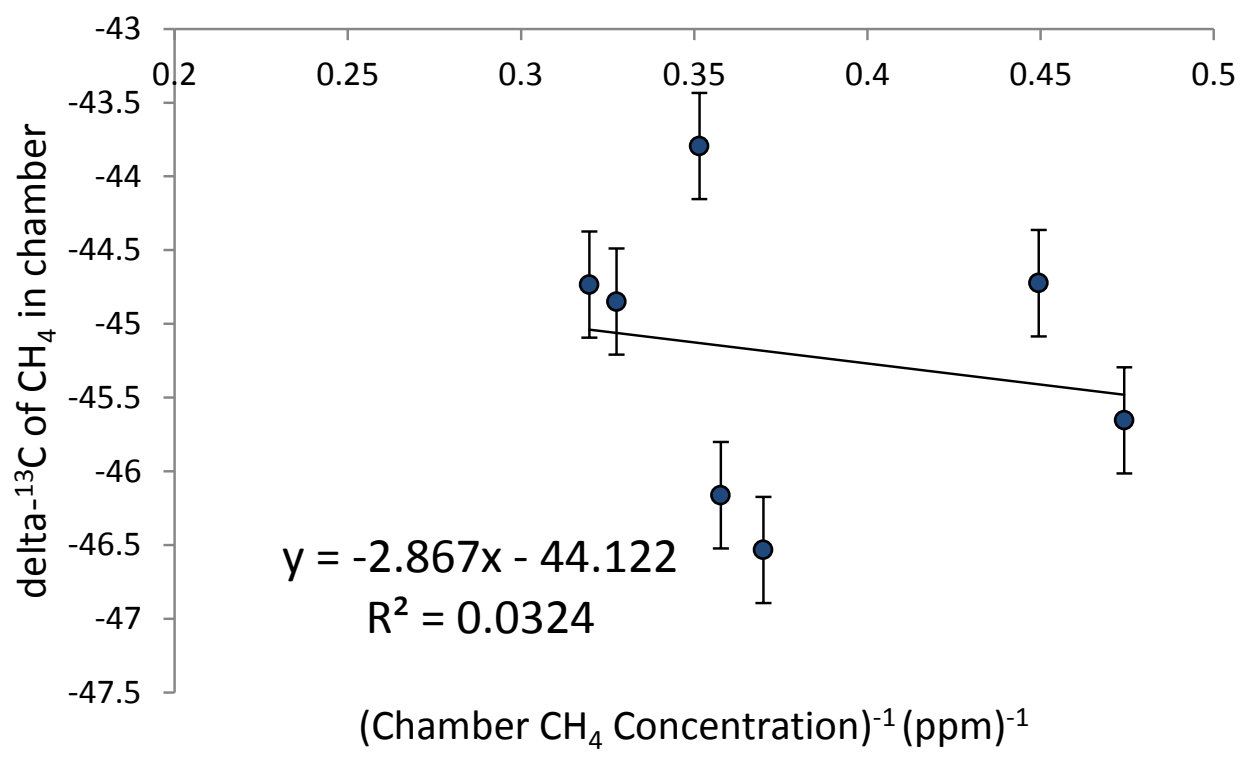

Figure 42: Keeling plot showing the $\delta^{13} \mathrm{C}$ of chamber $\mathrm{CH}_{4}$ for the seven trials in the temperature experiment averaging $17.1^{\circ} \mathrm{C} ; \mathrm{n}=7$. Note that the $\mathrm{y}$-intercept shows the most depleted $\delta^{13} \mathrm{C}$ value of the three groups of temperature trials. Error bars show standard error. 2012 data. 


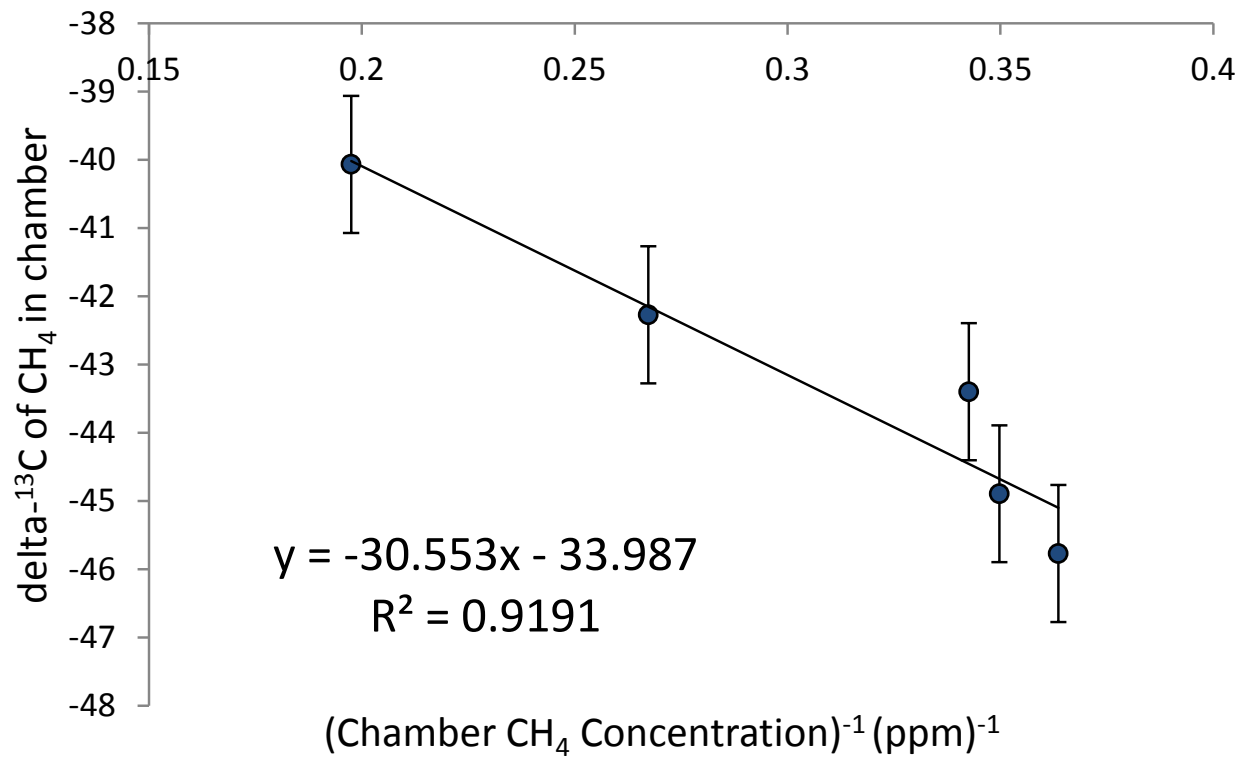

Figure 43: Keeling plot showing the $\delta^{13} \mathrm{C}$ of emitted $\mathrm{CH}_{4}$ for the five trials in the temperature experiment averaging $22.3^{\circ} \mathrm{C} ; \mathrm{n}=5$. Note that the y-intercept shows an intermediate $\delta^{13} \mathrm{C}$ value of the three groups of temperature trials. Error bars show standard error. 2012 data.

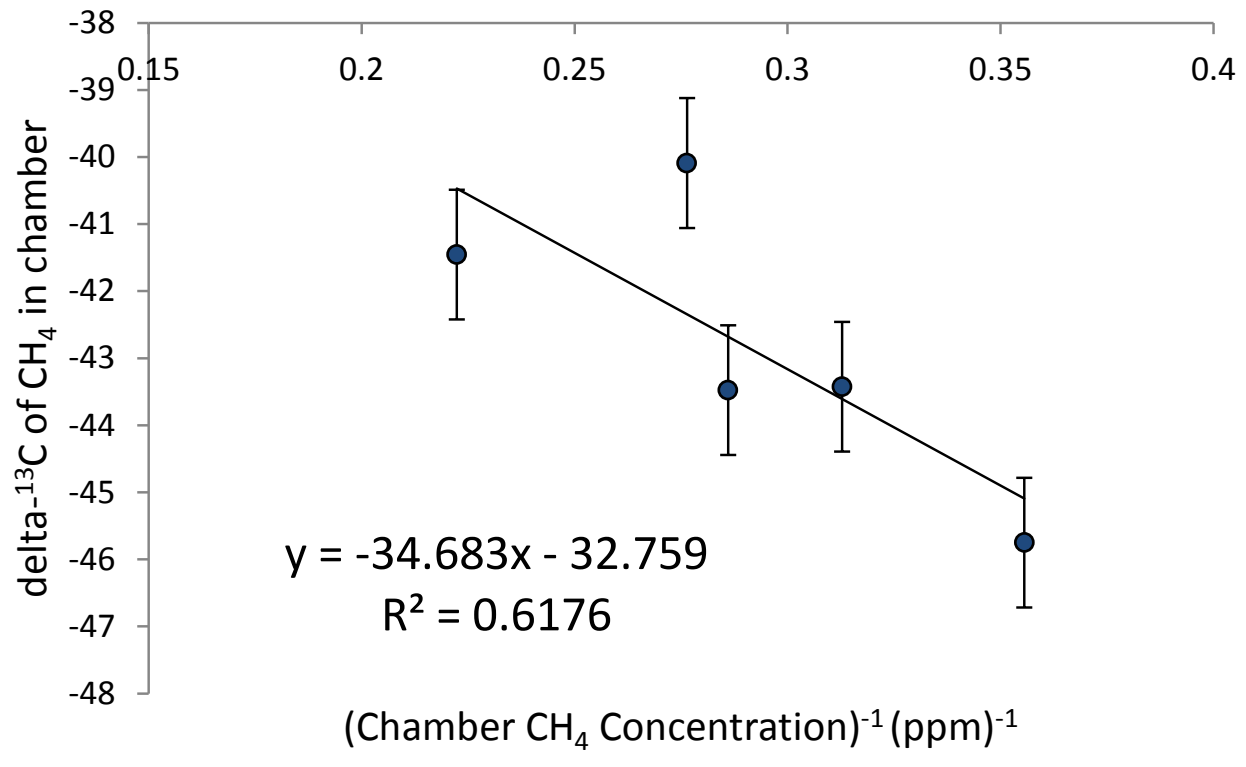

Figure 44: Keeling plot showing the $\delta^{13} \mathrm{C}$ of emitted $\mathrm{CH}_{4}$ for the five trials in the temperature experiment averaging $25.2^{\circ} \mathrm{C} ; \mathrm{n}=5$. Note that the y-intercept shows the most enriched $\delta^{13} \mathrm{C}$ value of the three groups of temperature trials. Error bars show standard error. 2012 data. 


\section{$5.4 \mathrm{CH}_{4}$ Partitioning}

It was noticed during the canopy flux trials that the amount of $\mathrm{CH}_{4}$ leaving the root chamber during the three to five hours the tree was sealed in it was much greater than the amount emitted from the canopy as estimated from measured canopy fluxes. Several experiments were undertaken to determine whether this $\mathrm{CH}_{4}$ was leaking from the chamber, or whether it could be stored, at least temporarily, in the tree itself. The types of experiments are described in the methods above. Results and implications are discussed here.

As reported in the results, the average of the difference between the $\mathrm{CH}_{4}$ lost from the root chamber and that lost by canopy emissions and leaking was $980 \mu$ moles $\mathrm{CH}_{4}$. This missing $\mathrm{CH}_{4}$ is an average of three times higher than that accounted for by flux and leaking. Trees may have the capacity to hold these amounts of $\mathrm{CH}_{4} \cdot \mathrm{CH}_{4}$ concentration has been observed to be very high in rice plants; Nouchi et al. [1990] measured $\mathrm{CH}_{4}$ concentrations at 2900 times higher than ambient in rice plant cavities. The series experiments from 10-3-12 and 10-26-12 show that some $\mathrm{CH}_{4}$ accumulated in the root water chamber once the tree was placed in $\mathrm{CH}_{4}$-free water, however it is not nearly enough to account for any stored $\mathrm{CH}_{4}$.

Two destructive stem experiments were done to test whether the $\mathrm{CH}_{4}$ could be recovered from the tree. In the first, the tree was held in the root chamber for three hours and forty minutes following the same procedure as for a canopy flux experiment. At the end of this time, the tree was removed and a $10 \mathrm{~cm}$ section of stem between the roots and canopy was cut, placed into a blender, and ground. The tree was approximately $1 \mathrm{~m}$ high with a bottom stem diameter (above the roots) of 
approximately $0.02 \mathrm{~m}$. The amount of $\mathrm{CH}_{4}$ expected to be in the $10 \mathrm{~cm}$ stem section was estimated with a volume calculation of the tree and using the average amount of missing $\mathrm{CH}_{4}$ reported above. The amount of $\mathrm{CH}_{4}$ that should have been contained in the $10 \mathrm{~cm}$ stem section was $300 \mu$ moles assuming the missing $\mathrm{CH}_{4}$ was evenly distributed throughout the main tree stem. The measured concentration of $\mathrm{CH}_{4}$ in the blender after grinding the stem was about $20 \mathrm{ppm}$ (ambient was 2ppm). Based on the volume of the blender (approximately $1.9 \mathrm{~L}$ ), this is equivalent to about $2 \mu$ moles of $\mathrm{CH}_{4}$.

This experiment was repeated with an additional tree. In this case, five separate sections of the main tree stem were measured, up to a height of $50 \mathrm{~cm}$ along the main tree stem. The first $5 \mathrm{~cm}$ were predicted to contain $200 \mu$ moles of $\mathrm{CH}_{4}$, while only $2 \mu$ moles were measured in the blender. The second $5 \mathrm{~cm}$ would have contained $170 \mu$ moles, yet only $0.18 \mu$ moles were measured. This concentration continued to drop off until the final $16 \mathrm{~cm}$ of the tree stem were measured to yield $\mathrm{CH}_{4}$ levels in the blender comparable to ambient. This pattern follows that indicated by the stem chamber experiments where flux dropped off with an increase in main tree stem height. It cannot be concluded that all the $\mathrm{CH}_{4}$ potentially stored in the tree stems was extracted, since it is unknown how the $\mathrm{CH}_{4}$ might be stored within tree tissues. However, $\mathrm{CH}_{4}$ was measured in the lower sections of the stem. These results are taken to indicate that some amount of $\mathrm{CH}_{4}$ can be held by the tree, as opposed to merely transported through.

A time constant can be calculated for transport using the series experiments data. In the first series experiment, $1590 \mu$ moles of $\mathrm{CH}_{4}$ were lost from the root chamber (root water and headspace) over the course of 260 minutes (Table (5)). The average 
flux during this period was $1.6 \mu \mathrm{g} \mathrm{CH}_{4} \mathrm{~min}^{-1}$. Taking the time constant $\tau$ to be equal to the $\mathrm{CH}_{4}$ loss from the root chamber divided by the flux yields a value for $\tau$ of 11 days. Another way to regard transport efficiency is as a half-life; for a $\tau$ of 11 , the half-life of $\mathrm{CH}_{4}$ in the root chamber is 7.6 days. Other experiments yield even greater values for $\tau$; the third series experiment has a time constant of 16 days. This number may not represent transport time, which may be fast, but a transport efficiency that is restricted by pathway. In other words, the time spent by a single molecule of $\mathrm{CH}_{4}$ in the transport pathway of the tree can be very short; however, the efficiency of the tree in transporting $\mathrm{CH}_{4}$ is low. This has important implications for temperature changes that increase the production of $\mathrm{CH}_{4}$ in the soil. Since tree transport efficiency of $\mathrm{CH}_{4}$ seems to be low in spite of an increase in flux with temperature, the overall amount of $\mathrm{CH}_{4}$ transported by trees to the atmosphere will not increase at the same rate as the increase of $\mathrm{CH}_{4}$ production in the soil. 


\section{Conclusion}

A major difficulty in the analysis of tree transport mechanisms is the complexity, and from a pathway point of view relative inaccessibility, of the tree system. Although flux measurements themselves are not inscrutible, they are an indirect path to understanding actual physical transport mechanisms. The application of stable isotopic composition measurements to the plant transport problem is a novel feature of the work here and adds a number of insights, however this too is an indirect method of investigation. Variability in the data is partly a consequence of limited control of unknown factors affecting flux mechanisms. For example, even though all branch cuttings used for the temperature experiment in this work were taken from the same cottonwood tree on the same day, then subjected to identical growth conditions and nutrient solutions, differences in growth and development were observed. The extent to which these differences play a role in flux variation is unknown.

New insights were made in spite of these difficulties. The verification that trees emit $\mathrm{CH}_{4}$ when it is present in the root zone should not be overlooked as a significant outcome of this study, as it confirms and adds to what little research has been done on $\mathrm{CH}_{4}$ transport in trees so far. The isotopic composition data suggests that at least two mechanisms are at work in the tree transport of $\mathrm{CH}_{4}$, one dominating at lower fluxes and lower temperatures, and a different mechanism dominating at higher fluxes and higher temperatures. Most of the $\mathrm{CH}_{4}$ emission is through stems and not leaves

as some have proposed. A significant temperature effect on $\mathrm{CH}_{4}$ emission has been found, reflected in a $Q_{10}$ value that indicates a positive feedback. Data suggests that trees are capable of storing $\mathrm{CH}_{4}$ instead of merely transporting it from the soil to the 
atmosphere. All of this information adds to what little is currently understood about tree emission of $\mathrm{CH}_{4}$ and tree transport mechanisms in general.

In terms of results that have a more immediate impact, the calculated efficiency of transport has been found to be low compared to rice and probably other herbaceous wetland plants. Implications for the possibility of upland tree transport of $\mathrm{CH}_{4}$ are significant. First of all, most, if not all, $\mathrm{CH}_{4}$ transported by the trees in this study was emitted through the stems. This implies that any $\mathrm{CH}_{4}$ transported by transpiration is likely to be little. The proposed mechanism for upland tree $\mathrm{CH}_{4}$ transport is transpiration, as mentioned previously. Considering that the transport efficiency measured here was low, it is entirely possible that $\mathrm{CH}_{4}$ in upland soils will likely be oxidized in the soil before entering a tree transport pathway. Therefore, a potential upland source of $\mathrm{CH}_{4}$ from trees will be insignificant except perhaps over a very large scale.

Carrying this work further would require more controlled conditions to untangle some of the factors that influence $\mathrm{CH}_{4}$ emission; for example, the use of growth chambers to tightly regulate temperature and humidity may be necessary. Although a value for the $\mathrm{Q}_{10}$ of transport was obtained, this positive feedback should be verified and determined with more precision, again using greater temperature control. Global extrapolation of $\mathrm{CH}_{4}$ flux at the plant level is an eventual goal of this work. Either a tighter relationship between ecophysiological parameters and flux or the theoretical description of the transport mechanisms is first necessary. Further insights into tree transport mechanisms are possible but will likely require a deeper understanding of tree transport pathways from an empirical, plant physiological point of view. 


\section{References}

R. Abbasi, E. Allen, D. Berry, P. Chandler, K. Chiang, C. Christmann, R. Chou, B. Eya, D. Gallagher, J. Hu, J. Hwong, T. Johnson, D. Lofstrom, L. Nakashima, C. Papagni, Y. Rong, T. Williams, and P. Wong. Advisory - Active Soil Gas Investigation. California Environmental Protection Agency, March 2010.

J. P. Chanton. The effect of gas transport on the isotope signature of methane in wetlands. Organic Chemistry, 36:753-768, 2005.

K. Das and K. K. Baruah. Methane emission associated with anatomical and morphophysiological characteristics of rice (Oryza sativa) plant. Physiologia Plantarum, 134:303-312, 2008.

E. A. Davidson and I. A. Janssens. Temperature sensitivity of soil carbon decomposition and feedbacks to climate change. Nature, 440:165-173, 2006.

H. A. C. Denier Van Der Gon and N. Van Breemen. Diffusion-controlled transport of methane from soil to atmosphere as mediated by rice plants. Biogeochemistry, 21:177-190, 1993.

K. L. Denman and G. Brasseur. Couplings between changes in the climate system and biogeochemistry. In S. Solomon, D. Qin, M. Manning, M. Marquis, K. Averyt, M. Tignor, H. Miller, Jr., and Z. Chen, editors, IPCC AR4: Climate Change 2007, The Physical Science Basis. Cambridge University Press, New York, 2007.

K. N. Garnet, J. P. Megonigal, C. Litchfield, and G. E. Tayor Jr. Physiological control of leaf methane emission from wetland plants. Aquatic Botany, 81:141 - 155, 2005.

V. Gauci, D. J. G. Gowing, R. C. Hornibrook, J. M. Davis, and N. B. Dise. Woody stem methane emission in mature wetland alder trees. Atmospheric Environment, 44:2157-2160, 2010.

R. Gonfiantini, W. Stichler, and K. Rozanski. Standards and intercomparison materials distributed by the international atomic energy agency for stable isotope measurements. In Reference and intercomparison materials for stable isotopes of light elements TECDOC-825, pages 13-29. International Atomic Energy Agency, 1995.

J. Hoefs. Stable Isotope Geochemistry. Springer-Verlag, $5^{\text {th }}$ edition, 2004.

C. D. Keeling. The concentration and isotopic abundances of carbon dioxide in rural and marine air. Geochimica et Cosmochimica Acta, 24:277-298, 1961. 
M. A. K. Khalil, R. A. Rasmussen, M. J. Shearer, R. W. Dalluge, L. X. Ren, and C.-L. Duan. Measurements of methane emissions from rice fields in China. 103: 25,181-25,210, 1998.

M. Knox, P. D. Quay, and D. Wilbur. Kinetic isotopic fractionation during air-water gas transfer of $\mathrm{O}_{2}, \mathrm{~N}_{2}, \mathrm{CH}_{4}$, and $\mathrm{H}_{2}$. Journal of Geophysical Research, 97:20,33520,343, 1992 .

K. K. Lee, R. W. Holst, I. Watanabe, and A. App. Gas transport through rice. Soil Science and Plant Nutrition, 27:151-158, 1981.

Y. Lu, R. Wassmann, H. Neue, and C. Huang. Dynamics of dissolved organic carbon and methane emissions in a flooded rice soil. Soil Science Society of America Journal, 64:2011-2017, 2000.

E. A. Mason and T. R. Marrero. The diffusion of atoms and molecules. In D. R. Bates and I. Estermann, editors, Advances in Atomic and Molecular Physics, volume 6, pages 155-232. Academic Press, Inc., 1970.

M. C. McBain, J. S. Warland, R. A. McBride, and C. Wagner-Riddle. Laboratoryscale measurements of $\mathrm{N}_{2} \mathrm{O}$ and $\mathrm{CH}_{4}$ emissions from hybrid poplars (Populus deltoides x Populus nigra). Waste Management \&5 Research, 22:454-465, 2004.

J. P. Megonigal and A. B. Guenther. Methane emissions from upland forest soils and vegetation. Tree Physiology, 28:491-498, 2008.

I. Nouchi, S. Mariko, and A. Kazuyuki. Mechanism of methane transport from the rhizosphere to the atmosphere through rice plants. Plant Physiology, 94:59-66, 1990.

D. E. Pataki, J. R. Ehleringer, L. B. Flanagan, D. Yakir, D. R. Bowling, C. J. Still, N. Buchmann, J. O. Kaplan, and J. A. Berry. The application and interpretation of Keeling plots in terrestrial carbon cycle research. Global Biogeochemical Cycles, 17:22-1-22-15, 2003.

A. L. Rice, A. A. Gotoh, H. O. Ajie, and S. C. Tyler. High-precision continuousflow measurement of $\delta^{13} \mathrm{C}$ and $\delta \mathrm{D}$ of atmospheric $\mathrm{CH}_{4}$. Analytical Chemistry, 73: 4104-4110, 2001.

A. L. Rice, C. L. Butenhoff, M. J. Shearer, D. Teama, T. N. Rosenstiel, and M. A. K. Khalil. Emissions of anaerobically produced methane by trees. Geophysical Research Letters, 37:L03807, 2010.

H. Rusch and H. Rennenberg. Black alder (Alnus Glutinosa (L.) Gaertn.) trees mediate methane and nitrous oxide emission from the soil to the atmosphere. Plant and Soil, 201:1-7, 1998. 
W. Seiler, A. Holzapfel-Pschorn, R. Conrad, and D. Scharffe. Methane emission from rice paddies. Journal of Atmospheric Chemistry, 1:241-268, 1984.

R. D. Shannon, J. R. White, J. E. Lawson, and B. S. Gilmour. Methane efflux from emergent vegetation in peatlands. Journal of Ecology, 84:239-246, 1996.

L. Taiz and E. Zeiger. Plant Physiology. Sinauer Associates, Inc., $4^{\text {th }}$ edition, 2006.

K. Terazawa, S. Ishizuka, T. Sakata, K. Yamada, and M. Takahashi. Methane emissions from stems of Fraxinus mandshurica var. japonica trees in a floodplain forest. Soil Biology \&3 Biochemistry, 39:2689-2692, 2007.

C. D. Vann and J. P. Megonigal. Elevated $\mathrm{CO}_{2}$ and water depth regulation of methane emissions: Comparison of woody and non-woody wetland plant species. Biogeochemistry, 63:117-134, 2003.

G. J. Whiting and J. P. Chanton. Plant-dependent $\mathrm{CH}_{4}$ emission in a subarctic Canadian fen. Global Biogeochemical Cycles, 6:225-231, 1992.

H. Yao, K. Yagi, and I. Nouchi. Importance of physical plant properties on methane transport through several rice cultivars. Plant and Soil, 222:83-93, 2000. 


\section{Appendices}

\section{A Sandy River Delta Soil Experiment}

It has been proposed that anaerobic microsites in non-inundated soils or root zones near the water table may be sources of $\mathrm{CH}_{4}$. Tree roots in the vicinity of these sources may transport this $\mathrm{CH}_{4}$ to the atmosphere, bypassing oxidative soil zones [Megonigal and Guenther, 2008]. In order to test this hypothesis, three sites were chosen at the Sandy River Delta at the confluence of the Columbia and Sandy Rivers in Troutdale, Oregon where black cottonwood is ubiquitous. Since the ability for black cottonwood to transport $\mathrm{CH}_{4}$ has been demonstrated, testing the sites where it grows in noninundated conditions was the natural choice to investigate this hypothesis.

Three sites were chosen at the Sandy River Delta for soil testing. Sites one and two were located in the treeline of a black cottonwood stand and site three was located in the adjoining grassy meadow. Site one was among smaller black cottonwood saplings while site two was at a large, more mature group of trees. Approximate elevation for the three sites was six meters above sea level. Three soil gas vapor wells were installed at each site: one at a depth of one meter, one at a depth of $60 \mathrm{~cm}$, and one at a depth of $30 \mathrm{~cm}$. At the two treeline sites, well installation took place as close as possible to main tree roots. An auger was used to drill each well into which PVC pipe was inserted to the appropriate depth. After a depth of approximately 50 $\mathrm{cm}$, the soil was predominately sand. Pipe walls were solid except for the lowest 10 $\mathrm{cm}$, where slits perpendicular to the pipe axis had been cut to allow soil gas to move into the pipe. Figure (45), excerpted from Abbasi et al. [March 2010], represents soil vapor well construction. A sand pack was filled around the tip of the PVC pipe, 
followed by a layer of granular bentonite, and finally a layer of hydrated bentonite. The hydrated layer effectively sealed the belowground portion of the well from the atmosphere. Each layer's thickness depended on the overall length of the pipe. The tops of the pipes were fitted with valves to which a hose and pump could be connected. Purge time for sampling was calculated based on the pump rate of a given pump, the volume of the pipe and the deadspace in the sand and dry bentonite layers. Sampling involved pumping this volume into a tedlar bag, after which syringe samples would be taken from the bag. Typically this was done twice, so that the below ground volume was pumped out, sampled, and then sampled again. The first purge would draw any accumulated gases, while the second would be representative of actual fluxes from any soil gas sources. Ambient air samples were also taken. Samples were run as described above on both the GC-FID for $\mathrm{CH}_{4}$ and GC-ECD to test for the presence of nitrous oxide $\left(\mathrm{N}_{2} \mathrm{O}\right)$.

Soil gas vapor wells were originally installed on February $24^{\text {th }}, 2012$. The first set of samples were taken on February $25^{\text {th }}$ and repeated on February $27^{\text {th }}$. A spring set of samples were taken on April $24^{\text {th }}$ and April $26^{\text {th }}$. Summer sampling was conducted on June $26^{\text {th }}$ and June $29^{\text {th }}$, although only the 1 meter pipes were sampled on the $29^{\text {th }}$. One treeline site was also sampled on July $3^{\text {rd }}$. Pipes were removed shortly afterward. Results of these measurements are reported in Tables (9), (10),(11) and (12).

Stem sampling was also conducted on saplings in one of the two treeline sites. Additionally, tedlar bag enclosures around sapling brances were made for 48 hours, and syringe samples drawn. No detectable $\mathrm{CH}_{4}$ flux was measured from either the stem chamber sampling nor the tedlar bag enclosures. Stem samples were also taken 
on July $5^{\text {th }}$ from one Oregon ash (Fraxinus latifolia) and one black cottonwood on the bank of a flooded area in the Sandy River Delta. The difference between ambient and chamber concentrations of $\mathrm{CH}_{4}$ was significant for both Oregon ash $(p$-value $<0.001)$ and black cottonwood ( $p$-value 0.028); however, the absolute differences were very small. The average ambient $\mathrm{CH}_{4}$ concentration was $1.93 \mathrm{ppm}$, while for Oregon ash the average chamber concentration was $1.98 \mathrm{ppm}$ and for black cottonwood it was $1.96 \mathrm{ppm}$. Concentration did not increase monotonically in either chamber.

$\mathrm{CH}_{4}$ and $\mathrm{N}_{2} \mathrm{O}$ concentrations varied by site and by depth, although the differences were small. $\mathrm{CH}_{4}$ was continually below ambient levels. At the time when the pipes were originally installed, ambient air was present in the tubes. However, by the sampling time the next day, $\mathrm{CH}_{4}$ levels were already well below ambient in all wells. Either $\mathrm{CH}_{4}$ was consumed in the soil or the $\mathrm{CH}_{4}$ orginally in the tubes diffused into the surrounding soil. $\mathrm{N}_{2} \mathrm{O}$, however, was measured at above ambient levels. No evidence of $\mathrm{CH}_{4}$ producing microsites was found in any sampling location. Microsites may exist only in the rhizosphere; although sites one and two were among trees, there may not have been enough root matter in close enough proximity to the soil well bases to support anaerobic microsites. It may also be that not enough $\mathrm{CH}_{4}$ is produced to be detected. 


\title{
Figure 1 - Permanent/Semi-permanent Gas Vapor well Construction Diagram
}

To the surface
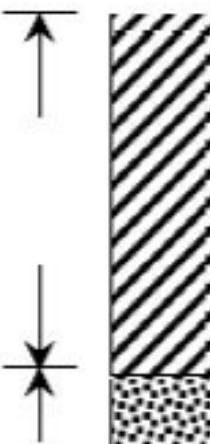

Approx. 1-ft

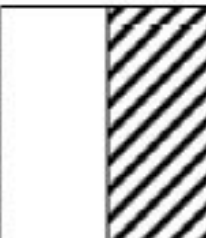

Hydrated granular bentonite in thickness

Approx. 1-ft in thickness

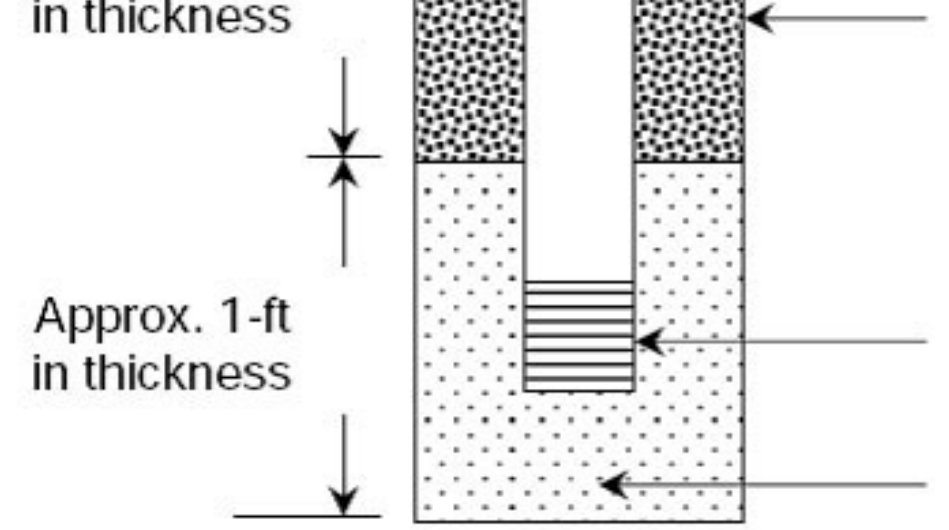

\author{
Dry \\ granular \\ bentonite
}

Probe tip

Sand pack

Figure 45: Soil vapor well construction. Excerpt from Abbasi et al. [March 2010] 

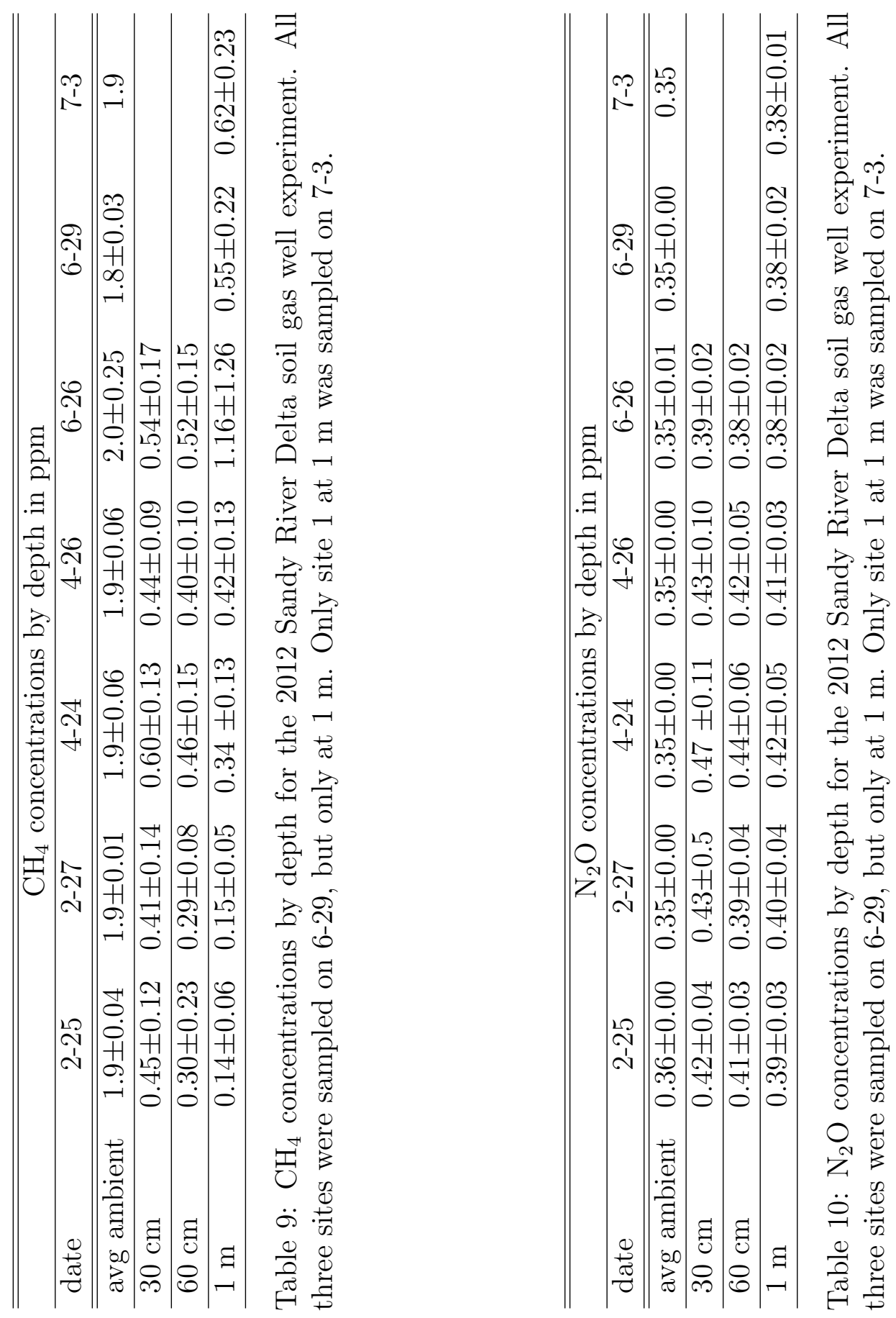

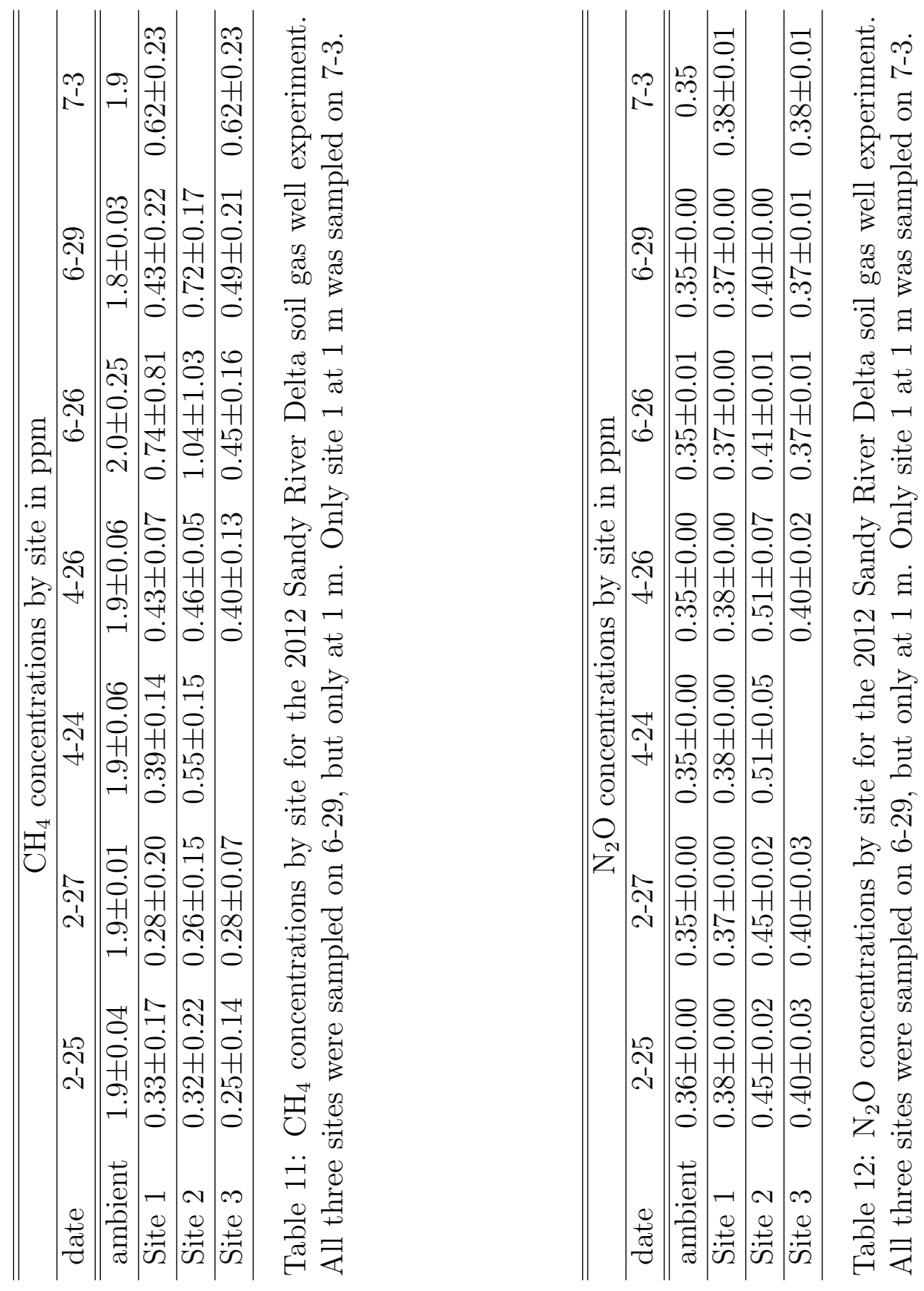


\section{B Root Water Concentration}

The high concentration of $\mathrm{CH}_{4}$ in the root chamber was verified by several tests. A $1.93 \mathrm{ppm}^{\mathrm{CH}_{4}}$ standard is used to calibrate the GC-FID when canopy and water samples are run. While this is a sufficient concentration for canopy sample calibration, root chamber water samples are significantly higher at around 7000-10000 ppm. The first test to verify the accuracy of the root chamber water concentration GC-FID measurements was to run a $100 \mathrm{ppm}$ and $10,000 \mathrm{ppm}$ standard. This is not done during every GC-FID calibration because the system becomes saturated with $\mathrm{CH}_{4}$ when running these standards and subsequent sample measurement is inaccurate. The 100 ppm standard and 10,000 ppm standard were run three times on each of the two GC-FIDs. Departure from the $10,000 \mathrm{ppm}$ standard was $+550 \mathrm{ppm}$ for one machine and $+160 \mathrm{ppm}$ for the other. This indicates that the root water chamber measurements are likely accurate to within several hundred ppm.

A second test was performed on the root water chamber. The chamber was filled as described for an experiment and natural gas bubbled through the DI water for 50 minutes. Six $10 \mathrm{~mL}$ water samples were taken from the sampling port on the chamber. All samples were processed with $\mathrm{N}_{2}$ as previously described. Three samples were run immediately according to the method outlined above on the GC-FID. The other three samples were injected into 3L tedlar bags, one sample per bag, that had been filled with $\mathrm{N}_{2}$. These bags were left to equilibrate overnight. $20 \mathrm{~mL}$ samples were drawn from the bags the next day and run on the GC-FID. The average concentration of these samples for all three bags was $60 \mathrm{ppm}$. Based on the three original root water samples run immediately after being taken from the root chamber that averaged 11500 
ppm, this concentration would have been $77 \mathrm{ppm}$. Alternatively, $60 \mathrm{ppm}$ represents a concentration of $9000 \mathrm{ppm}$ in the root chamber water. This test was repeated at a later date. The average root chamber concentration for the second test was 13000 ppm, which predicts $87 \mathrm{ppm}$ as the concentration in the bags. The actual concentration for the bags was measured to be $85 \mathrm{ppm}$, equivalent to $12700 \mathrm{ppm}$ for the root chamber water. These tests demonstrate that there is a range in the accuracy of the root chamber water measurements. Although the first of these two concentration tests appears to have departed significantly from the actual water concentration value, it is clear that a small variation in the measured bag concentration equates to a large variation in the predicted root water concentration, so the test is sensitive to that value. Since the samples were taken, processed, then diluted, it cannot be expected that this test would be as accurate as directly measuring standards on the GC-FID. However, it does generally back up those results. The values for the root water concentrations should therefore be taken as accurate to within several hundred ppm. 